\title{
Determination of Rx expression in the adult mouse retina and delineation of the $\mathrm{Rx}$ mediated gene regulation
}

\author{
Supriya A. Shah \\ West Virginia University
}

Follow this and additional works at: https://researchrepository.wvu.edu/etd

\section{Recommended Citation}

Shah, Supriya A., "Determination of Rx expression in the adult mouse retina and delineation of the Rx mediated gene regulation" (2005). Graduate Theses, Dissertations, and Problem Reports. 4190.

https://researchrepository.wvu.edu/etd/4190

This Thesis is protected by copyright and/or related rights. It has been brought to you by the The Research Repository @ WVU with permission from the rights-holder(s). You are free to use this Thesis in any way that is permitted by the copyright and related rights legislation that applies to your use. For other uses you must obtain permission from the rights-holder(s) directly, unless additional rights are indicated by a Creative Commons license in the record and/ or on the work itself. This Thesis has been accepted for inclusion in WVU Graduate Theses, Dissertations, and Problem Reports collection by an authorized administrator of The Research Repository @ WVU. For more information, please contact researchrepository@mail.wvu.edu. 


\title{
Determination of Rx expression in the adult mouse retina and delineation of the $\mathrm{Rx}$ mediated gene regulation
}

\author{
Supriya A. Shah \\ Thesis submitted to the \\ School of Medicine \\ at West Virginia University \\ in partial fulfillment of the requirements \\ for the degree of \\ Master of Science \\ in \\ Biochemistry
}

Associate Professor Peter H. Mathers, Ph.D., Chair

Professor F. Bradley Hillgartner, Ph.D.

Professor Michael R. Miller, Ph.D.

Associate Professor Ashok Bidwai, Ph.D.

Department of Biochemistry and Molecular Pharmacology

Morgantown, West Virginia

2005

Keywords: Rx gene, BMP-4, Eye Development, Retinal expression 


\title{
Abstract \\ Determination of $\mathrm{Rx}$ expression in the adult mouse retina and delineation of $\mathrm{Rx}$-mediated gene regulation
}

\author{
Supriya A. Shah
}

The Retinal homeobox gene, $\mathrm{Rx}$, is expressed in the anterior neural plate and the optic vesicle shows $\mathrm{Rx}$ expression throughout development. $\mathrm{Rx}$ is required for the proliferation of retinal progenitor cells during eye development.

Our expression studies of the $\mathrm{Rx}$ gene in the adult mouse retina show $\mathrm{Rx}$ expression in the Photoreceptor and inner nuclear layer of the adult neural retina and ciliarybody. The cotransfection assays indicate that $\mathrm{Rx}$ supports the transcription of neural retinal markers, as well as the RPE-markers. Therefore we characterize Rx as a proliferation marker for the entire optic vesicle region.

To determine the mechanism of Rx-mediated regulation of its target genes, we studied the BMP-4 promoter sequence. The mutation in one PCE-1 site significantly reduced the activity of BMP-4 promoter. Also the construct with all three PCE-1 mutated sites, show decreased activity. The 3' end of the promoter by itself also shows reduced promoter activity. 


\section{$\underline{\text { Acknowledgement }}$}

I would like to thank my adviser, Dr. Peter Mathers for guiding me in my research. I am thankful to him for sharing his ideas with me for my project and I am even more thankful to him for guiding me through my proposal and thesis writing. I would like to thank my committee members Dr. Bradley Hillgartner, Dr. Michael R. Miller and Dr. Ashok Bidwai, for their constructive inputs and guidance for my research. I also want to thank the Chair of the department Dr. Diana Beattie and to Dr. Lisa Salati and the staff of the Department of Biochemistry and Molecular Pharmacology.

I want to thank my fellow graduate students for being just wonderful colleagues whom I could always count on for any kind of advice. I specially want to thank Sanjeev Kumar, Jason Morgan, Patrick Apopa and Anindita Biswas for their help and friendship. I also want to thank the Mathers lab people, especially Jason, David, Elena and Dennis for the three wonderful years of my life.

Finally, I want to thank my brother Harshad and sister Pradnya because of whom I could follow my dream of having a career in research. 


\section{Table of Contents}

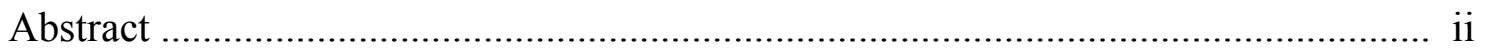

Acknowledgments .............................................................................................

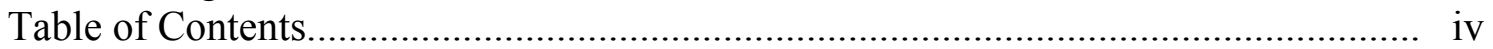

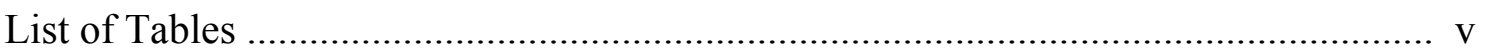

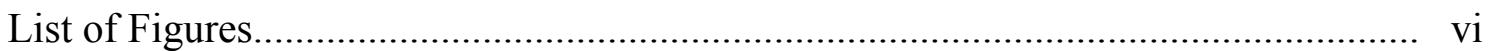

List of Symbols, Abbreviations, and Nomenclature..................................................... vii

Chapter I. Literature Review

A. Introduction

1. Eye Development.............................................. 2

2. Neural Retina Formation............................................ 3

3. Homeobox Genes Important For Eye Development................... 7

B. Overview of molecular network involved in eye development

1. Distal verses Proximal development of the eye........................ 16

2. Dorsal Verses Ventral Boundary Formation.......................... 17

C. The Retinal Homeobox (Rx) gene

1. Isolation of $\mathrm{Rx}$ gene ................................................. 20

2. Structure of the Rx gene and protein.................................. 20

3. The Rx expression pattern........................................... 23

4. Functional studies on Rx gene........................................ 26

5. Rx downstream target genes...................................... 30

6. Rx mutation leads to anophthalmia

1. Rx mutation in Human............................................ 31

2. Rx mutation in Fish.......................................... 32

3. Rx Mutation in Mouse.............................................. 35

Chapter II. Determination of expression pattern of the Rx gene in the adult mouse eye

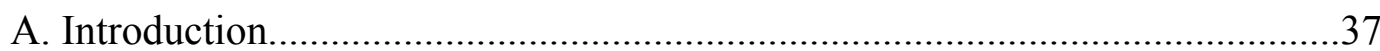

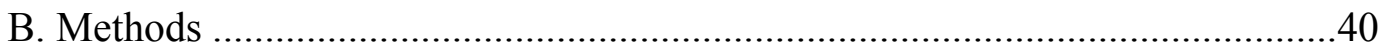

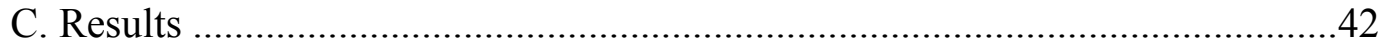

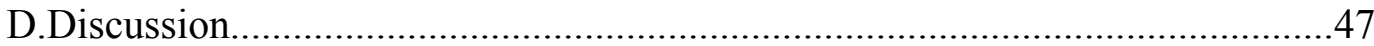

Chapter IIIA. Determination of the downstream target genes of the Rx transcription factor using cotransfection assays
A. Introduction. .51
B. Methods .54
C. Results .57
D.Discussion. .60 
Chapter IIIB. Determination of the Rx regulatory sequence or region in the BMP-4 promoter
A. Introduction.
B. Methods
70
C. Results
.75
D.Discussion.

Chaper IV. Summary and Future Direction

Appendix A

Chapter V.References. 


\section{List Of Tables}

Table 1: Strategy for the cotransfection assays.................................. 74

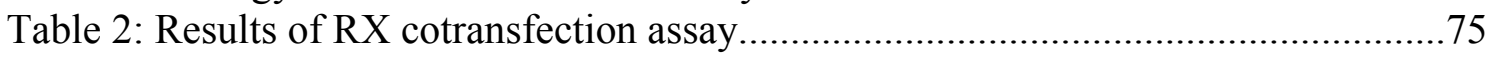

Table 3: Cotransfection results for mutated BMP-4 promoter $\ldots \ldots \ldots \ldots \ldots \ldots \ldots \ldots \ldots \ldots . . .86$ 


\section{List of Figures}

Figure 1: Schematic representation of neural retina formation......................4

Figure 2: Formation of neural retina and organization of neural retinal cells............6

Figure 3: Regulation of transcription factors for eye development ................... 19

Figure 4: Schematic representation of conserved domains of $\mathrm{Rx}$ protein.............22

Figure 5: Expression pattern of Rx in the Xenopus embryos......................24

Figure 6: Rx expression in mouse neuroretina, hypothalamus and pituitary at various

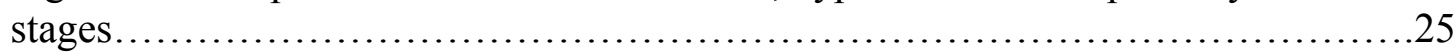

Figure 7: Rx Over-expression Experiments...................................28

Figure 8: Rx Knockout Embryo..............................................29

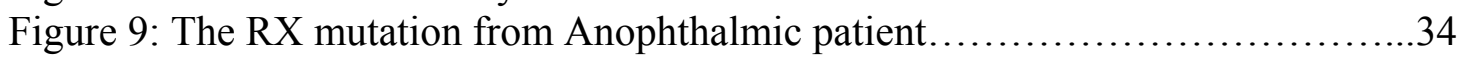

Figure 10: Rx expression in the adult mouse retinas...............................43

Figure 11: Rx continues to express in the adult mouse retinas.....................44

Figure 12: Rx expression in the ciliary margin of adult mice..................... 46

Figure 13: Patterning of neural retina and RPE by extrinsic and intrinsic factors.......63 


\section{List of Symbols, abbreviations and Nomenclature}

BMP-4- Bone Morphogenetic protein 4

Coloboma- Developmental defect of eye that leads to loss of vision

Crx- Cone rod homeobox-containing gene

Cyclopia: Developmental abnormality leading to only one eye formation

DIG- Digoxigenin

E\#- Embryonic day

Epiblast: The outer layer of blastula that gives rise to the ectoderm after the gastrulation

FISH- Fluorescent in situ hybridization

hRX- human retinal homeobox

holoprosencephaly: Developmental disorder leading to abnormalities in the forebrain

formation

IRBP- interphotoreceptor retinoid-binding protein

MitF- Microphthalmia

Mrx- murine retinal homeobox

OAR- paired-tailed transactivation domain

Otx- Orthodenticle homolog

P\#- postnatal day

Pax- paired-box

PCE1 - photoreceptor conserved element-1

PCR- polymerase chain reaction

Pfu-Turbo- DNA polymerase with proof reading exonuclease activity.

Prox 1- vertebrate homolog of the drosophila prospero homeobox gene

P-Tween- 1x PBS and 0.1\% tween-20

RACE-rapid amplification of cDNA ends

Ret1- PCE1 sequence: A Rx binding sequence of seven nucleotides

RNA- ribonucleic acid

RPE- retinal pigment epithelium

Rx- retinal homeobox

SDM- Site Directed Mutation

Six- vertebrate homolog of Drosophila sine oculis and Optix genes

Trp1: Tyrosine related protein-1

Trp2: Tyrosine related protein-2

Tween-20- Polyoxyethylene sorbitan monolaurate

Tyr- Tyrosinase

X-gal-5-bromo-4-chloro-3-indolyl -D-galactopyranoside

Xrx-Xenopus retinal homeobox

Xrx1-Xenopus Retinal homeobox 1

Xrx2- Xenopus Retinal homeobox 2

Zrx- Zebrafish Retinal homeobox 


\section{Chapter 1}

\section{Literature Review}




\section{A. Introduction}

\section{Eye Development}

Eyes have been the subject of research for their development, structure and signal transduction for over one-hundred years. Early experiments done in 1901 by Hans Spemann, showed that removal of the optic vesicle leads to an absence of lens (Grainger et al., 1992). Eye development in vertebrates involves the participation of signals from three types of embryonic tissues. The neural retina and the retinal pigment epithelium (RPE) are derived from the neural tube or neuroectoderm, the lens is derived from the surface ectoderm (Grainger et al., 1992;Li et al., 1994), and the corneoscleral and uveal tunics are derived from the mesoderm.

During neurulation, the anterior neural plate invaginates from the lateral walls of the forebrain and gives the bilaterally paired optic pits. The optic pit later forms the optic vesicle, which contacts the lens placode invaginating from the surface ectoderm. The surface ectoderm gives rise to the lens (Grainger et al, 1992; Saha et al., 1992). In mouse at the E9 stage, the optic vesicle stretches towards the thickened surface ectoderm forming the lens vesicle. In the later stages of development, the lens vesicle forms the lens pit by closing the opening in the surface ectoderm invagination. The optic vesicle invaginates during this process and forms the optic cup at around E10.5. At the optic cup stage, the multipotent retinal stem cells show the capability to differentiate into any of the neural retinal cell types or the retinal pigment epithelium (RPE) cells (Nguyen and Arnheiter, 2000; Tropepe et al., 2000; Wetts et al., 1989). Upon differentiation of the retinal stem cells, the inner layer of optic cup forms the neural retina (NR) and the outer layer forms the retinal pigment epithelium (RPE) (Adler et al., 1993) (Fig-1). The neural retina plays a key role in converting the light response into the electrochemical signal in photoreceptor cells, from where it is then carried to the brain by the optic nerves, whereas the RPE supplies the support and the necessary nutrients to the neural retinal photoreceptor layer. In fish, amphibians, and chicks, RPE cells also provide the stem cells for retinal regeneration (Orts-Llorca and Genis-Galvez, 1960; Reh and Levine, 1998). 


\section{Neural Retina Formation}

The neural retina is comprised of seven different neural retinal cells. These cells are rod and cone photoreceptors, amacrine cells, bipolar cells, horizontal cells, Müller glial cells and ganglion cells. These cells are organized into three cell layers. The rod and cone photorecepots are in the outer nuclear layer, the amacrine, bipolar, horizontal and the Müller glial cells are in the inner nuclear layer and the ganglion cells are in the ganglion cell layer as seen in Figure-2 (Jean et al., 1998). The photoreceptor cells have their nuclei in the outer nuclear layer and their axons spread into the outer plexiform layer.

The retinal pigment epithelium contains only one layer of pigmented epithelial cells. The pigmentation in these cells is conferred by the melanin-producing melanosomes in these cells. RPE plays an important role during retinal formation and in the regeneration of the retina (Rio-Tsonis et al., 2003). RPE is also known to support the photoreceptor cells in adult stages.

RPE can dedifferentiate into neural retina (Mitashov et al., 1997; Raymond and Hitchcock, 2000; Cheon et al., 2001; Sakakibara et al., 2002) by a process called transdifferentiation. Urodeles retain the transdifferentiation ability even in adult stages (Rio-Tsonis et al., 2003; Reh and Nagy, 1987; Klein et al. 1990). The RPE dedifferentiates in adult retinectomized newt eyes and forms a new retina with correct laminar orientation (Chiba et al., 2004), but this retinal regenerative capacity is absent in adult mammals. 


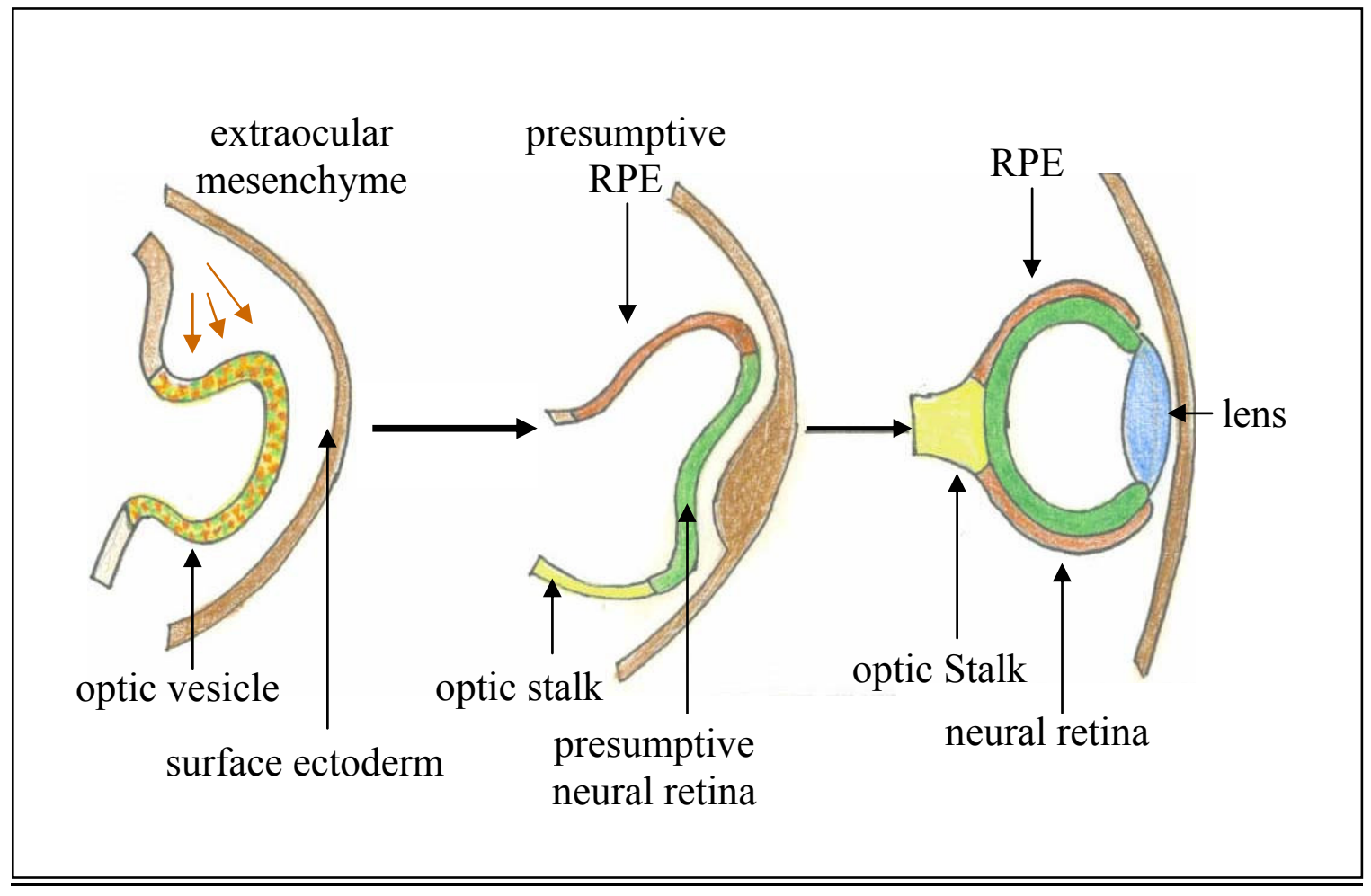

Figure 1: Schematic representation of neural retina formation

In mouse embryos the retinal progenitor cells at the E9 stage or at the optic vesicle formation stage express both RPE- and NR-specific markers. The red color represents the expression region of RPE-specific transcription factors while the green color represents the expression region of the neural retinal transcription factors. The signals from the extraocular mesenchyme promote RPE formation, whereas surface ectoderm promotes neural retina formation (Figure derived from Martinez-Morales et al., 2004). 
The periphery of most vertebrate retinas form a ciliary margin zone $(\mathrm{CMZ})$ at the conjuction of retina and iris. The CMZ contains the epithelial cells and in many species this CMZ epithelium is shown to contain the retinal progenitor cells (Fischer and Reh., 2000; Reh and Fischer.,2001). During the regeneration of retina, the RPE uses these progenitors from the $\mathrm{CMZ}$ for the neural retina formation in amphibians and urodeles (Mitashov et al, 1968; Mitashov and Maliovanova, 1982; Svistunov and Mitashov, 1985). During the formation of the optic cup, the optic vesicle forms a stalk like structure in the medial part of optic vesicle which upon differentiation forms the optic stock (Jean et al., 1998). 


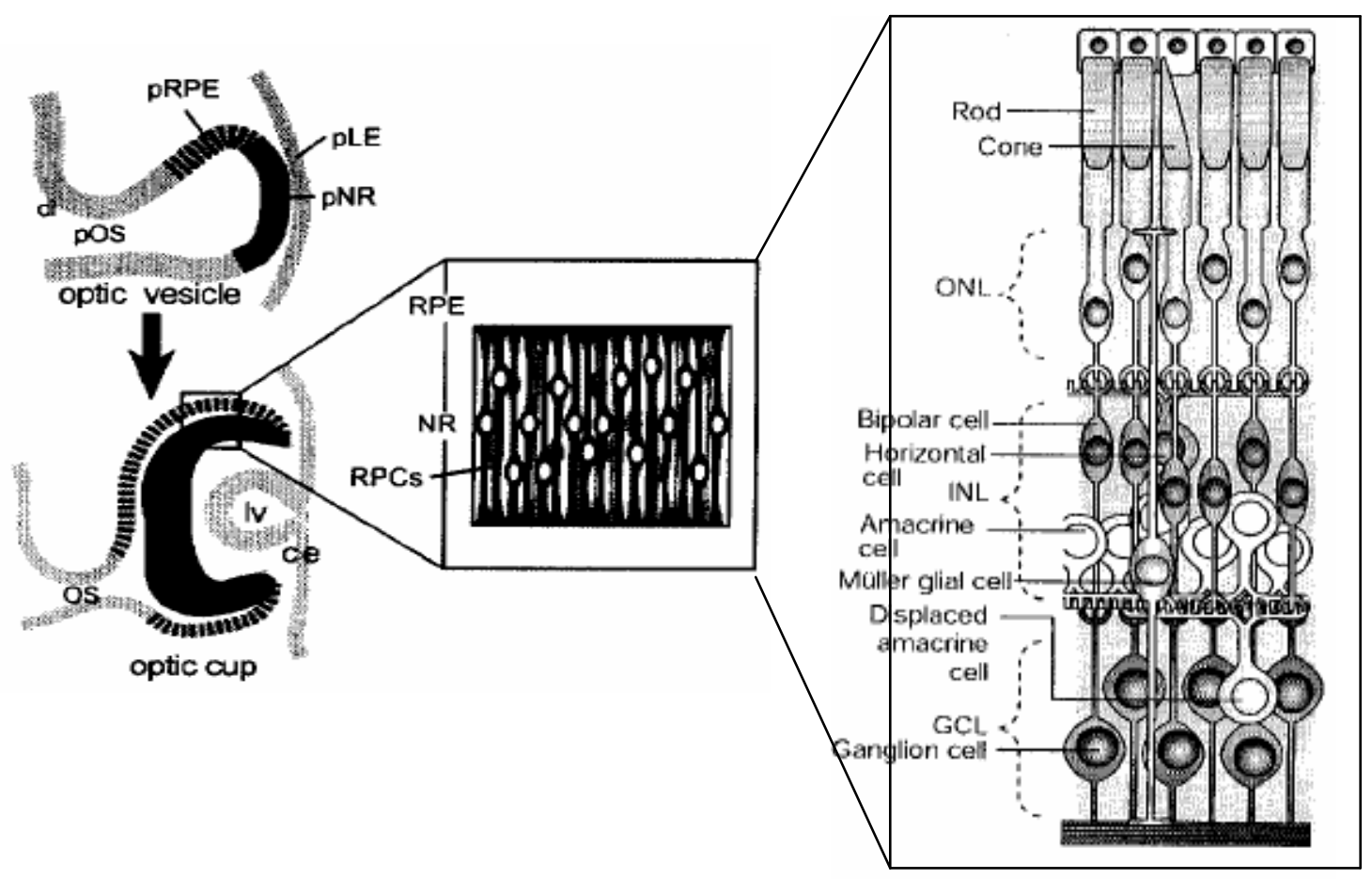

Figure 2: Formation of neural retina and the organization of neural retinal cells

The presumptive neural retina forms the neural retina as the surface ectoderm invaginates. The outer layer of the optic cup forms the pigmented RPE and the inner layer forms neural retina. All the seven cell types of the neural retina are derived from the multipotent retinal progenitor cells of the inner layer of optic cup. These seven cell types are organized to form the laminar neural retina. The three layers formed in the neural retina are outer nuclear (ONL), inner nuclear (INL) and ganglion cell (GCL). pOS: presumptive optic stalk, OS: optic stalk; lv: Lens vesicle, pLE: presumptive lens vesicle; pNR: presumptive neural retina; $p R P E$ : presumptive RPE (Figures taken from Marquardt et al., 2003 and Dyer et al., 2001). 


\section{Homeobox Genes Important For Eye Development}

The communication between cells via extracellular cues and the responses of cells to these cues through the expression of transcription factors such as homeobox genes comprise the developmental process. Therefore, the homeobox genes expressed in the anterior neural plate during various stages of development play very crucial roles for development. The developmental process progresses through balancing the time and location of signals for proliferation to those for differentiation for proper structure formation.

Differentiation of retinal stem cells to RPE or to neural retina is mainly controlled by various homeobox genes expressed in the developing optic vesicles (Nguyen et al., 2000). The homeobox genes encode transcription factors carrying structural motifs such as the helix-turn-helix motif which enables these transcription factors to bind DNA and regulate expression of the target genes. With their role in transcription regulation, the homeobox genes play important roles in development by activation or repression of other transcription factors. The genes currently considered crucial for neural retinal development include the homeobox genes Pax6, Six3, Rx, Chx10, Lhx2, Six6 (Marquardt et al., 2001; Carl et al, 2002; Mathers et al., 1997; Andreazolli et al., 1999; Porter et al., 1997; Bernier et al., 2000; Gallardo et al., 1999).

Genes that are expressed in the optic vesicle but are confined to retinal pigment epithelium (RPE) region are, Trp1, Trp2, Mitf, Tyrosinase, QNR71 and these genes are considered crucial for RPE development (Goding et al., 2000; Beermann et al., 1992; Nguyen et al., 2000; Hodgkinson et al.,1993). The genes expressed in the neural retina such as Rx, Pax6, Six3, Chx10 are not expressed in the RPE, which makes them useful neural retinal markers. The role of Otx2 in retinal development is less clear, as its expression is seen in the neural retina in the initial stages but then it gets restricted to RPE in the later part of development. Also some of the cell cycle regulators such as CyclinD1 and the growth factors FGF8 and FGF15 are considered to be important for neural retinal development (Sicinski et al., 1995; Vogel-Hopker et al., 2000; McWhirter 
et al., 1997). CyclinD1 is necessary for the proper proliferation and prevention of apoptosis in the neural retinal cells (Ma et al., 1998) whereas, FGF8 supports the neural retina formation by inhibiting the RPE specific genes from the neural retinal region (Pittack et al., 1997). The results obtained from earlier studies on all of the above mentioned genes have demonstrated the importance of these genes in retinal development. We will see this in detail here.

$\underline{\operatorname{Pax} 6}$

Pax6 plays an important role in the development of lens, retina and pancreas. Pax6 is initially expressed in the entire optic vesicles, but in the later stages Pax6 expression is confined to the lens and neural retina (Grindley et al., 1995). Pax6 is expressed in all mitotic retinal progenitor cells (RPC) throughout retinogenesis. After the differentiation of progenitors into seven individual cell types of retina, Pax6 continues to be expressed only in the amacrine cells, horizontal and ganglion cells (Hitchcock et al., 1996; Belecky-Adams et al., 1997; Koroma et al., 1997).

The Pax6 gene is required for normal ocular development in many species. In human, heterozygous mutation in Pax6 leads to Aniridia (Ton et al, 1991), Peter's anomaly and congenital cataract formation (Hanson et al., 1994). In mice heterozygous mutation in Pax6 leads to 'small eye' syndrome (Hill et al., 1991). The homozygous mutation in Pax6 in mice and human is lethal, because Pax6 also participates in the development of the islet cells of pancreas and the total absence of Pax6 gene leads to death due to diabetes (Yasuda et al., 2002). The injection of Drosophila homologues of Pax6 known as eyeless and the twin of eyeless is able to induce ectopic eyes in injected Xenopus embryos (Chow et al., 1999). The mutational analysis for the eyeless and the twin of eyeless genes show headless phenotypes in severe mutants and reduction or absence of eyes in the hypomorphic homozygous. These results implicate Pax6 as the key homeobox gene for eye development in Drosophila, but studies in vertebrates indicate that Pax is only one of the important genes required for eye development. 
Several studies confirm the idea that though Pax6 is crucial for vertebrate eye development, it is not the key regulator of eye development. The study in mice using the Pax6 inactivation by the flox gene showed that the retinal progenitor cells in Pax mutants fail to express other retinogenic genes, such as Ngn2, Mash1 and Math5 (Marquardt et al, 2001) and Pax6 absence leads to differentiation of these retinal progenitors to amacrine cells only (Marquardt et al., 2001). The same study further shows coexpression of Pax6 with Rx and Hes1 in the retinal progenitor cells prior to differentiation and retinogenesis (Marquardt et al., 2001), but targeted deletion of Pax6 expression using the Flox $\Delta$ mice showed no difference in Rx or Hes1 expression in the distal neural retina. This indicates that expression of Rx and its downstream target gene Hes1 (Furukawa et al., 2000) is not affected by Pax6 expression.

Other studies show that absence of the Rx or Lhx2 genes in vertebrates leads to anophthalmia (Mathers et al., 1997; Porter et al., 1997). Overexpression studies show that many genes, such as Rx and Six3 give ectopic eye formation even though Pax6 levels are not altered (Mathers et al., 1997; Loosli et al., 1999, Andreazzoli et al., 1999). On the other hand, the Rx homozygous germline mutation in mice showed complete absence of Pax6 gene expression in the presumptive optic area at E10.5 (Zhang et al., 2000). Combining this result with the second study by Voronina et al which showed the absence of Pax6 in the Rx OV-conditional knockout mice, further supports the idea that Pax6 is not the most vital gene for eye development.

\section{$\underline{\mathrm{Otx} 2}$}

The Otx2 protein is a bicoid-type homeodomain protein. The earliest expression of Otx2 in mouse is observed around E5.5 in the epiblast region (Ang et al., 1996). Later, Otx 2 shows expression in the midbrain, otic vesicles and optic vesicles (Simeone et al., 1992, Simeone et al., 1993). In the later stages of development, Otx2 expression is confined to the retinal pigment epithelium (Bovolenta et al., 1997), but during neural retinal differentiation around E17, Otx2 expression is again found in the neural retina along with the retinal pigment epithelium (Simeone et al., 1993). Otx2 plays 
an important role in the formation of the RPE by regulating the promoters of RPEspecific genes such as Tyr, Trp1 and QNR71 (Martinez-Morales et al., 2003). The same study shows that Otx2 by itself can induce the pigmented areas in neural retinal cultures, similar to the activity of Mitf (Martinez-Morales et al., 2003). This indicates that the presence of Otx2 is enough to change the cell fate towards pigmented cells.

Mice heterozygous for the Otx2 mutation develop otocephaly, a craniofacial malformation (Matsuo et al., 1995). Otx $2^{+/}$pups show absence or reduction of the eyes externally and histological study shows holoprosencephaly in these mice (Matsuo et al, 1995). The Otx $2^{-/}$mutation is a lethal mutation and leads to death during or shortly after gastrulation (Acampora et al., 1995; Matsuo et al., 1995). Phenotypic analysis at the E77.5 shows deformities like the absence of prechordal mesoderm and notochord precursors in Otx2 homozygous mutant embryos (Ang et al., 1996). The headfolds are completely absent in these embryos. By the E8.25 stage, these embryos show deletion of rhombomere 3 from the neural tube (Ang et al., 1996). The human mutation for this gene leads to the agnathia-holoprosencephaly complex (Wallis and Muenke et al., 2000). A few characteristics of this syndrome include coloboma of the retina or choroids and cyclopia.

In Rx germline knockout mice, Otx2 expression is totally absent in the distal optic vesicle at the E10 stage (Zhang et al., 2000). However, the Rx optic vesicle conditional knockout shows no reduction in the expression of Otx2. In these Rx conditional knockout mice, Otx2 was seen expressed in the entire distal optic vesicle (Voronina et al., unpublished observations).

\section{$\underline{\operatorname{Six} 3}$}

The Six 3 gene is a member of Six family of genes which share a conserved domain called Six. The Drosophila homologue of Six3, called optix, has $90 \%$ amino acid identity with the Six3 homeodomain of Optix2, the vertebrate ortholog of Six3 (Toy et al.,1998, Seimiya et al., 2000). In Drosophila, Optix is seen to be important for normal development of the entire visual system (Pasquier et al., 2000). Six 3 is also shown to be 
important in the mouse visual system development (Oliver et al., 1995). Six3 is expressed at E6.5 in the presumptive optic pit region prior to Rx expression at E7.5.

Six 3 overexpression in Medaka fish leads to ectopic retinal primordia (Loosli et al, 2001), whereas the inactivation of Six3 in Medaka fish leads to absence of eyes and forebrain (Carl et al., 2002). A Six3 heterozygous mutation leads to holoprosencephaly in humans (Pasquier et al., 2000). In mice, Six3 null embryos show an absence of the rostral forebrain at the early somite stages and the mutant head shows Wnt expression in the rostral region indicating posteriorization of the head (Lagutin et al., 2003).

The combined studies in the Medaka fish and mouse show that injection of Six3 leads to ectopic neural retinas expressing Rx2 and Pax6 (Loosli et al., 1999). Also these retinas showed hyperplasia with twice the number of cells in the retinas (Loosli et al., 1999). The Six3 inactivation studies in Medaka showed that the embryos have abnormalities in the forehead formation and lack eyes (Carl et al, 2002). Also the cells in these regions showed increased apoptosis. These observations suggest that Six 3 blocks apoptosis of cells and thus helps in the formation of the eyes and forehead structures. Six 3 and Pax6 are able to activate each other's expression and are able to form ectopic eyes together (Loosli et al., 1999, Chow et al., 1999, Kobayashi et at., 1998). Several studies indicate that Six 3 might be acting in a feedback loop involving Pax6, Rx and Six3 itself. For example, Six3 injections in the Pax2-Six3 transgenic mouse embryos form ectopic optic vesicles expressing Pax6 (Lagutin et al., 2001). Also the same study showed that Pax6 controls the expression of Six 3 in the lens placodal ectoderm (Lagutin et al., 2001). These genes show overlapping expression in the developing retina.

Rx optic vesicle conditional knockout pups showed normal expression of Six 3 at E9.5 but it was downregulated at E10.5 (Voronina et al, unpublished observations). The Rx homozygous mutants in another study also show that in the absence of Rx the Six 3 expression in the presumptive optic area is lesser than that seen in the Rx wild type embryos (Zhang et al., 2000). 


\section{$\underline{\text { CyclinD1 }}$}

High expression of CyclinD1 is seen in the proliferating mouse neural retina and also in the chick retina (Sicinski et al., 1995, Godbout et al, 1996). CyclinD1-deficient mice show defects in eye development (Sicinski et al., 1995; Fantl et al., 1995). CyclinD1 homozygous mutant mice possess all the neural retinal cellular layers, but the layers were reduced in size. On the contrary, the RPE cell layer demonstrated perfect morphology (Sicinski et al., 1995). This shows that CyclinD1 is necessary for normal proliferation of the neural retina. In another study, the CyclinD1-deficient mice showed degeneration of the photoreceptors, creating holes in the photoreceptor layer (Ma et al., 1998). The holes were developed as a consequence of an increased rate of apoptosis. Since this defect was congenital but it persisted throughout adulthood, CyclinD1 might be crucial for preventing degeneration of the photoreceptor layer in adulthood along with its earlier function in development.

The importance of CyclinD1 in development of the retina is emphasized further by its colocalization with Pax6 in retinal precursor cells in the embryonic (E12.5 and 15.5) and postnatal neuroretina (Marquardt et al., 2001). Retinogenesis is still taking place at these early stages (E12.5 and 15.5). Experiments have shown that the Rx optic vesicle conditional knockout pups show an absence of CyclinD1 in the distal optic vesicles. The neural retina failed to form in these animals (Voronina et al., unpublished observations).

\section{Hes1 (Hairy enhancer of split) \& Notch1}

Hes1 and Notch1 are coexpressed in retinal progenitor cells (Tomita et al., 1996, Bao and Cepko, 1997). Experiments done in mice showed that the activated Notch protein activates Hes1 transcription through KBF2-binding sites in the promoter region (Jarriault et al., 1995). Hes 1 prevents the differentiation of the retinal progenitor cells by inhibiting the pro-neural transcription factors such as NeuroD1, Math1 and Mash1. The null mutation of Hes1 in mice leads to early neuronal differentiation due to increased Mash1 expression and leads to defective eyes and brain structures (Kageyama et al., 
1997). At nine days postpartum (P9) stage in mouse, the Hes1 and Notch1 genes show overlapping expression with $\mathrm{Rx}$ in the inner nuclear layer of the retina (Furukawa et al., 2000). These cells also express the Müller glial marker, CRALBP (Cellular retinaldehyde binding protein). The induced expression of Rax using retroviral expression indicated that the progenitor cells expressing Rax take the Müller glial pathway. The forced expression of Hes1 and Notch1 also indicated that the progenitor cells differentiate as progenitors. To determine the correlation between expression of these genes, the levels of Hes 1 and Notch1 were determined in the Rax transfected cells specifically and the nested RT-PCR showed that in the presence of Rax, Notch1 and Hes1 are also expressed. This leads to the conclusion that the Rx mediated expression of Notch1 and Hes1 leads to Müller glia development (Furukawa et al., 2000).

\section{$\underline{\text { FGF8 }}$}

In chick eyes, FGF8 is expressed only in the presumptive neural retinal region of the optic vesicles, and FGF8 continues to be expressed in the neural retina during later stages of development. The injection of FGF8-soaked beads into the presumptive RPE of chick changed the RPE to neural retina cells (Vogel-Hopker et al., 2000). Neural retina formed in this manner shows the expression of neural retinal markers such as Rx, Sgx1 and FGF8 itself, but the RPE markers Mitf and BMP7 are not expressed (Vogel-Hopker et al., 2000). This FGF8-induced secondary neural retina showed all the neural layers. This means that FGF8 by itself is able to induce the formation of neural retina. Interestingly, FGF8 is absent in Rx OV-conditional knockout embryos at E10.5 where the neural retinal fails to develop (Voronina et al., Unpublished observations).

\section{$\underline{\text { FGF15 }}$}

FGF15 is another member of the fibroblast growth factors family. In situ hybridization studies in mice have shown that FGF15 is expressed in the midbrain, hindbrain \& optic cup during development (McWhirter et al., 1997). The FGF15 expression pattern was noticeable in the optic cup from E9.5 to E16. FGF15 expression was restricted to the inner cell layer of the optic cup, which eventually forms the neural 
retina. FGF15 expression is absent in Rx optic vesicle conditional knockout mice at E10.5 (Voronina et al., unpublished observations).

\section{BMP-4 (Bone Morphogenetic Protein)}

BMP-4 comes under the category of the TGF- $\beta$ family of genes. This family is considered to be important for embryonic tissue development (Hogan et al, 1996). BMP4 is particularly important for the formation of the dorsal-ventral axis in Xenopus embryos (Maeno et al., 1994) and for patterning of the facial primordium (Barlow et al., 1997). Later during the development, BMP-4 is expressed in the optic vesicles, where it is crucial for lens induction (Furuta et al., 1998).

A study in our lab showed that Rx protein can activate the BMP-4 promoter nearly six-fold, and the Rx optic vesicle conditional knockout pups showed no expression of BMP-4 in the distal optic vesicle at E10.5 stage. (Voronina et al., unpublished observations). This strongly suggests that BMP-4 expression in the optic vesicle is controlled by Rx protein. The in situ hybridization study on the normal mice retina shows that BMP-4 mRNA is expressed in ganglion cells, inner nuclear cells and photoreceptor inner layer (Mathura et al., 2000), but the in situ hybridization study on the retinas of the FVB mice carrying the $r d$ mutation showed decreased levels of BMP-4 in degenerating photoreceptor cells (Mathura et al., 2000). This further supports the idea that the BMP-4 expression level is a good representative of the neural retinal state. The role of BMP-4 in the optic vesicle becomes clearer as BMP-4 shows significant inhibition of proliferation of cultured RPE cells (Mathura et al., 2000).

\section{Mitf (Microphthalmia associated transcription factor)}

Mitf is expressed in the optic vesicle in the initial stages (Nguyen et al., 2000) and then later on its expression remains restricted to the RPE during its development (Hodgkinson et al., 1993). This transcription factor has basic helix-loop-helix and leucine zipper motif (bHLH-LZ). The isoforms Mitf-A and Mitf-D are expressed mostly in the RPE and the A isoform is believed to be important for RPE formation (Goding et al., 2000). One of the other isoforms called Mitf-M, is expressed in the neural crest derived 
melanocytes. Each of these isoforms has unique amino termini, which indicate that these isoforms are transcribed from different promoters.

The mutational analysis of the Mitf gene showed impaired development of RPE in mice leading to laminated second neural retina formation (Nguyen et al., 2000, Nakayama et al., 1998). The overexpression of this gene shows pigmentation in the avian neural retina (Planque et al., 1999). Also the Mitf mutations in human lead to Waardenburg syndrome type 2 (Tassabehji et al.1994). These patients show abnormal pigment formation and deafness (Tassabehji et al.1994). The Mitf gene regulates RPE specific genes, as QNR71, Tyr, TRP-1, TRP-2, which are crucial in terminal differentiation of RPE (Goding et al., 2000; Martinez-Morales et al., 2003). This regulation is achieved by specific binding of the Mitf to the M-box hexameric motif CATGTG present in the promoter regions of all these genes (Goding et al., 2000).

\section{$\underline{\text { Trp1 \& Trp2 (Tyrosinase Related Proteins) }}$}

Trp1 (also known as Tyrp1) and Trp2 (also known as Tyrp2 or Dct) are involved in melanin biosynthesis in the pigment cells. Trp1 and Trp2 act downstream to the tyrosinase in the melanin production and control the amount of melanin to be synthesized (Goding et al., 2000). In the developing mouse eye, Trp1 expression is seen only in the RPE (Raymond et al., 2003). Trp2 however is expressed in RPE and in the developing telencephalon (Raymond et al., 2003). In the adult stages, however these two are characterized as RPE markers. In the Rx optic vesicle conditional knockout mice at the embryonic day 10.5, the Trp2 expression was seen all over the mutated optic vesicle called the distal optic vesicle (Voronina et al, submitted). This Trp2 expression region later gave pigmented cells and developed into RPE.

\section{Tyrosinase}

Tyrosinase along with Trp1 and Trp2 helps in the formation of melanin in the melanosomes. Tyrosinase acts as the rate limiting enzyme in the earlier stages of melanin production (Gimenez et al., 2003). Tyrosinase converts Tyrosine to DOPA quinone, which is essential for melanin production. Tyrosinase expression is observed in two types 
of cells, in the melanocytes and in the RPE cells. During mouse development, tyrosinase starts to show expression in the RPE at E10.5 (Beermann et al., 1992).

The promoter region for the tyrosinase gene contains one $11 \mathrm{bp} \mathrm{M}$ box sequence (AGTCATGTG) which is important for its expression. There is an E box sequence lying within this sequence (CATGTG), which is recognized by the bHLH and bHLH-LZ transcription factor (Goding et al., 2000). This goes hand in hand with the fact that this gene is shown to be regulated by Mitf gene (Goding et al., 2000), which has a bHLH-LZ motif and is able to bind the $\mathrm{E}$ box motif. Tyrosinase is also seen to be activated by Otx2 (Maritnez-Morales et al., 2003).

Some other genes such as Chx10, Lhx2, Gas1, Prox1, Vax1, Vax2, and hesr1, are also important for the normal eye development. Chx10 promotes the proliferation of cells and the mutation in Chx10 leads to microphthalmia (Liu et al., 1994). Similarly, expression of the other genes is seen to be very essential for proper ocular development, but since the regulatory region for the transcription of these genes is not well characterized we could not include these in our study.

\section{B. Overview of molecular network involved in eye development}

\section{Distal versus proximal development of the eye}

Pax6 and Pax2 are important for delineation of the distal versus proximal development of eye. During the delineation of the optic vesicle from the anterior neural tube, Pax6 is expressed in the presumptive optic vesicle whereas the Pax 2 is expressed in the presumptive optic stalk (Schwarz et al., 2000; Torres et al., 1996). During development, both of these genes mutually repress the expression of the other gene and thereby form the optic cup/ optic stalk boundaries in the eye (Schwarz et al., 2000). Pax6 continues to be expressed in the neural retina in the adult stages and Pax 2 maintains expression in the RPE and optic stalk.

During development, Pax2 expression is also restricted to the optic stalk region by other genes (Barbieri et al., 1999; Schulte et al., 1999). Vax2 overexpression in Xenopus 
showed enhanced expression of Xpax2, whereas the expression of a dorsal marker, Xvent2, was decreased. Sonic Hedgehog is also a strong candidate for the regulator of Pax2 gene expression. Sonic Hedgehog is proven to play an important role during the proximo-distal specification of the optic vesicle. The mutated form of shh leads to ocular conditions such as microphthalmia and coloboma in humans (Schimmenti et al., 2003). Shh participates in eye development by promoting proximal optic vesicle formation while negatively regulating the distal optic vesicle. The proximal optic vesicle gives rise to the optic stalk, whereas the distal optic vesicle gives rise to the optic cup. The formation of optic stalk by Shh is most likely achieved through the homeobox genes, Vax1 and Pax2 (Hallonet et al., 1999; Ekker et al., 1995), as the increased expression of Shh showed Vax1 and Pax2 induction in the respective studies. Vax1 overexpression in Xenopus showed Rx downregulation affecting the eye phenotype (Hallonet et al., 1999). Shh overexpression leads to expression of Vax1 and Pax2 over an extended area, compromising Pax6 and Rx expression (Hallonet et al., 1999).

\section{Dorsal Versus Ventral Boundary Formation}

The Dorsal versus ventral boundary formation is regulated at a higher level than Vax2 and Pax2 regulation. This regulation can be traced with the Shh-mediated ventral retinal formation and with the BMP-4-mediated dorsal retinal formation (Yang et al, 2004;Zhang and Yang, 2001). Shh expression can restrict the BMP-4 expression region from the ventral side of the chick optic vesicles (Zhang and Yang, 2001). Shh and BMP-4 mutually restrict the expression of other genes for the formation of the dorso-ventral and the proximo-distal boundary formation (Sasagawa et al., 2002). Shh regulates the expression of Vax (Take-Uchi et al., 2003) and Pax2 (Dakubo et al., 2003). Vax upregulates Pax2 expression (Zhang and Yang, 2001), while downregulating Rx and Pax6 expression from the optic stalk region as explained earlier (Zhang and Yang, 2001; Hallonet et al., 1999; Sasagawa et al., 2002). Vax controls the dorso-ventral boundary formation by regulating the expression of Ephrins (Eph B2 and B3) (Take-uchi et al., 2003; Yang et al., 2004). Ephrin receptors and ligands are required for the fusion of various epithelias and are also required for the retinal axon pathfinding (Take-uchi et al., 2003). 
While on the dorsal side, several factors including Rx activate the expression of BMP-4 (Voronina et al., Unpublished observations) and BMP-4 activates the transcription factor Tbx5 (Koshiba-Takeuchi et al., 2000; Sasagawa et al., 2002). Tbx5 controls the expression of Vax, Eph B2 and B3 in the dorsal region of the optic vesicle while supporting the expression of Eph B1 and B2 (Sasagawa et al., 2002;Zhang and Yang, 2001).

This mutual suppression between Tbx5 and Vax leads to regulation of the downstream targets Pax2, Pax6 and Rx, for the specification of the dorso-ventral boundaries (Yang et al., 2004). Along with these regulators, Rx is also necessary for the formation of the proximo-distal axis in the optic vesicle (Voronina et al., Unpublished observations). The $\operatorname{Rx} \Delta 2{ }^{\text {Foxgl }}$ mice show disrupted proximo-distal specification. The mutated distal optic vesicle shows the expression of RPE specific markers while the optic stalk region shows expression of distal optic vesicle markers like Rx, Otx2 and Pax6.

A key role is played by FGF in neural retinal formation by facilitating the degradation of Mitf. The RTK-mediated Ras/ERK pathway phosphorylates the Mitf protein in neural retina. The Phosphorylation increases the transcription of Mitf, but also facilitates the ubiquitin-dependent degradation and results in elimination of Mitf from the neural retinal region (Yang et al, 2004). Also, the RPE cells transdifferentiate and form the neural retinal layers when treated with FGF-2 (Fischer and Reh, 2001; Pittack et al., 1997). The FGFs and BMP secreted from the surface ectoderm facilitate neural retinal formation while downregulating RPE-specific markers. 


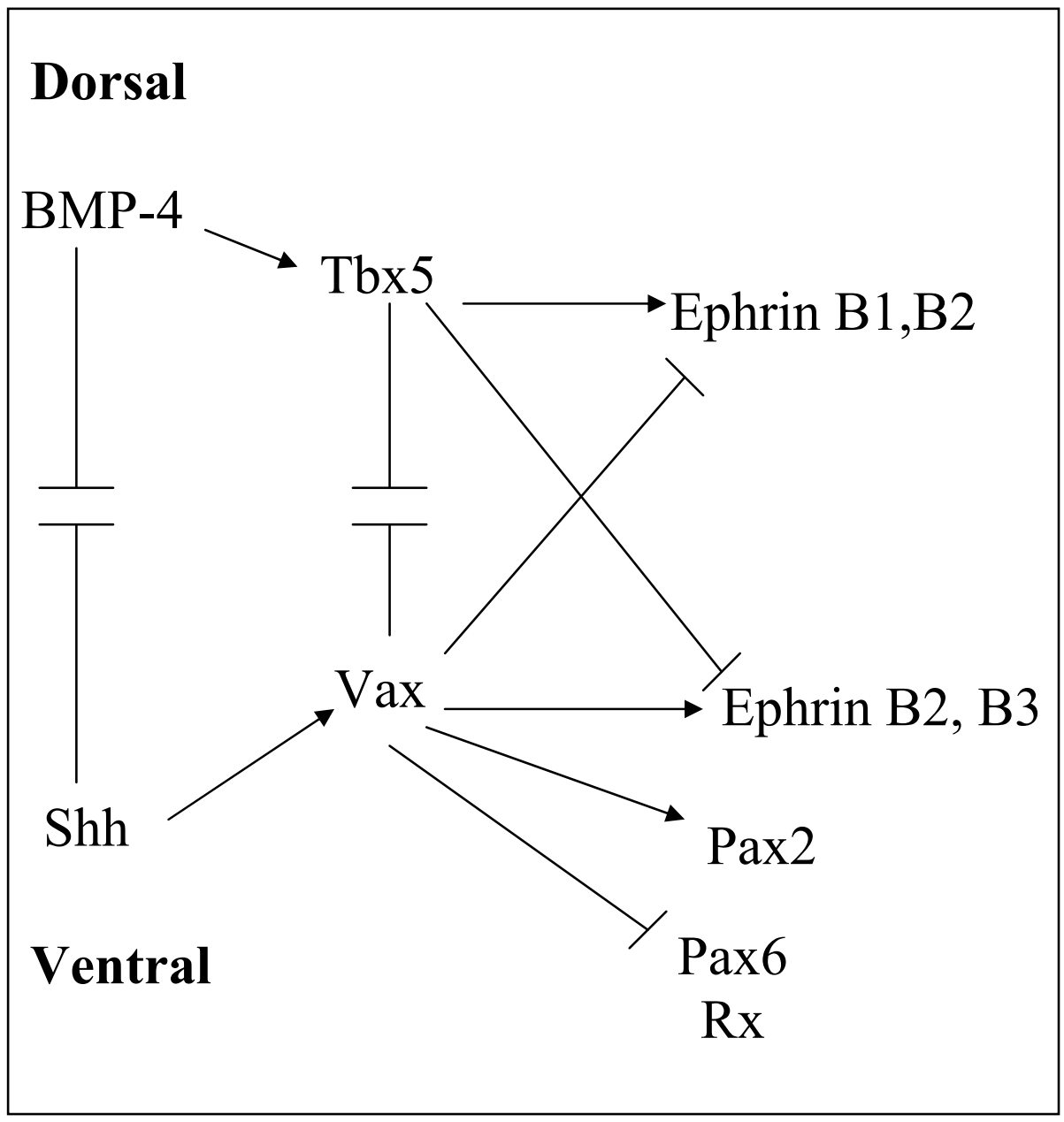

Figure 3: Schematic representation of the regulation of transcription factors for eye development in the vertebrate eye

Shh supports the expression of factors necessary for the formation of the ventral retina while inhibiting the expression of dorsal optic vesicle markers. Similar inhibition of Shh and the downstream targets of Shh are seen on the dorsal side by BMP-4 and by the downstream effectors of BMP-4. (Figure derived from Yang et al., 2004). 
The extraocular mesenchyme also plays a critical role in the formation of RPE by antagonizing the pro-neural retinal signals from the surface ectoderm while activating the expression of RPE-specific markers. One of the known regulators from the extraocular mesenchyme is the TGF- $\beta$ family protein called activin (Fuhrmann et al., 2000;Pittack et al., 1997). In the presence of extraocular mesenchyme or just activin, the RPE-specific markers Mitf, Wnt13 and the melanosomal matrix protein MMP115, were upregulated in retinal explants, whereas the neuroretinal markers, Pax6 and Optx2, were down regulated (Fuhrmann et al., 2000;Pittack et al., 1997).

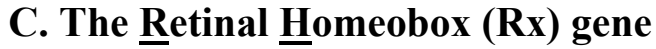

\section{Isolation of Rx gene}

The Rx gene was isolated by three groups simultaneously. One group screened a Xenopus cDNA library with the murine Orthopedia gene at low stringency (Casarosa et al., 1997). The recovered gene showed expression in the optic vesicle, ventral diencephalon, and pineal gland during development. Another group isolated the gene from the animal cap explants of Xenopus after treatment with $\mathrm{NH}_{4} \mathrm{Cl}$ (Mathers et al., 1997). $\mathrm{NH}_{4} \mathrm{Cl}$ induces the expression of the genes involved in anterior head formation.

Another group used the random-primed cDNA made from rat retinas to isolate this gene (Furukawa et al., 1997). Rx was later found to be expressed and studied in other species. $\mathrm{Rx}$ is seen to have different copy number is each species. For example, Drosophila (Eggert et al., 1998;Mathers et al., 1997) mouse (Furukawa et al., 1997;Mathers et al., 1997) and human (Kimura et al., 2000;Mathers et al., 1997) have just one Rx gene. Zebrafish has the maximum, with three Rx genes (Chuang et al., 1999;Mathers et al., 1997). Xenopus (Casarosa et al., 1997;Mathers et al., 1997), Medaka fish (Deschet et al., 1999) and chicken (Chen and Cepko, 2002;Ohuchi et al., 1999) carry two Rx genes.

\section{Structure of the Rx gene and protein}

The Rx gene contains three highly conserved domains, which are the octapeptide, the homeodomain and the carboxy terminal paired-tail region (Mathers et al., 1997). The paired-like homeobox region of the $\mathrm{Rx}$ gene forms three alpha helices in the protein and 
binds to DNA. The second and third helical regions form a helix-turn-helix motif (Beebe et al., 1994). The octapeptide region of Rx is homolgous to the Drosophila Engrailed corepressor sequence, eh1. The eh1 sequence and similar GEH sequence from goosecoid from Drosophila are required for transcriptional corepression (Mailhos et al.,1998; Smith and Jaynes.,1996). A probable mechanism hypothesized for Rx-mediated corepression assumes a combined effect of Rx with the groucho family of corepressors. A mutation in the conserved amino acid of the third helix of some of the helix-turn-helix proteins prevents the protein from binding to DNA (Beebe et al., 1994). The homeodomain recognizes a seven to eight nucleotide sequence on DNA which contains the 'TAAT' core sequence flanked by additional bases, which help the homeodomain in specific binding (Beebe et al., 1994). The carboxy terminal paired-tail region of several homeodomain proteins contains a fourteen amino acid-conserved motif, called the OAR (otp, aristaless, and rax) or $\mathrm{C}$ terminal domain, and this region is also seen in the $\mathrm{Rx}$ homeodomain protein (Furukawa et al 1997; Mathers et al., 1997). This domain was assumed to be important for trans-activation and for protein-protein interactions (Furukawa et al., 1997, Simeone et al., 1994). The transactivation function of OAR domain was confirmed when a deletion mutant of Xrx1 that truncates the protein before the OAR domain, failed to show the functional effects of anteriorization and proliferation in the neural plate that are seen with full-length Xrx1 over expression (Andreazolli et al, 1999). 
A.

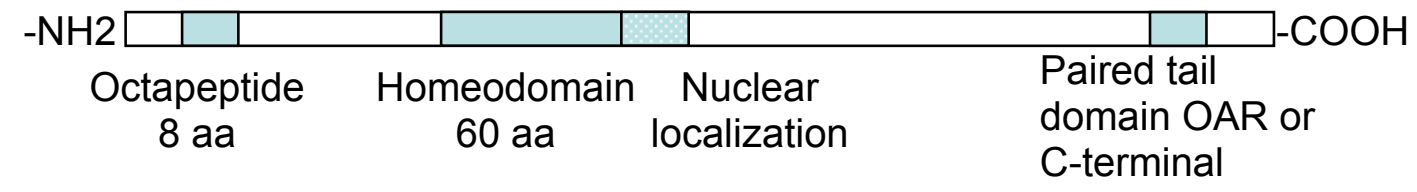

B.

\begin{tabular}{|c|c|c|c|c|c|c|c|c|c|}
\hline & & 1 & \multirow{2}{*}{\multicolumn{2}{|c|}{ YQLHELERAF }} & 21 & 31 & \multicolumn{2}{|l|}{41} & 51 \\
\hline DRx & KKK & HRRNRTTFTT & & & AKSHYPDVYS & RBELAMIKVNL & \multicolumn{2}{|c|}{ PEVRVQVWEQ } & NRRAKIVRRQE KSE \\
\hline XRX1 & $\cdots$ & $\ldots \ldots \ldots$ & $\cdots \cdots$ & $\cdots$ & $\ldots \ldots \ldots$ & $\ldots \ldots \ldots$ & \multicolumn{2}{|c|}{$\ldots \ldots \ldots$} & $\ldots \ldots \ldots \ldots . L_{1}$ \\
\hline MRx1 & $\cdots$ & $\ldots \ldots \ldots$ & $\ldots \ldots$ & $\cdots$ & $\ldots \ldots \ldots$ & $\ldots$ G... & \multicolumn{2}{|c|}{$\ldots \ldots \ldots$} & $\ldots \ldots \ldots \ldots$. \\
\hline ZRx1 & $\cdots$ & $\ldots \ldots \ldots$ & $\ldots \ldots$ & $\cdots$ & $\ldots \ldots \ldots$ & $\ldots \ldots \ldots$ & \multicolumn{2}{|c|}{$\cdots \cdots \cdots$} & $\ldots \ldots \ldots+K \cdot I D$ \\
\hline $\mathrm{ZR} \times 3$ & $\cdots$ & $\cdots \cdots \cdots$ & F.... & & $\cdots \cdots \cdots$ & $\ldots$. L $\ldots$ & \multicolumn{2}{|c|}{$\ldots \ldots \ldots \ldots$} & $\ldots \ldots \cdots \cdots$ \\
\hline DRX & HTID & AILG & $\mathrm{DRx}$ & SGL & LPVDPWLSPPLI & LSALP & DRx & RSNS & IA'TLRIKAKEHLDNLNKGMVSIV * \\
\hline $\mathrm{XR \times 1}$ & . S.E & .... & $\mathrm{XRx1}$ & . S. & .L.S..T.T. & SNSTA & $\mathrm{XR} \times 1$ & .N. . & $\ldots S \ldots$ M. . . IQFIG. PW* \\
\hline $\operatorname{MRx} 1$ & $. \mathrm{S} . \mathrm{E}$ & $\ldots$ & $\operatorname{MRx} 1$ & A. & .LE. .G.T. & PGGGA & MRX1 & .NS. & .A. .L.... IQAIG. PWQAL* \\
\hline $\mathrm{ZR} \times 3$ & S.E & IS. . & $\begin{array}{l}\mathrm{ZRx} 1 \\
\mathrm{ZR} \times 3\end{array}$ & $\begin{array}{l}\text { NS. } \\
\ldots\end{array}$ & $\begin{array}{l}\ldots \text { L. . .P. . } \\
\text {.LE...TG.IS }\end{array}$ & $\begin{array}{l}\text { S. .T. } \\
\text { STSSS }\end{array}$ & $\begin{array}{l}\mathrm{ZR} \times 1 \\
\mathrm{ZR} \times 3\end{array}$ & $\begin{array}{l}. \mathrm{SS} . \\
. \mathrm{NT} \text {. }\end{array}$ & $\begin{array}{l}\text {. A. .M. . . I IQSMD. TWQPMC* } \\
\text {. S. .M. . . . IQSIG. TW* }\end{array}$ \\
\hline
\end{tabular}

\section{Figure 4: Schematic representation of conserved domains of $R x$ protein}

(A) This figure schematically indicates the various domains in the Rx protein and their functions. The octapeptide domain acts as corepressor upon binding with the groucho family of corepressors, the homeodomain region enables binding of this protein to the DNA and activate the transcription of target genes, the nuclear localization signal (NLS) localizes the protein to the nucleus and the C-terminal OAR domain or the Paired tail domain acts as coactivator during protein-protein interaction. The figure shows the conserved sequences in various domains in the Rx protein across species. The domains above are Homeodomain (B) octapeptide $(C)$, Rx domain $(D)$, and OAR domain $(E)$ of Drosophila (DRx) and vertebrate Rx genes from Xenopus laevis (XRx1), mouse (MRx1), and zebrafish (ZRx1 and ZRx3) (Figure taken from Eggert et al., 1998). 


\section{The Rx expression pattern}

$\mathrm{Rx}$ expression is first noticed around the embryonic day 7.5 to 8.0 in mouse (Furukawa et al., 1997). Rx expression gets restricted to the anterior neural plate at embryonic day 8.0. At later stages of development Rx expression is mainly in the region that forms the primordial retina along with the ventral forebrain. During retinal specification Rx is expressed mainly in the proliferating cells of the retina (Mathers et al., 1997, Furukawa et al., 1997). The retinal progenitors show high levels of Rx expression during retinal differentiation. During this stage, $\mathrm{Rx}$ is also seen to be expressed in the self-renewing retinal stem cells (Wetts et al., 1989) of the Xenopus ciliary margin (Mathers et al., 1997, Casarosa et al., 1997).

Similar study on fish also shows the presence of Rx in the ciliary margin (Chuang et al., 1999). Study on mouse adult ciliary margin show the presence of a stem cell population in this region (Wetts and Fraser, 1988;Tropepe et al., 2000). Study on Xenopus show that Xrx1 continue to express in the ciliary marginal zone even though Xrx1, has disappeared from the differentiated retinal cells (Perron et al., 1998).

RX continues to express in the retinas of medaka fish even after the organogenesis. The Rx homologue in medaka fish, Ol-Rx3, is expressed in the inner nuclear layer of the retina even after the completion of organogenesis (Deschet et al., 1999). In addition to the expression in the retina and ciliary margin, $\mathrm{Rx}$ is also found in the posterior pituitary and pineal glands of the adult rat brain (Asbreuk et al., 2002). The studies in mouse at embryonic stages also show $\mathrm{Rx}$ expression in the ventral hypothalamus and in the posterior pituitary (Mathers et al., 1997). The Ol-Rx3 shows expression in the presumptive hypothalamus during organogenesis of medaka (Deschet et al., 1999). In the adult medaka, expression is seen in the hypothalamic nuclei surrounding the third ventricle. The studies in Xenopus also show that $\mathrm{Rx} 1$ is expressed in the pineal gland during development (Casarosa et al., 1997). Rx expression in the adult rat brain was also seen in the cells surrounding the bottom of third ventricles but was absent elsewhere in the hypothalamus (Asbreuk et al., 2002). All these Rx expressing areas are derived from the anterior neural plate (Eagleson et al., 1995). 


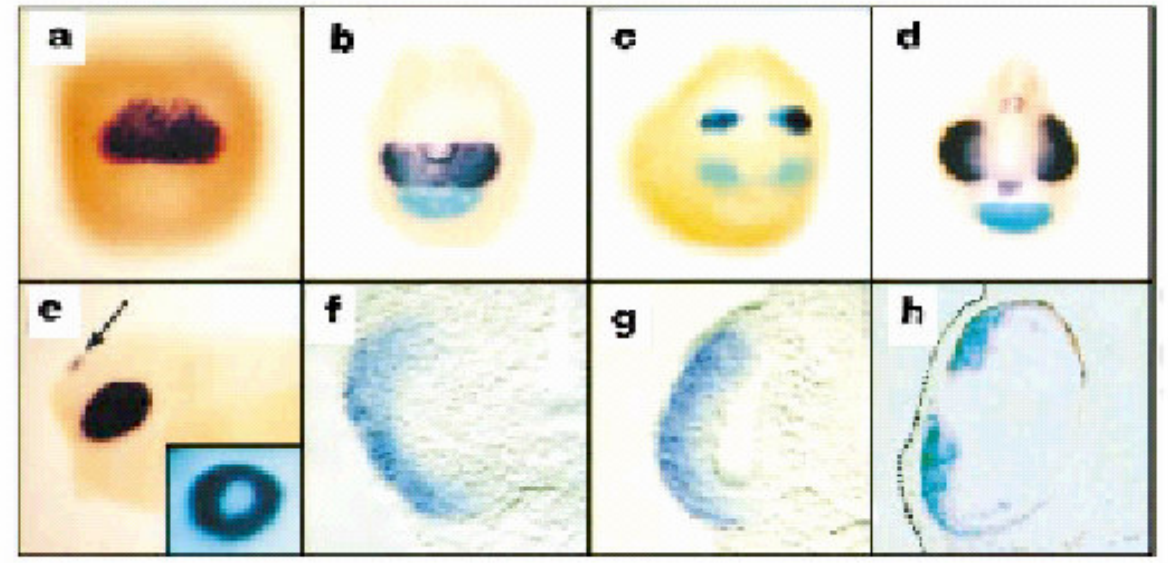

Figure 5: Expression pattern of $R x$ in the Xenopus embryos at different developmental stages detected using the $\mathrm{Rx}$ probes

a. Stage-14 embryo b. Stage-17 embryo (Purple staining) c. stage-18 embryos (light blue staining) d. Stage-27 embryo (Purple staining) e. stage-31 embryo. These in situs show the presence of Rx throughout the development of Xenopus embryos and in the ciliary margin of the stage 40 embryo (h). The figures f. and g. are sections at stage 19 and 23 respectively and show that the Rx expression throughout the retinal neuroepithelium in earlier stages (stage-19) confines to the inner neuroblastic layer in the later stages (stage23) (Figure from Mathers et al., 1997). 

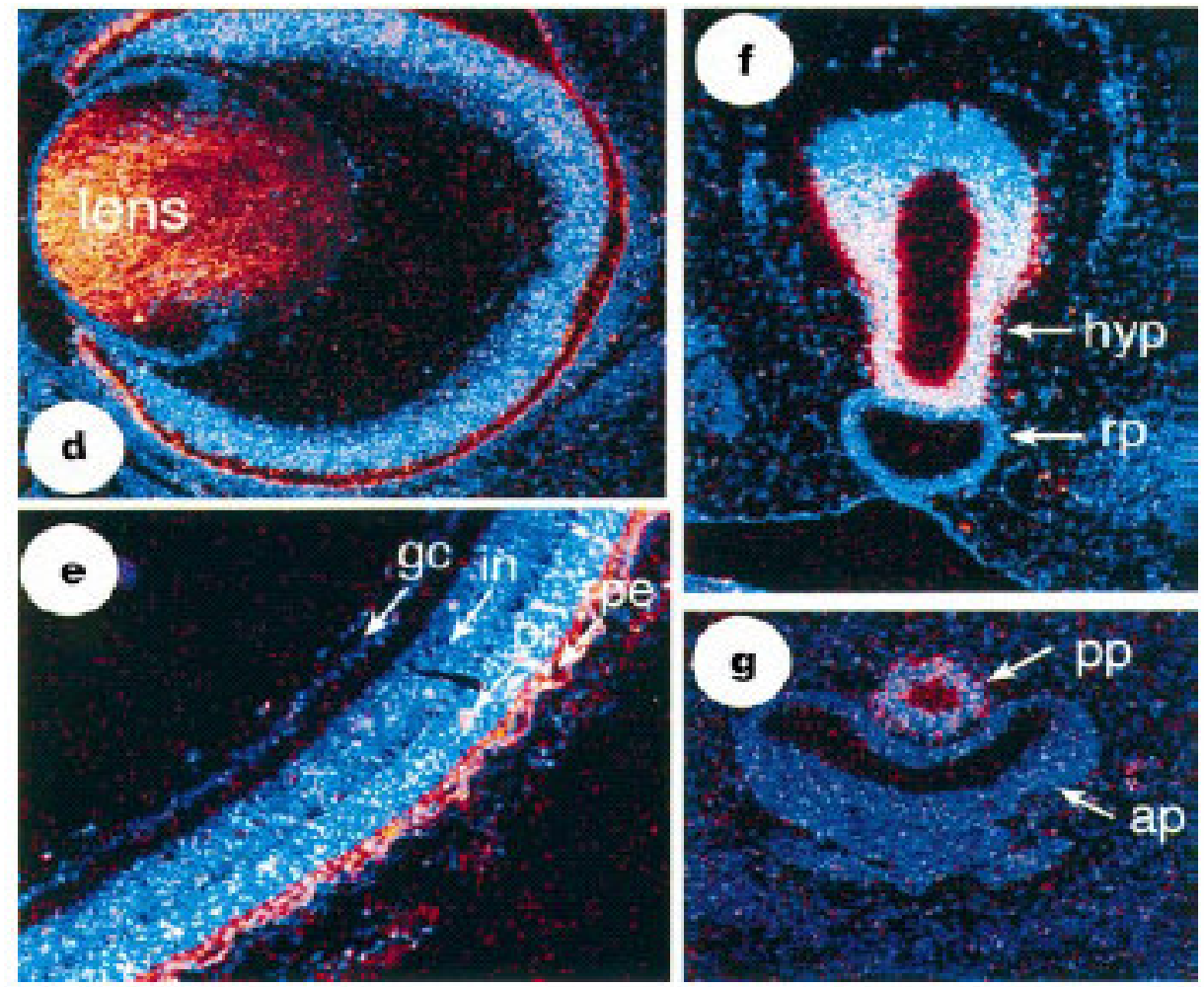

Figure 6: Rx expression in mouse neuroretina, hypothalamus and pituitary at various stages

a. In situ hybridization on the E15.5 mouse eye shows Rx expression in the neuroretina. b. Rx expression is absent in ganglion cell layer at P6.5 c. The Rx expression is seen in the hypothalamus at E10.5 adjacent to Rathke's pouch d. Rx expression is seen in the posterior pituitary at E12.5 (Figure from Mathers et al., 1997). 
Though Rx is not expressed in the Xenopus retinas after organogenesis, it continues to be expressed in the medaka fish. The Rx homologue in medaka fish $O l-R x 3$, is seen to be expressed in the inner nuclear layer of the retina even after the completion of organogenesis (Deschet et al., 1999). In addition to the expression in the retina and ciliary margin, $\mathrm{Rx}$ is also found in the posterior pituitary and in the pineal gland of the adult mouse and rat brain (Mathers et al., 1997; Asbreuk et al., 2002). The studies in mouse at embryonic stages also show $\mathrm{Rx}$ expression in the ventral hypothalamus and in the posterior pituitary (Fig-6) (Mathers et al., 1997). The Ol-Rx3 shows expression in the preumptive hypothalamus during the organogenesis of medaka (Deschet et al., 1999). In the adult medaka the expression is seen in the hypothalamic nuclei surrounding the third ventricle. The studies in Xenopus also show that Rx1 is expressed in the pineal gland during the development (Casarosa et al., 1997). Rx expression in the adult rat brain was also seen in the cells surrounding the bottom of third ventricles but was absent elsewhere in the hypothalamus (Asbreuk et al., 2002). All these Rx expressing areas are derived from the anterior neural plate (Eagleson et al., 1995).

\section{Functional studies on Rx gene}

The overexpression of $\mathrm{Rx}$ shows hyperproliferation of neural retina and retinal pigment epithelium (Mathers et al., 1997, Andreazzoli et al., 1999, Chuang and Raymond et al., 2001). One of the deletion experiments for $\mathrm{Rx}$ involved deletion of the protein initiation site and N-terminal end of homeodomain of the murine Rx gene. All of the homozygous pups carrying two copies of mutated Rx gene gave an eyeless phenotype (Mathers et al., 1997). Also these anophthalmic pups showed deformities in the forebrain and midbrain regions (Mathers et al., 1997).

The Rx functional studies were done either by overexpressing this gene or by performing targeted deletion of $\mathrm{Rx}$ in the mouse embryonic stem cells. One $\mathrm{Rx}$ overexpression study was carried out by injecting the Xrx1 synthetic RNA into the 4-8 cell stage Xenopus embryos. The majority (86\%) of embryos developed ectopic retinal pigment epithelium (Andreazzoli et al., 1999). Since retinal pigment epithelium forms 
only in the proximity of the anterior neural tube, this suggested that the injected RNA is providing the signal needed for the retinal formation. These Rx-injected embryos also showed duplication of retina (Mathers et al., 1997; Andreazzoli et al., 1999).

The Rx germline knockout showed normal eye formation in the heterozygous animals although the homozygous knockout gave no visible eye structures (Mathers et al., 1997). Some newborn anophthalmic homozygous pups also showed severe ablation of forebrain and midbrain that led to lethality (Figure 8) (Mathers et al., 1997). This indicated that $\mathrm{Rx}$ is also required for patterning the brain. 


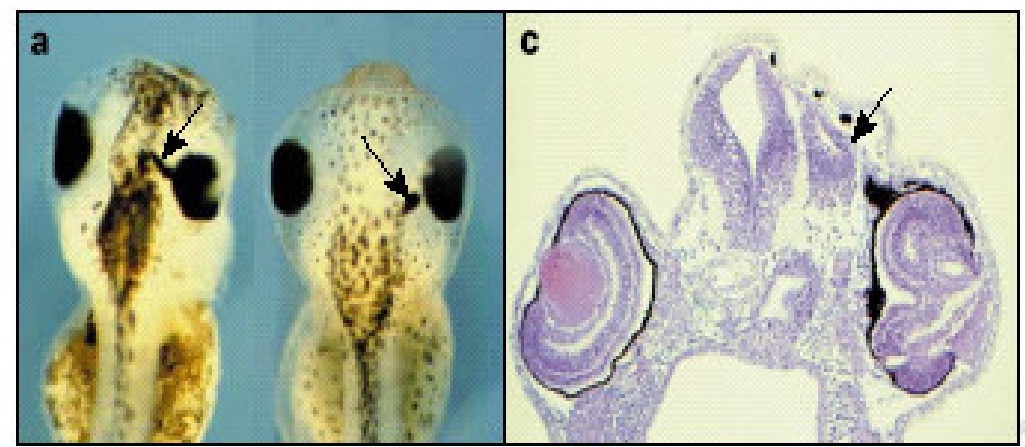

\section{Figure 7: Rx Over-expression Experiments}

These are Xenopus embryos at stage 41 after injection with synthetic Rx1 at cleavage stage. a. The arrow indicates the development of ectopic retinal pigment in these Rxinjected embryos. b. A cross-section of the Rx-injected retina show ectopic RPE formation along with duplication of the anterior neural tube and neural retina, suggesting that $\mathrm{Rx}$ is playing a role in proliferation of the retinal region (Figure from Mathers et al., 1997). 


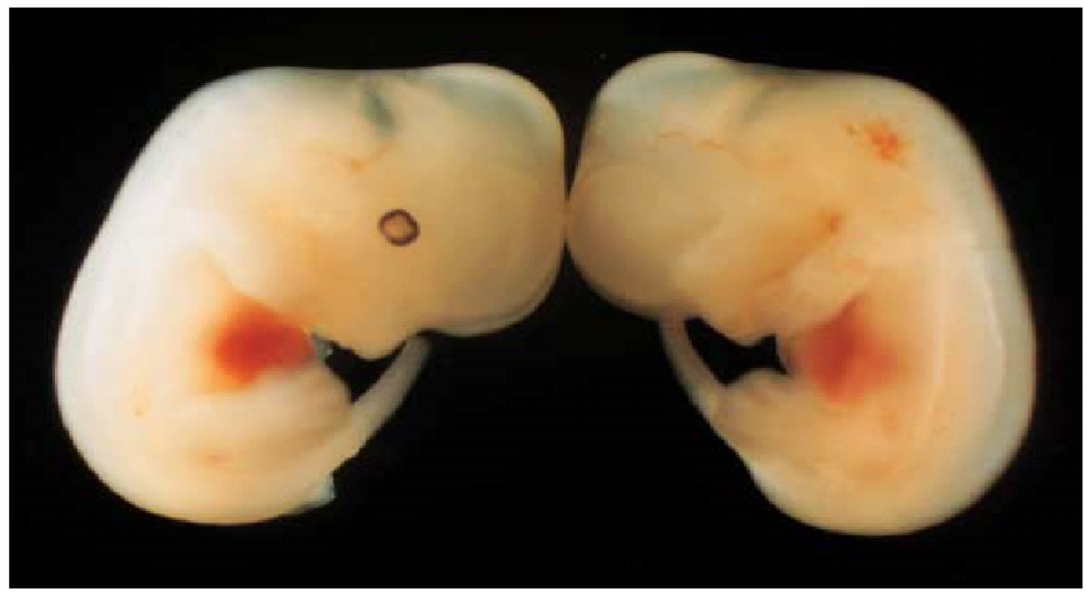

Figure 8. Rx Knockout Embryo

A wildtype E13.5 murine embryo (left) shows normal eye development, whereas the Rx knockout murine embryo shows complete absence of eye development (Mathers et al., 1997). 


\section{Rx downstream target genes}

RX (Human form of Rx) is seen to bind the Photoreceptor Conserved Element-1 (PCE1) sequence in the promoter regions of the Photoreceptor cell-specific genes (Kimura et al., 2000). The interphotoreceptor retinoid binding protein (IRBP) and arrestin are required for the maintenance of the photoreceptor layer since IRBP functions in the visual cycle by shuttling vitamin A between the RPE and the photoreceptors and arrestin downregulates the phototransduction pathway in the photoreceptor cells. Another photoreceptor cells related gene Opsin also shows the presence of same core binding site in the promoter region (Ret1) (Morabito et al., 1991). Binding of RX protein to these promoters leads to 6.4-fold induction in these promoter activities (Kimura et al., 2000).

The fact that Rx is expressed before Hes1 or Notch1 in the retina and that their expression is seen to be upregulated five times by $\mathrm{Rx}$ protein in the cotransfection experiments asserts that Rx regulates their expression (Furukawa et al., 2000). Hes1 activation could be indirect, that is the activation of Notch1 by Rx binding leading to activation of Hes1 or could be directly through Rx binding to the Hes1 promoter region. The cotransfection of $\mathrm{Rx}$ with Pax6 shows that $\mathrm{Rx}$ heterodimerizes with Pax6. The activation of the Pax6 cis-elements through this heterodimer was monitored using reporter constructs (Mikkola et al., 2001). As mentioned in introduction BMP-4 is also regulated by $\mathrm{Rx}$ gene as measured by cotransfection assays in Cos-7 cells (Voronina et al., unpublished observations).

The in vivo experiments to detect the genes affected by $\mathrm{Rx}$ are either done by overexpression of the Rx RNA or by the removal of the Rx gene using knockout technology (Andreazzoli et al., 1999; Andreazzoli et al., 2003; Chuang and Raqymond, 2001; Mathers et al., 1997; Voronina et al., unpublished observations; Zhang et al., 2000). The Rx RNA injection into Xenopus embryos show increased expression of Zic2 and Xhairy while the expression of $\mathrm{p} 27 \mathrm{Xic} 1$ is reduced during the early neurula stage (Andreazzoli et al., 2003). Zic2 and Xhairy delay neuronal differentiation by repressing the transcription of proneural factors. Since $\mathrm{Rx}$ overexpression leads to overproliferation of cells, it seems logical that Rx supports the proliferation of cells by inhibiting the 
expression of proneural factors. Overexpression of Xrx1 also represses X-ngnr-1, XDelta-1, N-tubulin, XRALDH2 (Andreazzoli et al., 1999; Chuang and Raymond., 2001).

The optic vesicle conditional knock-out experiments which delete the Rx gene at E8.75 show that RPE formation is not affected in the mutated distal optic vesicle (Voronina et al., unpublished observations). Conversely, the expression of neural retinal specific genes was severely affected in these mutant embryos. The genes like Cyclin-D1, FGF8, FGF15, BMP-4, Pax6, Six3 and Six6, which are expressed in the neural retina during development, were absent in the mutated distal optic vesicle. Also the surface ectoderm of these mutant mice showed an absence of Pax6 and Sox2 expression. However in these $\mathrm{Rx} \Delta 2^{\mathrm{Foxg} 1}$ mutants, the expression of RPE-specific genes is amplified. The entire distal optic vesicle shows the presence of the RPE-specific markers, like Mitf, Dct (Tryp2), Tryp1, unlike the expression in control mice.

These findings suggest that $\mathrm{Rx}$ is necessary for the activation of neural retinal specific genes, such as Cyclin-D1, FGF8, FGF15, BMP-4, Pax6, Six3 and Six6, while Rx is also necessary for the downregulation of the RPE-specific genes, Mitf, Tryp2, Tryp1.

\section{$\underline{\text { 6. Rx mutation leads to anophthalmia }}$}

\section{$\underline{6.1 \mathrm{Rx} \text { mutation in Humans }}$}

A mutation in the homeobox genes like Pax6, Six3, Otx2, Mitf, and Chx10 which are expressed in the optic vesicle during development, affect the formation of proper ocular structures in human (Ton et al, 1991; Hanson et al., 1994; Pasquier et al., 2000; Tassabehji et al.1994; Wallis and Muenke et al., 2000; Bar-Yosef et al., 2004; Percin et al., 2001). Since Rx knockout mice show complete absence of ocular development, it was predicted that RX might also be responsible for various ocular conditions in humans. The one known case of human RX mutation in an anophthalmic patient is discussed below.

The screening of anophthalmic or microphthalmic patients for mutations in the RX coding region showed that an anophthalmic patient carried mutations in both copies of 
the RX gene. One copy of RX showed a nonsense mutation (Q147X), which truncates the protein prematurely during the translation process. This truncated allele is unable to bind to the Rx-binding sequence called the PCE1 sequence (Voronina et al., 2004). Since the homeodomain region is truncated in this mutant, the mutated protein loses the nuclear localization signal downstream of the mutation site and localizes to the cytoplasm unlike the wildtype RX protein (Fig-9) (Voronina et al., 2004). The second mutation in the same patient is due to a missense mutation, which replaces the conserved arginine at position 192 to glutamine (R192Q). The electrophoretic mobility shift assay (EMSA) shows that the R192Q RX protein has a ten-fold reduction in binding capacity to the PCE-1 sequence. The R192Q and Q147X mutations don't affect eye development in the heterozygous condition, so only one functional copy of the RX gene is probably able to carry out its critical role during development. However, the mutation in both the RX copies in the patient leads to anophthalmia in that patient (Voronina et al., 2004).

\subsection{Rx mutation in Fish}

A temperature-sensitive mutation, called eyeless $(e l)$, is seen in the medaka fish (Winkler et al., 2000). This mutation $\left(e l^{\prime}\right)$ is a spontaneous recessive type and is activated by lower temperature. The optic vesicles of the mutants grown at $18^{\circ} \mathrm{C}$ are unable to evaginate, and therefore, the optic cups are not developed in subsequent stages of development (Winkler et al., 2000). The same mutant fish (52\%) show capability to form optic vesicles when grown at higher temperature of $28^{\circ} \mathrm{C}$. The in situ hybridization experiments showed that $\mathrm{Rx} 3$ expression is absent in the mutant fish grown at restricted temperature (Loosli et al., 2001). The PCR analysis revealed an insertion mutation in the Rx3 paralogue of the medaka fish. The 3' end of the second exon and the 5' end of the third exon code for the homeodomain region and the insertion is seen in intron 2. Since the insertion of $13 \mathrm{~Kb}$ is in intron 2 , it does not affect the open reading frame under normal temperature and gives wild type Rx3 product. The WT Rx3 expression plasmid rescues the phenotypes in 39\% of the embryos, proving Rx3 as the causative factor for these phenotypes (Loosli et al., 2001). 
Another study on the same mutation reports formation of optic cups in the prosencephalon of these fish without evagination (Ishikawa et al., 2001). These fish also showed partially differentiated retina-like structures but are reportedly blind as they do not respond to visual stimuli. In all, this mutation affects brain structures and reproductive systems along with the visual system (Ishikawa et al., 2001). In summary, this mutation emphasizes the function of $\mathrm{Rx} 3$ for optic vesicle evagination and for proliferation in the optic vesicle (Loosli et al., 2001). 

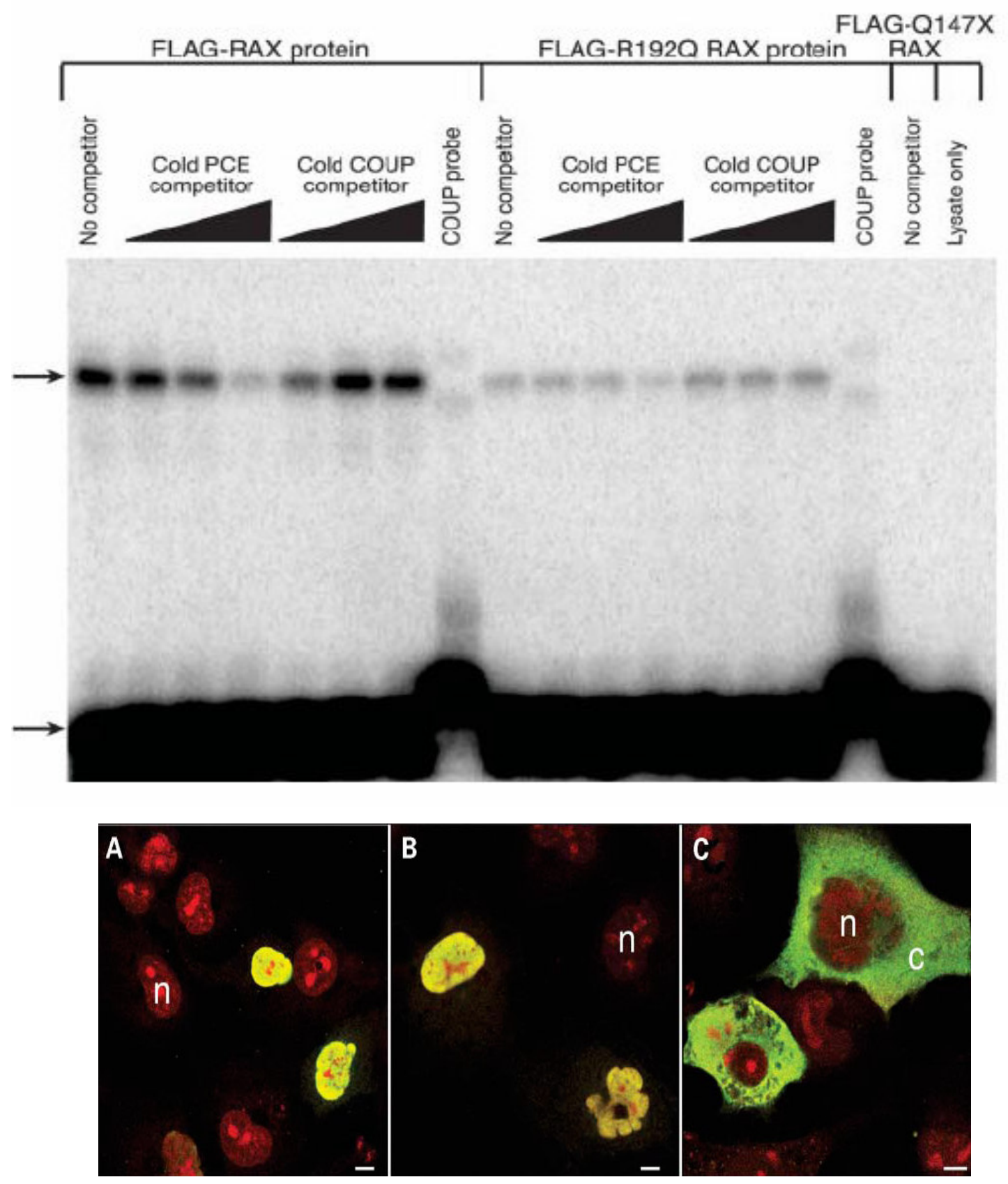

Figure 9: The RX mutations from an anophthalmic patient causes loss of binding and loss of nuclear localization signal

The first part of the figure shows EMSA (Electrophoretic mobility shift assay) using the WT FLAG- RAX, FLAG-R192Q RAX, FLAG-Q147X RAX. The WT RAX shows the concentration-dependent binding to the target site as the concentration of the unlabeled competitor oligo increases, but the mutated R192Q RAX does not have the ability to bind the PCE-1 site. The Q147X mutation in RAX damages the nuclear localization signal and disables the Rx protein from entering into the nucleus and is therefore localized to the cytoplasm as seen in the second part of the figure. (Figure taken from Voronina et al., 2004). 


\section{$\underline{6.3 \mathrm{Rx} \text { Mutation in Mouse }}$}

Almost fifty years ago, the inbreeding of microphthalmic laboratory mice by Chase resulted in anophthalmic progeny. This anophthalmic strain of mice was called ZRDCT (Chase and Chase, 1941) and this mutation was called eyeless. These anophthalmic mice are used for research of human anophthalmia due to the similarity in the phenotype to human clinical anophthalmia. The inbred mice of this strain produce more than 90\% progeny with no eyes (Chase and Chase., 1941; Silver and Hughes., 1974) and the hypothalamus of these mice show distorted structures (Laemle and Rusa., 1992). The remaining $10 \%$ of the inbred ZRDCT mice show colobomatous structures for the one or two small eyes that develop. These mice also show total absence of optic nerves (Silver and Hughes., 1974).

The detailed analysis at the embryonic stages in the eyeless mouse mutant show that optic vesicle evagination is not affected until E10, but the size of the optic vesicle is smaller than wild type mice, and therefore, it fails to contact the surface ectoderm efficiently (Harch et al., 1978; Webster et al., 1984). Lens development in some embryos shows a reduced lens placode, but lens differentiation is not affected (Zwaan and Silver., 1983).

Although it was used as a model for human anophthamia, the molecular mechanism behind the eyeless phenotype in this strain was not clear until 2001. A single

point mutation in the first exon of the Rx gene leads to a change in the codon and wrong amino acid is encoded during the translation (Tucker et al., 2001). The methioninecoding sequence, ATG, is mutated to the leucine-coding TTG sequence. This methionine is critical as it codes for codon number ten, which acts an alternative translation initiation site. In the ZRDCT strain, this Rx gene mutation (M10L) affects this alternative Rx translation process, and therefore results in lesser Rx protein abundance (Tucker et al., 2001). Therefore, unlike the complete Rx knockout mice, these mice are viable. 


\section{Chapter II}

Determination of the expression pattern of the Rx gene in the adult mouse eye 


\section{A. Introduction}

The Retinal Homeobox $(\mathrm{Rx})$ gene is a transcription factor which regulates the transcription of target genes during development. Rx is crucial for retinal development, and therefore, the Rx sequence is conserved among a range of species in the phylogenetic tree (Strickler et al., 2002). The embryonic expression of $\mathrm{Rx}$ in these species is well known. Rx expression is observed in the anterior neural plate region, which is responsible for the formation of the primordial retina and the ventral forebrain. Later during the development, Rx expression is also observed in the ventral hypothalamus and posterior pituitary (Mathers et al., 1997, Asbreuk et al., 2002) of both, mice and rat in separate studies.

The requirement of $\mathrm{Rx}$ expression for proper ocular development is verified using two main approaches which increased or decreased the Rx expression during the development. A complete Rx knockout in mice resulted in anophthalmic pups (Mathers et al., 1997). In these pups, the optic pit fails to evaginate and since optic pit evagination is crucial for optic vesicle formation, the subsequent steps in ocular development are affected. The defects in the ventral forebrain formation in these pups make this mutation lethal. The Rx overexpression studies show hyperproliferation of neural retina and retinal pigment epithelium (Mathers et al., 1997, Andreazzoli et al., 1999, Chuang and Raymond, 2001). Xrx1 overexpression by synthetic RNA injection into 4-8 cell Xenopus embryos shows the development of ectopic retinal pigment epithelium (Mathers et al., 1997; Andreazzoli et al., 1999). Combining this result with other observations of Rx expression, we can conclude that $\mathrm{Rx}$ is mainly expressed in the proliferating cells of the retina (Mathers et al., 1997, Furukawa et al., 1997), suggesting that Rx is playing a role in proliferation of the retinal region. These Rx overexpressing embryos extend the retinal expression to the forebrain region and affect the normal development of the embryo (Chuang and Raymond, 2001). This indicates that Rx plays a role in specification of the anterior neural plate while supporting the optimum proliferation of retinal cells. The Xenoput ciliary margin shows the Rx expression during the development (Mathers et al., 1997, Casarosa et al., 1997). Only the Xrx1 continues to express in the ciliary margin 
even after it is disappeared from the differentiated retinal cells (Perron et al., 1998). The ciliary margin in the fish also continues to express $\mathrm{Rx}$ even after completion of development (Chuang et al., 1999). Similar to Xenopus (Wetts et al., 1989) the adult ciliary bodies in mouse also contain stem cells (Wetts and Fraser, 1988; Tropepe et al., 2000)

The reports of Rx expression in the adult retinas of various species show very vague data. Furukawa et al., (1997) reported that mouse adult retinas don't show Rx expression and that the $\mathrm{Rx}$ expression decreases in the neural retina along with the mitotic activity. Rax and RaxL, the Rx homologues in chick showed no retinal expression one month after the birth though $\mathrm{Rx}$ is seen during the embryonic stages (Chen et al., 2002). In contrast, some other studies show that $\mathrm{Rx}$ is expressed in adult retinas (Kimura et al., 2000, Chuang et al., 1999). In zebrafish the adult retina showed Zrx1/2 expression only in the cone photoreceptors and in the ciliary margin, whereas Zrx3 was seen to be expressed in inner nuclear layer of the adult retina (Chuang et al., 1999). A study in rat shows that $\mathrm{Rx}$ is transcribed in the adult neural retina and iris. The neural retinal expression was seen in the outer nuclear layer, ganglion cell layer and the inner nuclear layer (Kimura et al., 2000). Another study of Rx expression using microarrays shows that $\mathrm{Rx}$ is expressed in the retinal region after the birth and even in adult stages (Dorrell et al., 2004). The Rx expression in mouse in the adult stages is nearly seventy percent lower compared to that in pups but it does continue to be expressed. Recently another study (Blackshaw et al., 2004) showed that Rx is expressed in the mouse retinas until the P6 stage, but is absent on $\mathrm{P} 7$ and is present again at $\mathrm{p} 8$ stage. This study does not give any information about the Rx retinal expression in adult stages. Though $\mathrm{Rx}$ is not expressed in the Xenopus retinas after organogenesis, it continues to be expressed in the medaka fish. The Rx homologue in medaka fish $O l-R x 3$, is seen to be expressed in the inner nuclear layer of the retina even after the completion of organogenesis (Deschet et al., 1999).

The presence of Rx expression in the adult retinas in several species (Kimura et al, 2000, Furukawa et al, 2000, Dorrell et al., 2004, Deschet et al., 1999) suggests that Rx 
might be important in the later stages of eye development and also in maintaining the adult retina. The location of Rx expression in specific layers of the adult retina can tell us a lot about the putative role of this transcription factor. For instance, if Rx is expressed in the photoreceptor layer, solely, it might be involved in rhodopsin expression, and therefore required for normal vision. The expression of $\mathrm{Rx}$ in the Müller glia will tell us that Rx might be playing a role in regeneration of retinal progenitor cells (Fischer and Reh et al., 2001). In zebrafish studies, Zrx expression was also found in the ciliary margin germinal zone (Chuang et al., 1999). The ciliary margin is the source of the proliferating retinal stem cells. Since Rx expression is seen in the amphibian and fish neural retinas, which have the capacity to regenerate, it becomes critical to resolve the domains of Rx expression in the adult mammalian eye.

To resolve the ambiguities in the $\mathrm{Rx}$ expression data, we performed in situ hybridizations on adult mouse retinas. Our results from these in situ hybridizations indicate strong $\mathrm{Rx}$ expression in the photoreceptor and inner nuclear layers of adult mouse neural retinas. This expression is seen to be uninterrupted from the postnatal stage to adult stage. The ciliary bodies of these adult mice also continue to show strong $\mathrm{Rx}$ expression in adults. These results emphasize a putative role for $\mathrm{Rx}$ in maintaining the adult neural retina and ciliary margin. 


\section{B. Material and Methods}

\section{A.1 Probe isolation for in situ Hybridization}

For detection of Rx expression in the mouse retinal samples, sense and antisense RNA probes are synthesized using Digoxigenin (Dig)-labeled nucleotides. The cDNAs required for MRx RNA probes were previously synthesized using the 3' RACE technique (Mathers et al., 1997). The mRx 3'RACE cDNAs were linearized using the EcoRI enzyme for the antisense probe and HindIII for the sense probe preparation, and the linearized DNA is isolated using the phenol-choloroform treatement, followed by isopropanol precipitation. The RNAs were then synthesized using Sp6 for the antisense and the T7 polymerases. The Dig-labeled RNAs were purified using the QIA-quick nucleotide removal kit. The purified probes were diluted in prehybridization buffer. (Prehybridization buffer: $50 \%$ formamide, $0.75 \mathrm{M} \mathrm{NaCl}, 1 \mathrm{X}$ PE, $1 \mathrm{mg} / \mathrm{ml}$ Torula RNA, $0.05 \%$ Heparin, $0.1 \%$ BSA, $1 \%$ SDS).

\section{A.2 Tissue preparation for in situ hybridization}

Three mice strains were used for the Rx expression study. The mouse strains used for this study were 129SvJ/C57BL/6 hybrids, CD-1 and FVB. CD1 albino mice were preferred for the retinal in situ hybridizations as the color detection is easy in these mice due to the albino eyes. The experiments were later carried out on FVB retinal samples. The FVB strain carries a mutation called $r d^{l}$ (retinal degeneration 1) that leads to postpartum degeneration of the rod photoreceptors (Chang et al., 1993). These mice serve as a good model to look at Rx expression in these degenerating photoreceptors. The lens was not included in the retinal samples for whole-mount in situ hybridization. The intact retinas were dissected from the sclera and the lens was removed from these retinas. Isolated retinal samples were fixed in 4\% paraformaldehyde in PBS for 2-4 hours, and stored in PBS after washing.

Ciliary body is attached to retina and also to sclera. In the case of FVB mice, the ciliary bodies were allowed to remain attached to the sclera for treatment in the wholemount in situ hybridization as this reduces the risk of losing this $1-2 \mathrm{~mm}$ size tissue. This sample was treated the same way as described above. For 129SvJ/C57BL/6 hybrids, the 
ciliary body was isolated along with retinas and was treated in the same way as that of retinas. Since these retinas were used for the in situ reactions on slides, the ciliary bodies were treated in the same way.

\section{A.3 Whole-mount in situ hybridization}

The whole mount in situ hybridization on intact retina and on the ciliary body attached to sclera was performed as described (Cygan et al., 1997) with some minor modifications. The positive samples along with controls were sectioned to determine the exact location of expression. For this, the samples were sectioned by embedding in the JB-4 Glycolmethacrylate resin (Polysciences, Pa, USA). The $14 \mu \mathrm{m}$ sections were obtained in the Leica microtome using a glass knife. The sections were mounted using water. The Dig-labeled oligonucleotides were detected after in situ hybridization using anti-Dig antibodies (Roche). Antibody localization is detected by alkaline phosphatase conjugated on these antibodies that converts the BM-purple substrate dye into the colored precipitate.

\section{A. 4 In situ hybridization on tissue sections}

The retinal sections for in situ hybridization were prepared by cryoprotecting the retinal sample right after fixing in $4 \%$ paraformaldehyde solution to prevent any tissue damage during the process. These samples were then cryosectioned using a Leica Cryostat (Leica, Germany). The thickness of these sections was $14 \mu \mathrm{m}$. For in situ hybridization on sections, another previously published protocol was used with some modifications (Conlon and Rossant, 1992). 


\section{Results}

\section{Expression of Rx mRNA in the adult mouse retina}

In situ hybridization to detect $\mathrm{Rx}$ transcripts was carried out using the probes derived from 3'RACE and detected using the BM-purple substrate. These reactions showed the presence of $\mathrm{Rx}$ in the adult neural retinas. All these in situ hybridizations were run with the test (antisense) probe and the control (sense) probe. Upon in situ hybridization, the antisense probe showed the presence of Rx mRNA by formation of blue color precipitate whereas the sense probe shows little or no coloration at all (Figs. 10-12). The in situ hybridizations carried out on CD1 adult retinas revealed that $\mathrm{Rx}$ is expressed in the photoreceptor and the inner nuclear layers. To verify that $\mathrm{Rx}$ expression in adult retina is not an exception for one strain, we carried out the in situ hybridizations on adult retinas of other two mouse strains C57BL/6 X 129Sv hybrids and FVB. Similar to the CD1 strain, C57BL/6 X 129Sv hybrid retinas showed Rx expression in the photoreceptor layer and the inner nuclear layer in adult stage (Fig. 10A and B). The third strain chosen for the retinal expression of Rx was FVB. The FVB strain carries the $r d^{l}$ mutation, which leads to retinal degeneration in the photoreceptor layer. The FVB whole-mount retinal samples show strong Rx expression in the intact retinas (Fig-10, C and D), and the sections of these whole-mount retinas show the location of Rx expression in these retinas (Fig-10, E and F). The in situ hybridizations carried out on FVB adult retinas show a strong expression in the inner nuclear layer, while the photoreceptor layer does not show strong expression due to the degeneration of these cells.

The Rx expression in retina at the neonatal stage is well known (Mathers et al., 1997; Dorrell et al., 2004) and now we can see the Rx expression even in the adult stage. Since there are many theories regarding the factors leading to the absence or onset of $\mathrm{Rx}$ expression during and after the maturation of the retina, we followed up the $\mathrm{Rx}$ expression in C57BL/6 X 129Sv hybrid mice from Week-0 to Week-6. The cryosectioned retinal sections were treated with the protocol for in situ hybridization on slides. The Week-0 tissue being too fragile, did not last the in situ hybridization process. The Week-2 (Fig-11, A and B), Week-4 (Fig-11, C and D) and Week-6 (Fig-11, E and F) retinas show Rx expression in the photoreceptor layer and the inner nuclear layer (Fig- 
Rx antisense probe

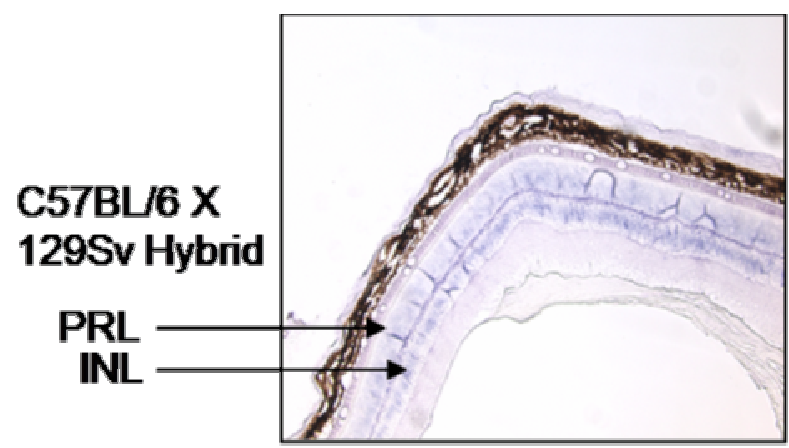

FVB retinas

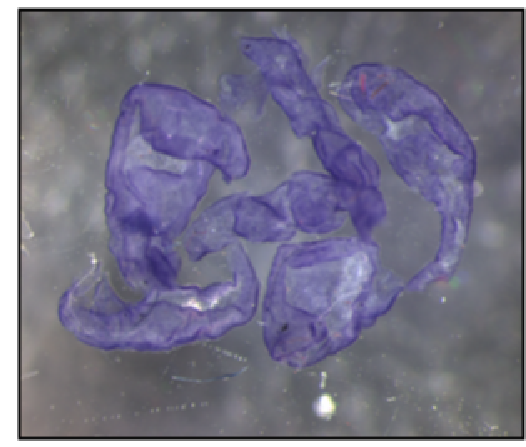

Sections of FVB retinas

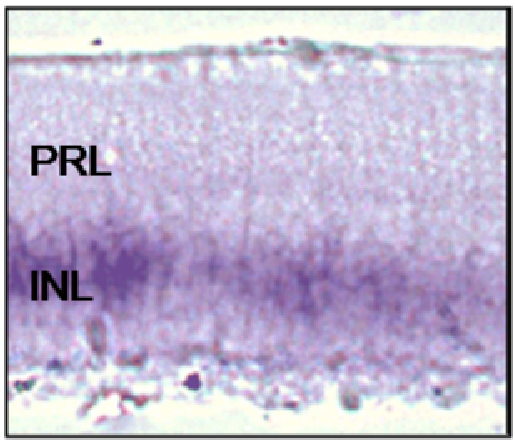

Rx sense probe
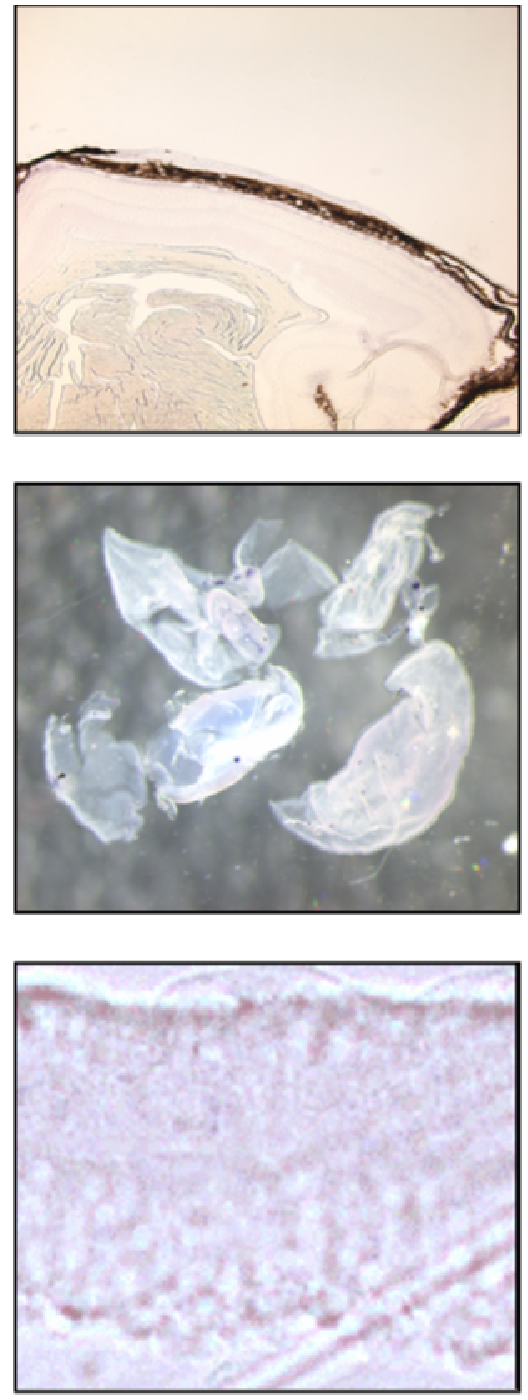

Figure 10: Rx expression in the adult mouse retinas

In situ hybridizations performed on adult mouse retinas of strains C57BL/6 X 129Sv and FVB revealed Rx expression in adult retinas. The four weeks old C57BL/6 X 129Sv mouse retinal sections show Rx expression in the photoreceptor layer and inner nuclear layer. The sections of FVB mice showed strong Rx expression in the inner nuclear layer while the photoreceptor layer shows lesser expression than in the inner nuclear layer. 

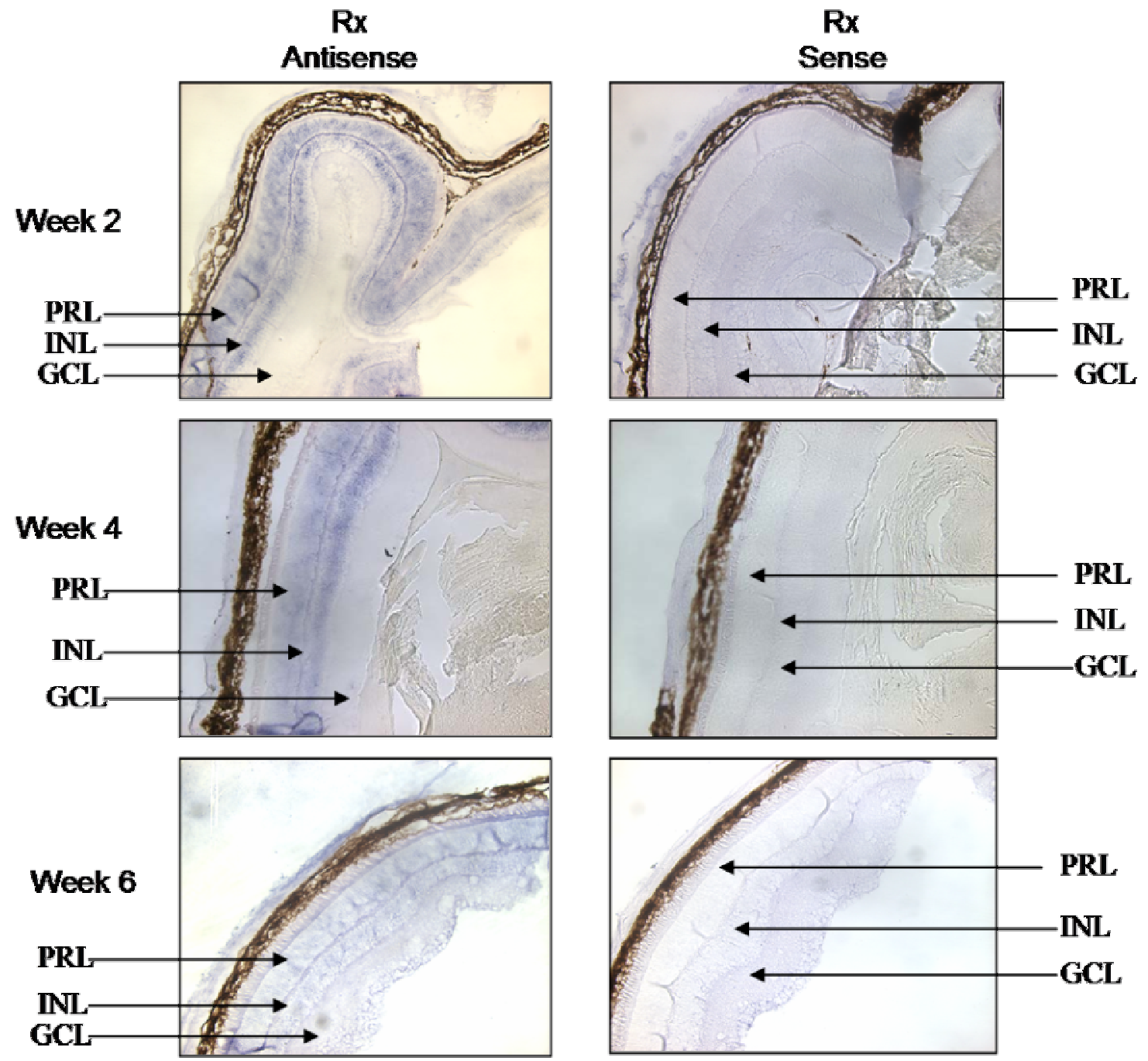

C57BL6 X 129Sv

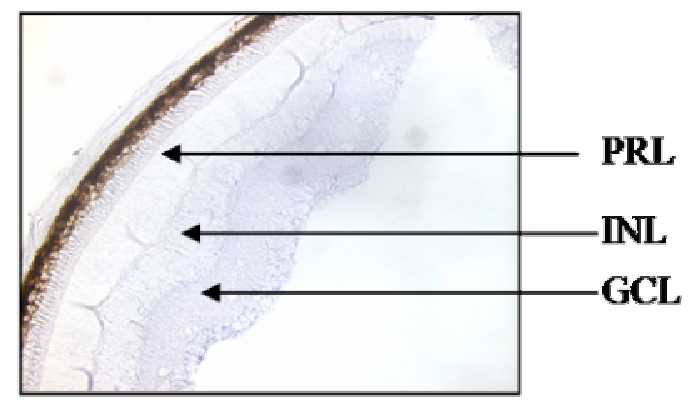

C57BL $6 \times 129 S v$

Figure 11: Rx continues to express in the adult mouse retinas

In situ hybridizations performed on the retinal sections of week-2, week-4 and Week-6 C57BL/6 X 129Sv mice shows continual Rx expression in adult retinas. The probe used and the age of the mouse is indicated in the figure. 
11). These results confirm the previous observation by RT-PCR (Voronina et al., Unpublished observation) that Rx expression in mouse retinas is seen in the retinas even in the adult stage.

\section{Expression of Rx mRNA in the adult mouse ciliary body}

Since the in situ hybridizations performed on the adult mouse retinas confirmed $\mathrm{Rx}$ expression in adult retinas, we decided to check Rx expression in the adult ciliary bodies as well. \{What does the ciliary body do?\} The same Dig-mRNA probes used for the determination of retinal $\mathrm{Rx}$ expression were used for determination in the ciliary body. The ciliary bodies used for this procedure were extracted from eyes along with retinas and were still attached to retinas after cryosectioning of the tissue. For the in situ hybridization, the ciliary bodies were treated the same way as the retinas. Also, the same three strains of mouse were used to confirm the expression data.

The ciliary bodies isolated from FVB mice and still attached to the sclera showed strong expression of Rx compared to the control in situ hybridization with sense probe (Fig-12, A and B). The Rx expression in the ciliary body of the FVB mice is stronger than that observed in the retinal region. Similar to the expression in FVB mice, the other strain used, CD-1, also shows strong Rx expression (Figure-12, C and D).

The $\mathrm{Rx}$ expression profile in ciliary bodies was carried out from Week-0 to Week-6, similar to the expression profile in adult retinas. As seen in Figure-12, the Week-2 (E and F), Week-4 (G and H) and Week-6 (I and J) ciliary bodies show strong $\mathrm{Rx}$ expression in all these retinal samples. Therefore, we conclude that Rx expression in the ciliary bodies remain uninterrupted from week-2 to adult stage. 

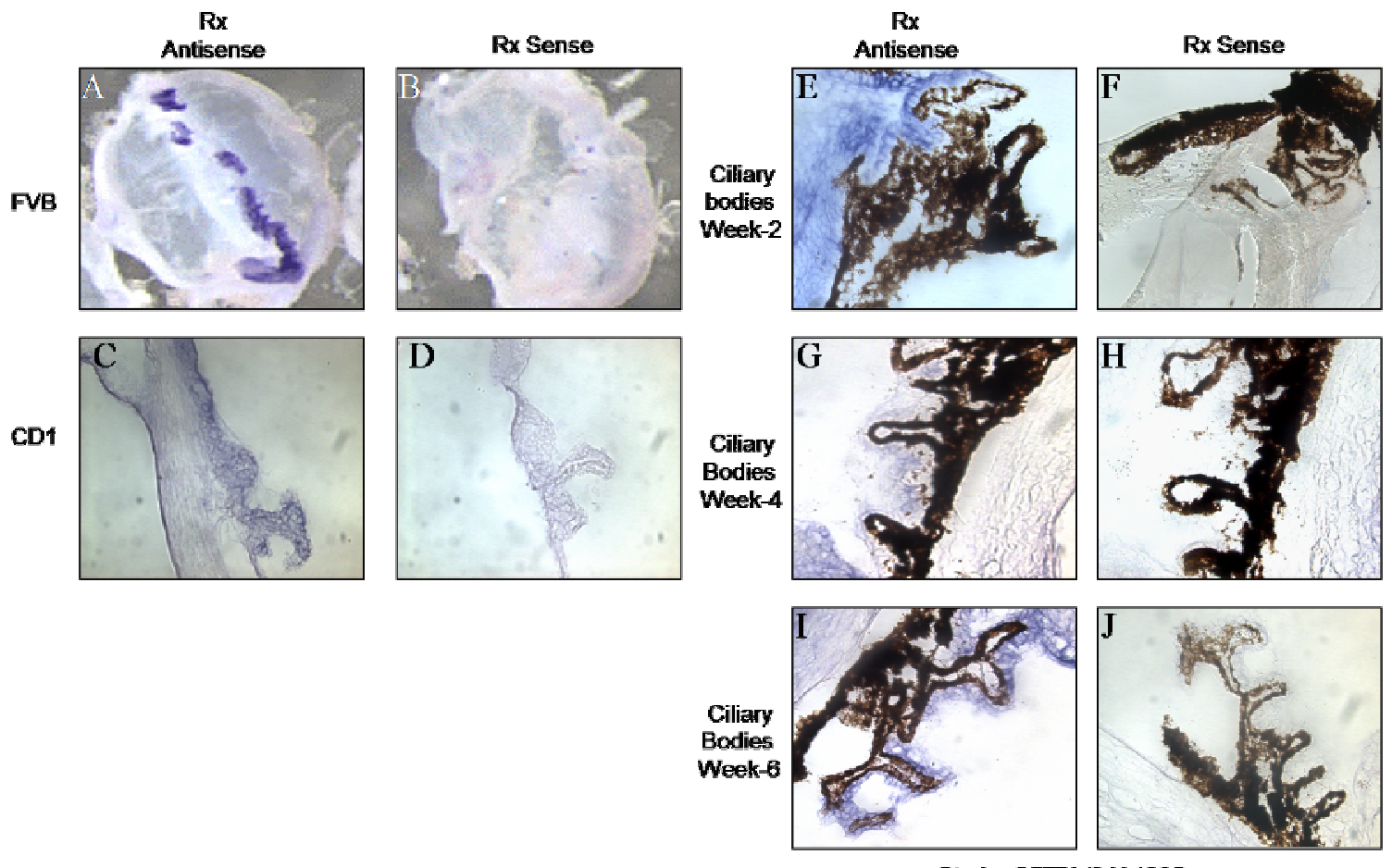

Strain: C57BL 6 X $1295 \mathrm{y}$

Figure 12: Rx expression in the ciliary margin of adult mice

The in situ hybridizations performed on adult FVB mice and adult CD1 mouse strains show strong Rx expression in the ciliary body. The in situ hybridizations performed from week-2 to week- 6 shows the continuous expression of Rx in the adult mouse ciliary body. The FVB ciliary body is attached to sclera. The probes used and the strain information is indicated in the figure. 
We analyzed $\mathrm{Rx}$ expression in the adult mouse neural retina and in the adult mouse ciliary bodies in the present study. The results obtained from the in situ hybridization analysis indicate strong Rx expression in the photoreceptor layer and the inner nuclear layer, but with even stronger expression in the ciliary body. This Rx expression in neural retina and ciliary margin did not change during the maturation to adult stage and continues to be expressed in the adult stage. This suggests that along with playing a critical role during development, $\mathrm{Rx}$ might also be playing a role in maintaining retinal tissue in the adult stage.

Our study emphasizes a putative role for Rx in maintenance of the adult retinal, which was earlier suggested by some observations. The key report suggesting the role of $\mathrm{Rx}$ in adult stage is the Rx-mediated regulation of photoreceptor cell-specific proteins, called interphotoreceptor retinoid binding protein (IRBP) and arrestin (Kimura et al., 2000). A DNA control region, called Photoreceptor Conserved Element-1 (PCE1) sequence, is found in the promoter regions of IRBP and arrestin (Kimura et al., 2000). IRBP functions in the visual cycle by shuttling vitamin A between the RPE and the photoreceptors. Arrestin protein is necessary for the downregulation of the phototransduction pathway in the photoreceptor cells. The same core sequence binding site as PCE1 is also identified in the 5' flanking region of the rat Opsin gene (Morabito et al., 1991). Rx homeodomain binds to these PCE-1/Ret1 sites and activates the 'TATA' less promoter in the arrestin and IRBP genes (Kimura et al., 2000). The RX (Human form of Rx) binding to the IRBP and arrestin promoters showed upregulation in their expression by 6.4-fold (Kimura et al., 2000). IRBP and arrestin are present and are functional in fully delineated photoreceptor cells of the adult mouse retina, and since our data show the presence of $\mathrm{Rx}$ in the adult mouse, it leads to the possibility of colocalization of $\mathrm{Rx}$ with these proteins. This coexpression of $\mathrm{Rx}$ with these proteins increases the possibility of an in vivo interaction of these factors as seen in in vitro conditions (Kimura et al., 2000). The expression of $\mathrm{Rx}$ in the photoreceptor layer therefore seems to be required for the maintenance of this layer. 
Similar interaction is also reported between the promoter regions of the transcription factor Hes1, the transmembrane receptor, Notch1 and Rx. At nine days postpartum (P9) stage in mouse, Hes1 and Notch1 mRNA show overlapping expression with $\mathrm{Rx}$ in the inner nuclear layer of retina (Furukawa et al., 2000). Our data shows Rx expression in the inner nuclear layer of the mouse retina, in the adult stages. The in vitro cotransfection assays indicate that Rx upregulates Hes1 and Notch1 promoter expression by five times (Furukawa et al., 2000). Hes1 activation could be indirect, that is the Rx binding to the Notch promoter activates Notch1, which in-turn activates the Hes1 promoter through KBF2-binding sites in the promoter or could be directly through Rx binding to the Hes 1 promoter region. Since, the colocalization of Rx with Hes1 and Notch1 is observed nine days after birth in this study and our study indicates Rx expression in the inner nuclear layer in adults, it again supports the idea that Rx might be playing some role even after completion of organogenesis and after the completion of maturation of the retina. One such role of Rx is already proposed in the same study (Furukawa et al., 2000) which suggests that Rx, Hes1 and Notch1 enables the retinal progenitor cells to take the Müller glial pathway, while inhibiting the formation of neural cells in the inner nuclear layer of retina.

Our expression study for ciliary body showed more intense staining than that of retina. Amphibians and fish also retain Rx expression in the ciliary marginal zone during adult stage (Chuang et al., 1999; Perron et al., 1998, Casarosa et al., 1997, Mathers et al., 1997). Study on Xenopus shows that Xrx1 continues to be expressed in the ciliary marginal zone even though Xrx1 disappeared from differentiated retinal cells (Perron et al., 1998). Amphibians and fish show a retinal regenerative capacity that uses the stem cells from the ciliary marginal zone along with the rod progenitors and Müller glia. The adult mouse ciliary bodies show the presence of a stem cell population according to the previous reports (Tropepe et al., 2000). Since Rx continues to be expressed in the ciliary bodies and since $\mathrm{Rx}$ is also seen to be present in the adult mouse retinas, we can speculate that $\mathrm{Rx}$ is required for maintenance of the stem cells in the ciliary bodies and it further supports the proliferation and proper differentiation of these retinal progenitors as they 
are incorporated into the adult mouse retina from ciliary bodies. For confirmation of these speculations, further study is necessary. 
Chapter III

2a. Determination of the downstream target genes of the $R x$ transcription factor using cotransfection assays

And

$2 b$. Determination of the $\mathrm{Rx}$ regulatory sequence or region in the BMP-4 promoter 


\section{A. Introduction}

During the development, the differentiation of stem cells in the optic cup depends on the transcription factors expressed by these cells. At the optic vesicle stage, the cells express both neural retinal and RPE-specific markers, and therefore, are able to differentiate into either of the cell groups. The evagination of the optic vesicle plays a very crucial role in formation of neural retina versus RPE, since this evagination exposes these structure to two different signaling environments, which affect their cell lineage. The presumptive neural retinal region contacts the surface ectoderm at the distal end while the presumptive RPE region comes in contact with the mesenchyme at the dorsal region (Fig-1) (Martinez-Morales et al., 2004). The signals from the extraocular mesenchyme in the form of activin favor the RPE formation, whereas surface ectoderm signals such as BMP-4 and FGFs favors the neural retina formation (Martinez-Morales et al., 2004; Hyer et al., 1998; Fuhrmann et al., 2000). FGF can downregulate the MitF expression and as a result of this the retinal progenitor cells differentiate into neural retinal cells versus the pigmented RPE cells (Nguyen et al., 2000; Pittack et al., 1997). The TGF- $\beta$ family protein activin supports the RPE formation by increasing the expression of RPE specific proteins, Mitf and MMP115 (Fuhrmann et al., 2000).

The Rx gene helps in delineation between neural retina and RPE by affecting the expression of critical genes in this region. The Chx10, Six3, Pax6, Six6, Hes1, and Notch1 genes are known to be important in the specification and proliferation of the neural retina, and the expression of each of these genes is related to the Rx expression (Loosli et al., 1999; Furukawa et al., 2000; Marquardt et al., 2001, Voronina et al., unpublished data). The cell cycle regulators, such as CyclinD1 and growth factors including FGF proteins, also affect neural retina formation when absent or overexpressed (Sicinski et al., 1995; Ma et al., 1998; Pittack et al., 1997; Hyer et al., 1998). On the other hand, the markers of retinal pigmented epithelium (RPE), including Trp1, Trp2, Tyrosinase, Otx2, QNR71 and Mitf; are expressed exclusive of Rx protein; Rx is expressed in the neural retina specifically, and these genes are expressed in the RPE specifically (Marinez-Morales et al., 2003). 
The optic vesicle conditional knock-out $\left(\mathrm{Rx} \Delta 2^{\mathrm{Foxg} 1}\right)$ that abolishes $\mathrm{Rx}$ gene expression at the E8.75 stage show that RPE formation is not affected in the mutated distal optic vesicle (Voronina et al., unpublished observations), whereas the expression of the neural retinal specific genes was severely affected in these mutant embryos. The genes like Cyclin-D1, FGF8, FGF15, BMP-4, Pax6 and Six3 which are expressed in the neural retina during development showed complete absence in the mutated distal optic vesicle. However, in these $\mathrm{Rx} \Delta 2^{\mathrm{Foxg} 1}$ mutants, the expression of RPE-specific genes is expanded. The entire distal optic vesicle shows the presence of RPE-specific markers like Mitf, Dct (Tryp2), Tryp1. This expression pattern differs from that seen in control mice, which shows restricted expression of RPE-specific markers in the proximal region of the optic cup, near the optic stalk. This expression pattern in the Rx optic vesicle conditional knock-out suggests that $\mathrm{Rx}$ supports neural retinal formation while inhibiting RPE formation by regulating the transcription of RPE-specific genes in the presumptive neural retinal region while simultaneously supporting the transcription of neural retinal specific genes in the presumptive neural retina.

The cotransfection of the RX gene with the promoter region from these genes controlling a luciferase reporter gene will tell us which genes are activated or repressed by $\mathrm{RX}$ protein activity. The results from this study will help us to speculate the downstream effectors of RX for defining the proper neural retinal cell identity.

We chose a number of genes as putative downstream effectors of $\mathrm{Rx}$, but due to either the absence of well defined upstream regulatory sequences or failure to isolate some of the comparatively large regions, we focused our study on only the key regulators. The final list of genes included the neural retinal specific genes, Cyclin-D1, BMP-4, Six3, and the RPE-specific genes, Mitf, Tryp1, Otx2 and Tyrosinase.

The final list of genes included the neural retinal specific genes, Cyclin-D1, BMP-4, Six3, and the RPE-specific genes, Mitf, Tryp1, Otx2 and Tyrosinase. Using cotransfection assays, we determined that $\mathrm{Rx}$ can activate not only selected neural retinal 
promoters, but also some RPE-specific promoters, while inhibiting other RPE promoters. Our results suggest that a complex transcriptional network is involved in neural retinal versus RPE specification and differentiation. 


\section{B. Material and Methods}

\section{$\underline{\text { 1.Plasmid Isolation and Purification }}$}

The plasmids for the cotransfection assays were gifts from various labs. The basic luciferase vector pGL3, the basic renilla luciferase vector pRL (both from Promega, Madison, WI), and the $1.8 \mathrm{~Kb}$ BMP promoter region subcloned into the pGL3 basic luciferase vector were gifts from Dr. Mark Lewandoski (National Cancer Institute, Frederick, MD). The genomic human Cyclin D1 promoter subcloned into the pA3Luc vector was a gift from Dr. Richard Pestell (Georgetown University, Washington, DC). The CyclinD1 promoter was analyzed in three constructs of varying lengths as specific regions showed responses to particular signaling molecules (Albanese et al., 1995). The construct with the entire region of genomic promoter of Cyclin D1 is called 1745CD1Luc and the 5' deletions of this construct were labeled as -1093CD1 Luc and 964CD1Luc (Albanese et al., 1995). The Otx2 promoters of length $2.4 \mathrm{~Kb}$ and $1.8 \mathrm{~Kb}$ in the pXP2 luciferase vector were gifts from Dr. Paula Bovolenta (International Institute of Genetics and Biophysics, Naples, Italy). The $1.8 \mathrm{~Kb}$ Otx2 shows expression in the mesodermal region during development. The effectors released from this region help to form the RPE, later during the development. The Six 3 promoter region was provided by Dr. Guillermo Oliver (St. Jude Children's Research Hospital, Memphis, Tennessee). The $1.4 \mathrm{~Kb}$ mouse Six 3 promoter region subcloned into the pGL5 vector is shown to be regulated by the Six3 protein itself and the groucho corepressor proteins (Zhu et al., 2002). The human MitFA promoter region of $2.2 \mathrm{~Kb}$ was provided in the pGL3 luciferase reporter vector. Human Tyr $(3.6 \mathrm{~Kb})$ and $\operatorname{Trp} 1(3.7 \mathrm{~Kb})$ promoter regions were provided in the luciferase reporter vector (Martinez-Morales et al., 2003; Yasumoto et al., 1997). The cloned promoter regions of MitF, Tyr and Trp1 were also gifts from Dr. Paula Bovolenta (International Institute of Genetics and Biophysics, Napels, Italy).

The DNAs were reconstituted from filters and used for the transformation of DH5 $\alpha$ competent E. coli cells. The maxipreps were performed using the Endofreeplasmid purification kit from Qiagen and the minipreps were done using Bio-Rad Quantum Prep Plasmid Miniprep kit. 


\section{Cos-7 cells Transfections}

We used the commercially available Cos7 Monkey Kidney cells (ATCC) for the cotransfection assays and Lipofectamine-2000 reagent (Invitrogen) for the transfection. The transfection experiments done using the $\beta$-Gal construct showed $95-100 \%$ transfection efficiency for these cells. The experiments were carried out in presence of the empty vector and then in the presence of the promoter region, in presence of the RX plasmid. The cells are then harvested 48 hours after transfection. The upregulation or downregulation of the particular promoter region is then detected using the TD 20/20 luminometer (Turner Biosystems), which is designed for Dual luciferase assays.

\section{Dual luciferase assay}

The dual luciferase assay gives us an additional control for transfections and the up or down regulation by the gene of our interest is detected more definitely. The parent vectors pGL3, pG5, or PXP2 containing the promoter region was cotransfected with the pRL vector, which gives constitutive expression of Renilla luciferase. The standard reaction will look like this, Rx-expression plasmid or control + test promoter driving luciferase + Renilla control. The firefly luciferase has a different substrate specificity than that of renilla luciferase.

The firefly luciferase substrate (LAR II) was added first in the Cos-7 cell lysate and the luminescence is recorded. The second reagent (Stop and Glow) quenches the luminescence by firefly luciferase and provides substrate for the Renilla luciferase. The ratio of these two readings using a Rx-empty vector control and the test promoter with luciferase is considered as the basal level. The ratio was then compared with the ratio for the cotransfection of the test promoter plasmid and the Rx-expressing plasmid. The difference between the control and test ratio indicated the upregulation or downregulation of the target promoter by $\mathrm{Rx}$ (Table -1$)$. 
Additional control transfections, such as the parent vector without promoter region in the presence and absence of the Rx protein, are carried out. For each promoter of interest, the transfections were carried out six times on separate days and in separate wells, and the cell lysate from each well is then sampled for luminescence. This gave us a sample number of six, which is necessary for determining the statistical significance of these results. The unpaired student T-test was used to determine the statistical significance of the readings. A significance value $\mathrm{P}<0.05$ was used.

The detailed protocol standardized for these dual luciferase assays is as follows

a. $250 \mu \mathrm{l}$ optimem transfection medium $+4 \mu \mathrm{g}$ of test promoter in luciferase plasmid $+4 \mu \mathrm{g}$ of Rx DNA $+0.2 \mu \mathrm{g}$ of Renilla luciferase vector

b. $250 \mu 1$ of Optimem $+8 \mu 1$ of lipofectamine

c. Incubate at room temperature for 30 minutes

d. Change the solution after 5 hours with the serum containing DMEM medium

The Cos-7 cells are lysed 48 hours after transfection using Promega's DLR kit. $500 \mu 1$ of the Passive lysis buffer (PLB) is added in each of the six well plates and the lysed cells are collected after a 15 minutes incubation. $20 \mu l$ of this cell lysate is used with the $100 \mu \mathrm{l}$ of LARII firefly luciferase substrate in the TD 20/20 luminometer for the firefly luciferase activity. The luciferase activity is read for 10 seconds. The firefly luciferase reaction is stopped using $100 \mu$ l of the Stop and glow reagent and the renilla luciferase activity is read for 10 seconds similar to that of firefly luciferase. 


\section{B.Results}

\section{Effect of RX activity on the promoter region of neural retinal genes}

Determination of the RX-mediated regulation of the promoter regions of potential neural retinal target genes was achieved using the dual luciferase assay. The activity of promoter region in the firefly luciferase construct is noted in presence and absence of the RX gene. The controls run in the reaction and the calculations used for these assays are explained in detail in the Materials and Methods section above.

The pA3 parent vector was analyzed for the variation in luciferase activity in the presence of RX gene. The pA3 parent vector does not show any change in the activity in the presence of RX gene, since the ratio of luciferase readings in the presence or absence of $R x$ was 1.0 and was not significantly different $(p=1.000)($ Table-2). Similar tests were run for the other parent vectors, pXP2, pGL3 and pG5, and none of these were RXresponsive $(\mathrm{p}=0.982, \mathrm{p}=0.852, \mathrm{p}=0.822)$. The $1.8 \mathrm{~kb}$ BMP-4 promoter region was used as the positive control for these cotransfections, since it was previously observed that RX induces the BMP-4 promoter activity by six-fold (Voronina et al., unpublished observations). The BMP-4 cotransfection reaction was run along with every set of cotransfections. Since only the incubation period of 48 hours induced the reported sixfold induction, we used this incubation period for all the assays reported here. The BMP4 promoter induction was statistically significant $(\mathrm{p}=0.0001)$ in twenty representative cotransfection readings.

The human CyclinD1 promoter in the pA3 vector was analyzed in three constructs of varying lengths. These specific regions respond to different signaling molecules (Albanese et al., 1995). In our cotransfection assays, the construct covering the entire Cyclin-D1 promoter in the reporter luciferase vector (-1745CD1Luc), and the 5'end deletion constructs of this main promoter region (-1093CD1 Luc and -964CD1Luc), were all completely non-responsive to RX (Table-2). These cotransfections were carried out 24 hours, before taking the luciferase readings. The ratios of luciferase activity in the 
presence or the absence of RX did not vary much from 1.00 for all the three constructs $(0.92,1.07$ and 0.98$)$. The unpaired t-test results indicate that these readings are not statistically significant $(\mathrm{p}=0.615, \mathrm{p}=0.885$ and $\mathrm{p}=0.316$ respectively). These readings indicate that cyclin-D1 promoter is not responsive to RX-mediated activation.

However, another neural retinal promoter, Six3, shows RX-mediated induction. A $1.4 \mathrm{~Kb}$-long mouse Six 3 promoter region subcloned into the pGL5 vector showed a fourfold induction in the activity when cotransfected with RX. The effect of RX mediated activation was not prominent in the 24 hours transfection assays $(\mathrm{p}=0.200)$ but the longer incubations showed prominent induction in the promoter activity, which was very close to being significant $(\mathrm{p}=0.112$ ). Upon using the 'Least Square Fit' test for the control and test readings, we found that the readings were statistically significant $(\mathrm{p}=0.0245)$.

\section{Effect of RX activity on the promoter region of RPE-specific genes}

To verify our hypothesis that the RX gene supports neural retinal development in the presumptive neural retina by inhibiting the expression of RPE-specific markers from that region, we studied the promoter regions of RPE-specific genes. We tested MitF and Otx2, the RPE regulatory genes and their downstream effectors and the proteins required for the pigementation Trp1, Tyr. The cotransfection assay with RX gene and these promoter regions gave very intriguing results.

Contrary to our hypothesis that RX activity would inhibit RPE-specific promoters, human MitF-A (Microphthalmia Associated Transcription Factor) promoter region of $2.233 \mathrm{~Kb}$ in the pGL3 luciferase reporter vector showed induction in the presence of RX gene. This 3.34-fold induction of the MitF promoter in the presence of $\mathrm{RX}$ gene is statistically significant $(\mathrm{p}=0.019)$. 
The promoter region of another RPE-specific marker, Trp1, which also is one of the downstream effectors of the key RPE-specific gene, MitF, showed RX-mediated induction in the promoter activity similar to that seen for MitF. The 2.5-fold increase in Trp1 promoter activity was also statistically significant $(\mathrm{p}=0.005)$. Also, Trp1 was the only promoter region which showed statistically significant induction for the 24 hours transfection assays $(\mathrm{p}=0.016)$. Thus, similar to the induction in the promoter activity of MitF in presence of RX, the Trp1 promoter region is also categorized for Rx-induced activation, arguing against our original hypothesis.

However, the promoter region of another downstream effector of MitF, called Tyrosinase, was inhibited by RX activity as hypothesized. The ratio of this human Tyr promoter activity in the presence of RX gene became 0.68 , when compared to the promoter activity in the absence of RX activity. One of the six readings was showing drastically different results compared to other readings making these readings insignificant in the statistical analysis $(p=0.065)$. After 'censoring' the data for removal of this odd reading, the readings were statistically significant $(\mathrm{p}=0.035)$.

The promoter region of another RPE-specific gene, Otx2, was studied in two constructs. The $1.8 \mathrm{~Kb}$ promoter region, does show reduction in the transcription activity (0.84) when transfected with $\mathrm{RX}$, but this reduction was not statistically significant $(\mathrm{p}=$ 0.674). The longer Otx 2 promoter region of $2.4 \mathrm{~Kb}$ also turned out to be non-responsive to RX, with the ratio of promoter activity being very close to one (0.972) and statistically insignificant $(\mathrm{p}=0.404)$. 


\section{Discussion}

In the present study we have analyzed potential downstream effecter genes for RX activity, which would be necessary for proper development of ocular structures. The results obtained from the in vitro cotranfection assays, with the RX gene and the promoter region of the target genes fused to the firefly luciferase reporter gene, indicate that the RX gene can activate the promoter regions of neural retinal as well as the retinal pigment epithelial (RPE) marker genes. Among the neural retinal genes, the Six3 promoter demonstrates strong induction of activity in the presence of the RX gene, as does the positive control in our assays, the Bmp4 promoter. Some RPE promoters, such as Mitf and Trp1, show RX-mediated induction. On the other hand, Tyrosinase promoter activity was found to be reduced by RX activity, whereas the Otx 2 promoters $(1.8 \mathrm{~Kb}$ and $2.4 \mathrm{~Kb}$ ) remained non-responsive to $\mathrm{RX}$. The Cyclin-D1 promoter region was also found to be non-responsive to RX activity. These results suggest that RX gene expression plays a crucial role in the proliferation of retinal progenitor cells by supporting the expression of both neural retinal and key RPE-specific genes. This data also explains the ectopic RPE formation along with the duplication of neural retina upon injection of Rx mRNA into Xenopus embryos (Mathers et al., 1997). Since, RX does not seem to be involved in determining the identity of the progenitor cells towards either the neural retinal the RPE fate, we believe that extrinsic regulators such as the growth factors, BMP3 and BMP4 molecules play a crucial role in determining the cell fate verses that of intrinsic regulators such as the transcription factors, as was proposed earlier (Pearson and Doe, 2004).

Proper eye development is regulated by many homeobox genes, as well as non-homeobox genes expressed during development. A few critical genes for proper ocular development include Rx, Pax6, Six3, Mitf, and Otx2 (Mathers et al., 1997; Grindley et al., 1995; Tucker et al., 2001; Goding et al., 2000; Nguyen et al., 2000; Matsuo et al, 1995, Oliver et al., 1995). Misexpression of each of these gene leads to abnormal structure formation. The signaling pathways used by these genes and the hierarchy in the signaling pathways are not very well understood, but some observations suggest that the Rx gene regulates expression of all of these genes. Rx-null embryos do not form any optic structures including the optic vesicle (Mathers et al., 1997; Zhang et 
al., 2000). These Rx homozygous mutants also show reduced Six3 expression in the presumptive optic area (Zhang et al., 2000). However, a germline mutation in another key homeobox gene for eye development, Pax6, shows optic vesicle formation and normal Rx expression (Grindley et al., 1995; Zhang et al., 2000). In Rx germline knockout mice, Otx2 expression is totally absent in the retinal area at E10 (Zhang et al., 2000). This indicates that the expression of $\mathrm{Rx}$ is not affected by these genes but expression of these genes is decided by $\mathrm{Rx}$ to a certain extent, and that $\mathrm{Rx}$ might be delineating retinal cell fate by regulating the expression of these genes. To understand the role played by intrinsic factors, such as Rx and other homeoxbox genes compared to extrinsic factors, such as Activin, FGF-1/2, FGF-15, BMP-3 and BMP-4, it is necessary to understand the optic vesicle invagination and the spatio-temporal expression of all these factors.

Previous studies of optic vesicle development indicate that the entire optic vesicle is capable of differentiating into the neural retina (Hyer et al., 1998). But as the development progresses, the optic vesicle invaginates to form the presumptive RPE and presumptive neural retina (Fig-1). The presumptive RPE contacts the extraocular mesenchyme, and the presumptive neural retina contacts the surface ectoderm. As the presumptive RPE comes in contact with the extraocular mesenchyme, the expression of RPE-specific genes is increased in the presumptive RPE, while neural retinal genes expression is completely inhibited from this region. A reciprocal pattern is seen in the presumptive neural retina when it contacts the surface ectoderm. The extrinsic factors released from the surface ectoderm support neural retinal gene expression, while the expression of RPE-specific genes is completely abolished from this region as discussed below (Fuhrmann et al, 2000; Nguyen et al., 2000; Andreazzoli et al., 2003; Yang et al., 2004).

\section{Surface ectoderm supports the neural retina formation}

Earlier studies show that, as the presumptive neural retina contacts the surface ectoderm, the FGFs released from the surface ectoderm inhibit the expression of RPEspecific genes while facilitating neural retinal formation (Nguyen and Arnheiter, 2000). 
In fact, FGF treatment of the optic vesicle enables the transdifferentiation of the presumptive RPE into neural retina (Pittack et al., 1997; Hyer et al., 1998). In addition, the removal of FGF expression using antisense oligos or antibodies against FGF leads to discontinuation of neural retina formation (Desire et al., 1998; Pittack et al., 1997). The FGFs are also shown to downregulate MitF, the key regulator for RPE formation (Mochii et al., 1988; Nguyen et al., 2000). Another report suggests that the FGF1 and 2 released from the surface ectoderm increase the expression of Chx10 (Horsford et al., 2005). The Chx10 helps in delineation of neural retina by facilitating the expression of FGF8, FGF9 and FGF15 while repressing the expression of Mitf in the presumptive neural retinal region (Horsford et al., 2005). The cells spatially removed from the surface ectoderm do not receive the FGF1 and 2, and therefore, do not express Chx10 and continue to express Mitf (Fig-13) (Horsford et al., 2005). Thus the FGF-mediated repression of Mitf in the neuroretina, acting through $\mathrm{Chx} 10$, and the proper formation of neural retinal and RPE is achieved by the mutual exclusion of Chx10 and Mitf expression from the RPE and neural retina, respectively.

\section{Extraocular mesenchyme supports RPE formation}

The role played by Pax6 and Pax 2 for the development of distal versus proximal development of eye is described in detail in the chapter I. These factors along with the other key regulators for RPE formation, Mitf and Otx2, delineate the RPE formation. While the interaction of optic vesicle with surface ectoderm causes repression of RPEspecific markers in the presumptive neural retina, the expression of RPE markers, such as Mitf, is induced in the proximity of extraocular mesenchyme. A mutational analysis of the Mitf gene shows impaired development of RPE in mice leading to a laminated, secondary neural retinal formation (Nguyen et al., 2000, Nakayama et al., 1998). In support of Mitf playing a crucial role in RPE specification, the overexpression of this gene causes pigmentation in avian neural retinal cells (Planque et al., 1999). The Mitf gene imparts the pigmentation to the RPE cells by controlling the expression of genes required in the pigmentation pathway, such as Tyr, TRP-1, and TRP-2 (Goding et al., 2000; Martinez-Morales et al., 2003). 
A. Expression pattern during early Development

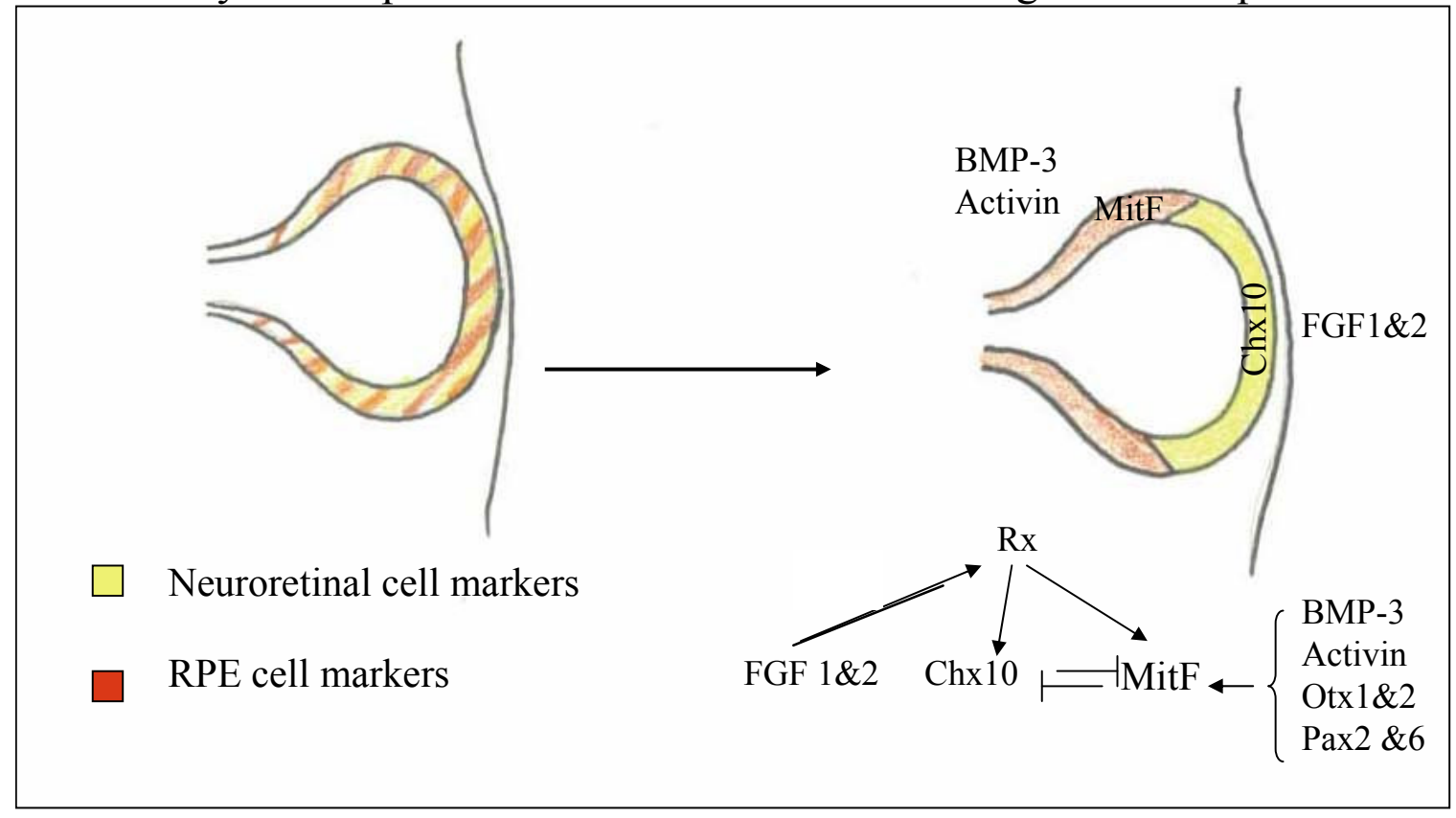

Figure 13: Patterning of neural retina and RPE by extrinsic and intrinsic factors

The extrinsic factors, such as FGFs, released from the surface ectoderm activate the expression of the intrinsic factor, Chx10, which is required for inhibiting the expression of RPE-specific genes, such as Mitf. The extrinsic factor activin released from the extraocular mesenchyme might be inducing the expression of Otx1\&2 along with Pax2\&6, which then activate Mitf expression. The Mitf expressing genes form pigments and become RPE. (Figure derived from Horsford et al., 2005) 
The induction of Mitf expression in the presumptive RPE is mainly observed due to the TGF- $\beta$ family proteins like activin and BMP-3 (Fuhrmann et al., 2000; Fuhrmann et al., Unpublished observations). Activin is released from the extraocular mesenchyme, and this region contacts the presumptive RPE. When the optic vesicle explants were grown in the presence of activin, they showed an increase in the RPE-specific marker genes, such as Mitf and MMP115 (Fuhrmann et al., 2000). However, the presence of surface ectoderm signals such as BMP-4 and BMP-7 did not show any variation in the Mitf expression in the same study. It was also postulated that along with acting on MitF, activin might also be able to induce the expression of other RPE-specific genes such as Otx1, Otx2, Pax2, and Pax6 (Horsford et al., 2005). Otx2, Pax2, and Pax6 act upstream of Mitf, and therefore, might be the direct regulators. This study supports the idea of a possible antagonism between FGFs from the surface ectoderm and activin from the extraocular mesenchyme for the patterning of the optic vesicle into RPE or neural retinal structures (Figure-13). Mitf expression, therefore, seems like the decisive factor in the cell fate decision in the retinal field. In the Mitf-downregulated region, the cells continue to express the neural retinal specific transcription factors, and the cells differentiate into the neuronal cell types. Alternatively, the cells with continued Mitf expression form pigmentation, show the absence of neural retinal markers, and result in the formation of RPE.

Even though it is a marker for the neural retinal cell lineage, the Rx gene supports the expression of Mitf and Trp1 genes, along with Six3. Mitf expression is associated with the proliferation of RPE cells (Goding et al., 2000), and Six3 expression is associated with neural retinal cell formation (Loosli et al., 1999; Oliver et al., 1995). The coexpression of Chx10 with $\mathrm{Rx}$ in the neural retina must be inhibiting the ability of Rx to induce Mitf, since Chx 10 inhibits the expression of MitF. Rx did not show any difference on the Cyclin-D1 promoter region even though $\mathrm{Rx}$ is a proliferation marker for neural retina, and Cyclin-D1 is the key cell cycle regulator expressed during proliferation of cells. Since Cyclin-D1 is absent in the Rx optic vesicle conditional knockout, we hypothesize that Rx might be activating Cyclin-D1 in an indirect manner as explained in detail later. 
To understand the disparities between our original hypothesis and the results in this chapter, it is also necessary to understand that Rx shows different effects on the downstream targets at different stages of development. For example, the overexpression of Xrx 1 repress Xotx2 and XAG-1 at early neurula stage, while overexpression of Xrx 1 at later stages results in ectopic activation of the same genes (Andreazzoli et al., 1999). The in vitro assay in the Cos-7 cell environment does not represent the cell environment of a developmentally active tissue. The reason that transcription of some of these genes is not affected in the cotransfection assays, though it does seem to be affected in the optic vesicle conditional knockout experiments or other experiments modifying Rx expression, could be for the following reasons.

a. $\mathrm{Rx}$ is seen as a proliferative marker, and in the absence of $\mathrm{Rx}$, the proliferation of retinal cells is affected through the pathways whose end products are the genes that we see affected. Therefore Rx could be affecting the expression of these genes in an indirect way. For example, Rx could be acting through the Wnt signaling pathway (Ahmad et al., 2004) which is known to activate $\beta$-Catenin, which in turn activates the expression of many downstream effectors leading to proliferation or differentiation. The exact mechanism of this pathway is not elucidated yet. Cyclins are downstream of pathways controlling the proliferation. Ideally, the absence of Rx does affect proliferation, which in turn will reduce the expression of the cyclinD1 in the optic vesicles. But under in vitro conditions, where the CyclinD1 promoter region is exposed just to the Rx protein, it will not show any effect on the Cyclin D1 promoter activity.

b. The other possibility could be that, we didn't have the right region of the CyclinD1 promoter that responds to RX.

c. The experiments were performed in the transformed Cos7 cell environment where the CyclinD1 is already maximally active and adding $\mathrm{Rx}$ has no further enhancement.

Since Rx activated both the neural retinal and the RPE cell markers, we characterize it as a proliferation marker for the entire optic vesicle region, rather than a gene required for patterning of the neural retina and RPE, as we proposed earlier. 


\begin{tabular}{|c|c|c|c|c|}
\hline $\begin{array}{l}\text { Reaction } \\
\text { Number }\end{array}$ & Transfections & $\begin{array}{c}\text { Reporter } \\
\text { Luciferase } \\
\text { Vector }\end{array}$ & Rx Vector & $\begin{array}{c}\text { Internal } \\
\text { Transfection } \\
\text { Control }\end{array}$ \\
\hline 1 & Test & $\begin{array}{l}\text { Test Promoter } \\
\text { in Luciferase } \\
\text { Vector }\end{array}$ & $\begin{array}{l}\text { pCMV- } \\
\text { Tag2BWT RX }\end{array}$ & $\begin{array}{c}\text { Renilla } \\
\text { Luciferase } \\
\text { Vector }\end{array}$ \\
\hline 2 & Control- 1 & $\begin{array}{l}\text { Test Promoter } \\
\text { in Luciferase } \\
\text { Vector }\end{array}$ & $\begin{array}{l}\text { pCMV-Tag2B } \\
\text { (empty vector) }\end{array}$ & $\begin{array}{c}\text { Renilla } \\
\text { Luciferase } \\
\text { Vector }\end{array}$ \\
\hline 3 & Control- 2 & $\begin{array}{l}\text { Luciferase } \\
\text { Vector (empty } \\
\text { vector) }\end{array}$ & $\begin{array}{l}\text { pCMV- } \\
\text { Tag2BWT RX }\end{array}$ & $\begin{array}{c}\text { Renilla } \\
\text { Luciferase } \\
\text { Vector }\end{array}$ \\
\hline 4 & Control- 3 & $\begin{array}{l}\text { BMP-4 } \\
\text { promoter in } \\
\text { Luciferase } \\
\text { Vector }\end{array}$ & $\begin{array}{l}\text { pCMV- } \\
\text { Tag2BWT RX }\end{array}$ & $\begin{array}{c}\text { Renilla } \\
\text { Luciferase } \\
\text { Vector }\end{array}$ \\
\hline
\end{tabular}

Table 1: Strategy for the cotransfection assays

The activity of the test promoter-driven luciferase is compared in the presence and absence of the $\mathrm{Rx}$ protein (reactions 1 and 2). The parent vector with no promoter sequence was used as the negative control to exclude the possibility of Rx activity on the empty parent vector (reaction 3). The previously identified $\mathrm{Rx}$ downstream effector BMP-4 (Voronina et al., unpublished observations) is used as a positive control for transfections and the assay itself, throughout these experiments (reaction 4). 


\begin{tabular}{|c|c|c|c|c|c|c|}
\hline & \multicolumn{3}{|c|}{24 hours transfection } & \multicolumn{3}{|c|}{48 hours transfection } \\
\hline $\begin{array}{l}\text { Promoter } \\
\text { region of } \\
\text { the gene }\end{array}$ & $\begin{array}{l}\text { Fold } \\
\text { induction }\end{array}$ & $\begin{array}{l}\text { Sample } \\
\text { Number }\end{array}$ & $\begin{array}{c}\mathrm{p} \text { Value } \\
\text { Significant if } \\
<0.05 *\end{array}$ & $\begin{array}{c}\text { Fold } \\
\text { induction }\end{array}$ & $\begin{array}{l}\text { Sample } \\
\text { Number }\end{array}$ & $\begin{array}{c}\mathrm{p} \text { Value } \\
\text { Significant if } \\
<0.05 *\end{array}$ \\
\hline \multicolumn{7}{|c|}{ Neural retinal specific genes } \\
\hline $\begin{array}{l}\text { CyclinD1- } \\
\text { 1700bp }\end{array}$ & 0.92 & 5 & 0.615 & NA & - & - \\
\hline $\begin{array}{c}\text { Cyclin D1- } \\
1100 \mathrm{bp}\end{array}$ & 1.07 & 5 & 0.885 & NA & - & - \\
\hline $\begin{array}{l}\text { CyclinD1- } \\
\text { 960bp }\end{array}$ & 0.98 & 4 & 0.316 & NA & - & - \\
\hline Six3 & 1.61 & 4 & 0.200 & 4.015 & 9 & $0.008 *$ \\
\hline \multicolumn{7}{|c|}{ RPE-specific genes } \\
\hline Mitf & 2.07 & 4 & 0.102 & 3.34 & 8 & $0.019 *$ \\
\hline Tyrosinase & 0.8 & 4 & 0.723 & 0.68 & 5 & $0.035 *$ \\
\hline Trp1 & 2.19 & 3 & $0.016 *$ & 2.5 & 6 & $0.005 *$ \\
\hline $\begin{array}{c}\text { Otx2 }(2.4 \\
\mathrm{Kb})\end{array}$ & 0.972 & 4 & 0.404 & 2.19 & 4 & 0.424 \\
\hline $\begin{array}{c}\text { Otx2 (1.8 } \\
\mathrm{Kb})\end{array}$ & 0.84 & 5 & 0.674 & $\mathrm{~N} / \mathrm{A}$ & - & - \\
\hline \multicolumn{7}{|c|}{ Control transfection reactions } \\
\hline BMP4 & 3.86 & 7 & 0.0004 & 6.3 & 20 & $0.0001 *$ \\
\hline pG5 & 1.03 & 3 & 0.822 & NA & & \\
\hline pA3 & 1 & 3 & 1.000 & NA & - & - \\
\hline $\mathrm{pXP} 2$ & 1 & 4 & 0.982 & - & - & - \\
\hline
\end{tabular}

\section{Table 2: Results of $R X$ cotransfection assay}

Cotransfection assays repeated multiple times in the presence or absence of RX protein, were evaluated using the 'Unpaired student t-test'. For the P test, the control reactions carried out in presence of the promoter but in the absence of the Rx gene comprised one group of samples. This group is compared to the one carried in the presence of both the promoter and the $\mathrm{Rx}$ gene. The asterisk mark indicates a statistically significant reading. 


\section{$2 b$. Determination of the $R x$ regulatory sequence or region in the BMP-4 promoter}

\section{A. Introduction}

The TGF- $\beta$ family protein, BMP-4, is one of the key regulators for eye morphogenesis. BMP-4 is secreted from the optic vesicle as the optic vesicle evaginates and contacts the surface ectoderm. In Xenopus BMP-4 is seen to be crucial for the dorsalventral axis formation (Maeno et al., 1994). BMP-4 supports the dorsal retinal formation by controlling the expression of Shh and inducing the expression of Tbx5 in the dorsal retinal region (Koshiba-Takeuchi et al., 2000; Furuta and Hogan, 1998; Sasagawa et al., 2002; Yang et al., 2004). Subsequently, Tbx5 negatively controls the expression of ventral markers, such as Vax, EphB2, and EphB3, in the dorsal region of the optic vesicle (Sasagawa et al., 2002; Zhang and Yang, 2001). BMP-4 is also necessary for proper lens formation (Furuta and Hogan, 1998).

In the $\mathrm{Rx}$ optic vesicle conditional knock out mice, the BMP-4 expression is completely absent in the distal optic vesicle at E10.5 stage (Voronina et al., unpublished observations). The cotransfection assays following this experiment showed a six-fold upregulation of the BMP-4 promoter by RX protein (Voronina et al., unpublished

observations). A $1.8 \mathrm{~Kb}$ BMP-4 promoter region contains a single copy of the previously characterized Rx-binding sequence, called the PCE-1 sequence, and along with other PCE1-related sequences. The PCE sequence is a seven-nucleotide motif with an interchangeable $(\mathrm{A} / \mathrm{G})$ nucleotide. The sequence is

\section{5' CAATTAA/G 3' 3' GTTAATT/C 5'}

Previous studies on the promoter region of interphotoreceptor retinoid binding protein (IRBP) and arrestin genes show that Rx activates these promoters through the PCE-1 sequences (Kimura et al., 2000). In the previous work in lab the RX mutation called R192Q was discovered in an anophthalmic patient (Voronina et al., 2004). In the 
EMSA assay between the RX protein and the labeled PCE-1 oligos show that, the wild type RX shows the concentration-dependent binding to the target site as the concentration of the unlabeled competitor oligo increases, but the mutated R192Q RAX does not have the ability to bind the PCE-1 site (Voronina et al., 2004). Since the BMP-4 promoter sequence also has the PCE-1 site, we believed that RX protein might be regulating this promoter using this site, too.

To analyze whether the Rx protein uses the PCE-I site to regulate the BMP-4 promoter region, we mutated this site using site-directed mutagenesis. We also mutated two PCE-1-related sites and studied the constructs carrying these mutations, as well as the combinations of these mutations. The promoter activity of constructs carrying these mutations at the PCE-1 sites was analyzed using the cotransfection assay. The results obtained from the cotransfections experiments did not yield a very clear picture regarding the most crucial binding site in the promoter region, but when all the PCE-1 sites were mutated, the promoter activity was reduced significantly. 


\section{B. Material and Methods}

\section{Site-directed Mutagenesis}

The Quik-Change Site-directed Mutagenesis kit (Stratagene) was used for mutating the PCE-1 and the PCE-1-related sites in the BMP-4 promoter. The strategy for this particular site-directed mutagenesis includes the primers containing the sequence of the desired mutation, which also introduces a restriction site after the mutation. These primers with the mutated sequence were used for PCR with the high fidelity Pfu-turbo DNA polymerase (Stratagene). The PCR products were treated with the endonuclease Dpn-1 before transfecting into the competent cells. Dpn1 degrades the template DNA, since it is methylated in the in vivo proof reading process in bacteria. The mutated PCR product stays intact during the Dpn1 treatment since it is not methylated. The Dpn-1treated nicked PCR product is used to transform the XL-1 Blue supercompetent cells. The nick in the mutant plasmids from PCR is repaired in the XL-1 cells after the transformation. This repaired vector imparts Ampicillin resistance to the cells. The colonies were isolated using Ampicillin plates. The digestion of the miniprep DNA with the appropriately introduced restriction enzymes tells us whether the mutagenesis is successful. Each mutation was further confirmed by sequencing.

The optimized PCR cycle for these mutations is given below. The pfu-Turbo DNA polymerase did not work for the ideal condition of one minute per one kilobase. The enzyme required twice the period of time to work in the reactions. Also, the relatively longer size of primers (40-50 nts) required for these reactions lead to secondary structures formation. This problem was solved by adding 5\% DMSO in the PCR reactions, which prevented hairpin formation by inhibiting the base-pairing. 


$\begin{array}{llll} & \text { Cycles } & \text { Temperature } & \text { Time } \\ 1 & 1 & 95^{\circ} \mathrm{C} & 30 \text { seconds } \\ & 18 & 95^{\circ} \mathrm{C} & 30 \text { seconds } \\ & 58^{\circ} \mathrm{C} & 1 \text { minute } \\ & 68^{\circ} \mathrm{C} & 2 \text { minutes/Kb of Plasmid }\end{array}$

The PCR conditions for Site-Directed Mutations: The PCR cycles for the site-directed mutagenesis start as the standard PCR protocols, which include the denaturation of the DNA at $95^{\circ} \mathrm{C}$ followed by annealing of the DNA strand with mutagenesis primers. However, since this mutagenesis reaction uses the high fidelity DNA polymerase the reaction becomes extremely slow and takes up to two minutes for amplifying about one $\mathrm{Kb}$ of the plasmid DNA. (Table derived from the Stratagene Quik-Change Site-directed mutagenesis manual)

The introduced mutations and the location of these mutations in the BMP-4 promoter region are indicated in the Figure-14. The activity of these mutated promoter constructs were then determined using the dual luciferase assay as described in the previous section. The BMP-4 original promoter is run as a positive control with these reactions. 


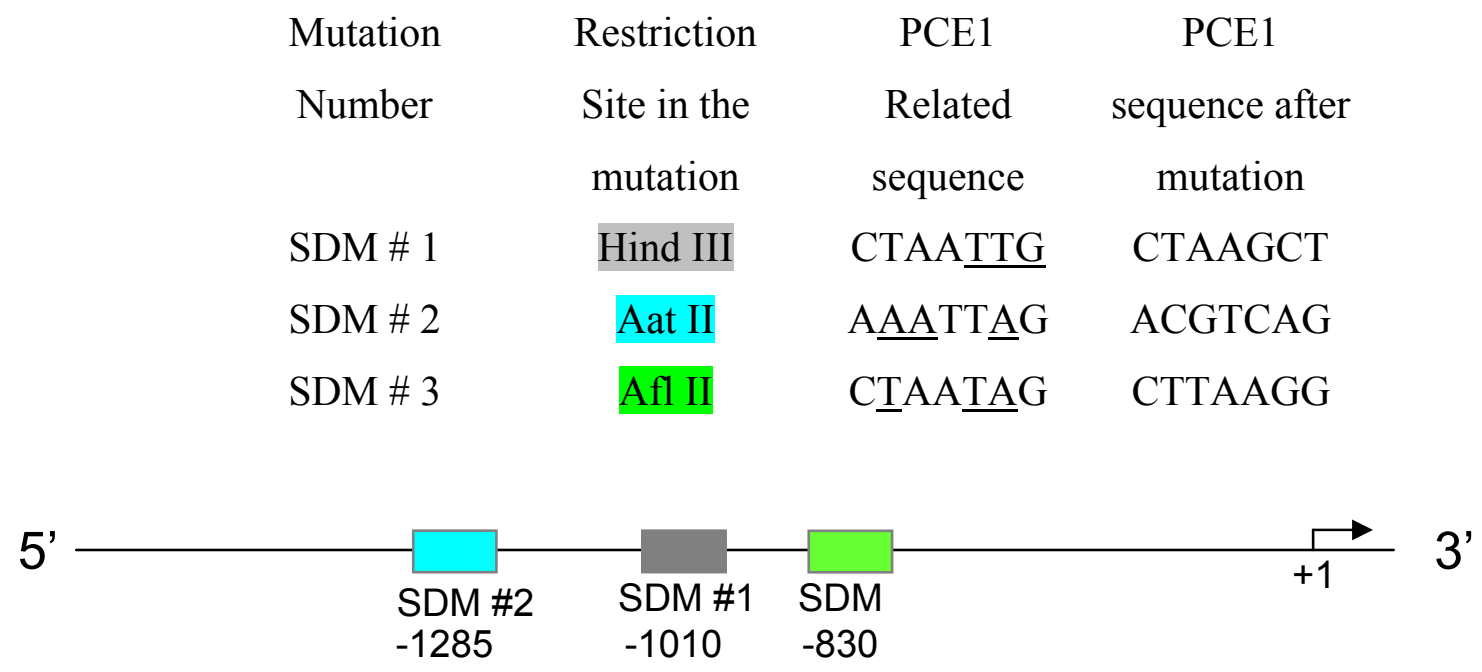

Figure 14: The mutated sequences and the schematic representation of location of these mutations introduced in the BMP-4 promoter for the analysis of Rx binding. The SDM\#1 (CTAATTG) site has identical sequence to that of Rx binding site called PCE-1 site. The SDM\#2 (AAATTAG) and SDM\#3 (CTAATAG) have one nucleotide difference from the PCE-1 site, but preserve the central core homeodomain binding element (ATTA). The restriction sites introduced by these mutations are listed in the second column. The mutated nucleotides are underlined in the table. 


\section{List of primer sequences used for the mutations}

The primers were designed to have a Tm value of more than $68^{\circ} \mathrm{C}$ since the optimum temperature for the pfu-Turbo DNA polymerase is $68-72^{\circ} \mathrm{C}$. The Tm values were calculated using the Quik-Change Tm formula.

$\mathrm{Tm}=81.5+0.41(\% \mathrm{GC})-675 / \mathrm{N}-\%$ mismatch

Site-Directed Mutation (SDM \#1)

Forward sequence

5' CAGAgAtATAAATAGgATtTTCTAATtGtCTTACAAGGCCTAGGCCTG 3'

Forward Primer (Mutated) $\mathrm{Tm}=78^{\circ} \mathrm{C}$

5' CAGAGATATAAATAGGATTTTCTAAGCTTCTTACAAGGCCTAGGCCTG 3'

Reverse Primer (Mutated)

5' CAGGCCTAGGCCTTGTAAGAAGCTTAGAAAATCCTATTTATATCTCTG 3'

Site-Directed Mutation (SDM \#2)

Forward Sequecne

GCTCCATCAGAGGCAGGGTGTGAAATTAGCTCCTGTTTGGGAA

Forward Primer (Mutated) $\mathrm{Tm}=86.53^{0} \mathrm{C}$

GCTCCATCAGAGGCAGGGTGTGACGTCAGCTCCTGTTTGGGAAGGTTTAAAAGCC

Reverse Primer (Mutated)

GGCTTTTAAACCTTCCCAAACAGGAGCTGACGTCACACCCTGCCTCTGATGGAGC

Site-Directed Mutation (SDM \#3)

Forward Sequence

GGGGGGAAAGTCACCTCCTAATAGGTTGAAGAGGTATCTCC

Forward Primer (Mutated): $\mathrm{Tm}=79.15^{\circ} \mathrm{C}$

GGGGGGAAAGTCACCTCCTTAAGGTTGAAGAGGTATCTCC

Reverse Primer (Mutated)

GGAGATACCTCTTCAACCTTAAGGAGGTGACTTTCCCCCC 
3. Isolation of the 3' end of the BMP-4 promoter region from the pGL3-BMP4 construct

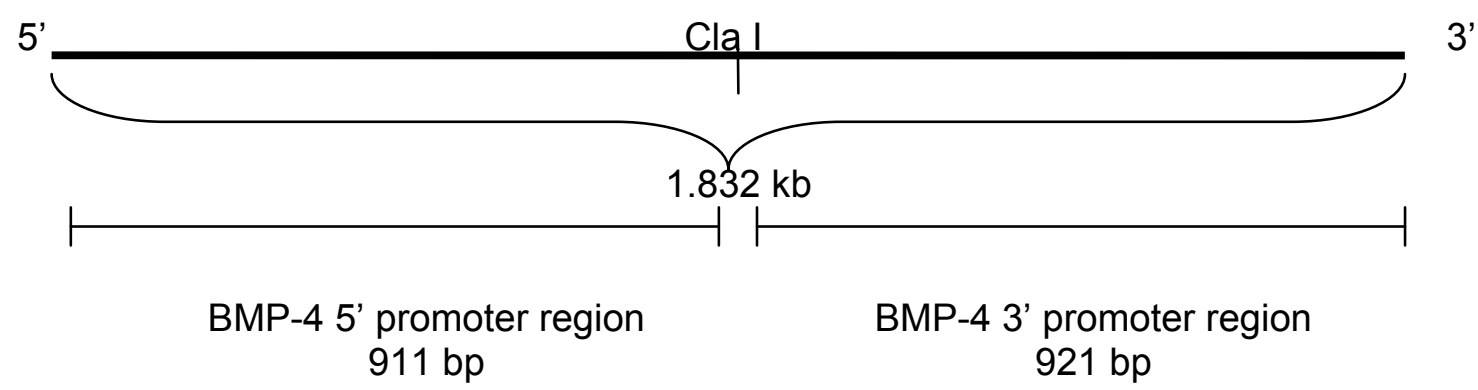

The Rx-responsive BMP-4 region is $1.8 \mathrm{~kb}$ in the size. To further characterize the Rxresponsive region, the $1.8 \mathrm{~kb}$ region was subdivided into two regions of nearly $900 \mathrm{bp}$ using the Cla I site in the center of the Rx-responsive BMP-4 promoter region.

\section{Cloning strategy for the 3' BMP-4 region}

The pGL3-BMP4 construct was isolated from dam bacteria to avoid the methylation of Cla-I target sequence, double digested with ClaI + XhoI, and the resulting $900 \mathrm{bp}$ fragment was gel-extracted for ligation into the carrier vector pBluescript. This ligated product (pBS-BMP4 3') was digested with SacI and XhoI for cloning back into the luciferase pGL3 vector and was used as the pGL3-BMP4 3' vector for cotransfection assays. 


\section{Results}

\section{Effect of PCE-1 mutations on BMP-4 promoter activity}

Determination of the effect of PCE-1 mutations on the BMP-4 promoter activity was achieved by mutating the PCE-1 sites using site-directed mutagenesis. The activity of these mutated promoters in the luciferase plasmid was determined using the dual luciferase assay. The activity of promoter region in the firefly luciferase construct is noted in the presence and absence of the RX gene. The calculations used in these reactions are explained in the previous aim. For all these reactions, the student t-test was used, and results were compared to the readings from the unmutated $1.8 \mathrm{~kb}$ BMP-4 promoter sequence.

The consensus PCE-1 sequence in the BMP-4 promoter region was our first target to see the effect of change in RX-binding. The mutation on this site (SDM\# 1) showed 6.6-fold RX-mediated activation (Table 3) and did not change the BMP-4 promoter activity $(p=0.48)$. The second site chosen for mutation (SDM\# 2) (Figure-14), had one nucleotide change compared to the PCE-1 site and the RX-mediated promoter activity was again not affected after mutating this site $(\mathrm{p}=0.504)$. The promoter showed six-fold RX mediated induction in the activity. The third PCE-1 site mutation (SDM\# 3) however showed a decrease in the RX-mediated promoter activity. The SDM\# 3 promoter showed only three-fold induction in the promoter activity and was statistically significant (0.0164).

To find out whether these PCE-1 sites are acting in combination for RX binding, we used combinations of mutations to determine the effect on Rx-mediated promoter activity. The mutation of the first two PCE-1 sites (SDM\# 1+2) showed nearly a five-fold Rx-mediated induction in the promoter activity (Table 3), which was very close to the original non-mutated promoter activity $(\mathrm{p}=0.402)$. The other combination $(\mathrm{SDM} \# 1+3)$ showed 7.8-fold promoter activity which also was not significantly different from the control BMP-4 promoter $(\mathrm{p}=0.063)$. The other combination of these mutations was SDM \# 2+3, which again was not significant with nearly a four-fold induction in promoter 
activity $(\mathrm{p}=0.2937)$. The combination of all these mutations (SDM\# $1+2+3$ ), however, was very significant $(\mathrm{p}=0.0001)$, with just 2.28 -fold $\mathrm{Rx}$-mediated induction in the promoter activity.

The analysis of BMP-4 promoter sequence in human, mouse and bovine genome revealed that the major part of the 3' end of this promoter region is conserved among these species. Therefore, we chose the BMP4-3' promoter for the cotransfection assays. This region by itself did not show as much RX-mediated induction as the original region. The BMP4-3' promoter showed 2.4-fold RX mediated induction, which was statistically significant $(\mathrm{p}=0.0072)$. 


\section{Discussion}

In the present study, we tried to analyze the sequence and the region of $\mathrm{RX}$ binding in the $1.8 \mathrm{~Kb}$ RX-responsive BMP-4 promoter region. The results obtained from the in vitro cotransfection assays, with the RX gene and the mutated promoter region fused to the firefly luciferase reporter gene, are very ambiguous. With regards to the RXbinding region in the promoter, we can speculate that RX might be binding to the 5' end of the $1.8 \mathrm{~Kb}$ BMP-4 promoter region, since just the 3'end promoter region shows reduced activity in the presence of RX (Table-3). The mutations on the PCE-1 sites indicate that mutation numbers $1 \& 2$ (SDM \#1\&2) alone do not affect the RX mediated BMP-4 promoter activity. However the third site (SDM \#3) does affect the BMP-4 promoter activity. Yet, when this mutation is present in combination with the other mutations (SDM \#1+3 and SDM \# 2+3), the BMP-4 promoter activity is not affected. The results for one combined mutation $(\mathrm{SDM} \# 1+2)$ also show no change in activity on the BMP-4 promoter. When all these sites were mutated in the same construct (SDM $\# 1+2+3)$, the BMP-4 promoter activity was severely affected. These results suggest that all of these sites are possible targets of RX binding, and in the absence of all these binding sites, the RX-mediated activation is considerably affected. However, we cannot conclude the RX binding region in this promoter promoter element solely by this data. Further studies need to be done using this data to characterize the exact binding site for $\mathrm{Rx}$. 


\begin{tabular}{|c|c|c|c|}
\hline $\begin{array}{c}\text { BMP-4 Mutation } \\
\text { number }\end{array}$ & $\begin{array}{c}\text { Ratio } \\
\text { WT/empty } \\
\text { vector }\end{array}$ & $\begin{array}{c}\text { Sample } \\
\text { number }\end{array}$ & $\begin{array}{c}\text { P Value Significant if } \\
<0.05(48 \mathrm{hrs} \\
\text { transfection) }\end{array}$ \\
\hline \hline SDM \# 1 & 6.6 & 7 & 0.48 \\
\hline SDM \# 2 & 5.97 & 5 & 0.5014 \\
\hline SDM \# 3 & 3.0 & 4 & $0.0164^{*}$ \\
\hline SDM \# 1+2 & 4.78 & 6 & 0.4028 \\
\hline SDM \# 1+3 & 7.82 & 5 & 0.0633 \\
\hline SDM \# 2+3 & 3.84 & 9 & 0.2937 \\
\hline SDM \# 1+2+3 & 2.28 & 6 & $0.0001^{*}$ \\
\hline BMP-4 3' (900 bp) & 2.4 & 7 & $0.0072^{*}$ \\
\hline BMP-4 Original & 6.3 & 20 & $0.0001^{*}$ \\
\hline
\end{tabular}

\section{Table 3: Cotransfection results for mutated BMP-4 promoter}

The BMP-4 promoter region carrying the PCE-1 sites was mutated at these sites using site-directed mutagenesis. Constructs carrying a combination of these mutations were made after the initial single mutations. The promoter was also analyzed by deleting the 5 , $900 \mathrm{bp}$ in the construct called BMP4-3'.The constructs and the RX-mediated fold induction in their activity is seen in the second column. The Table also indicates the statistical significance of these readings. The p-values in orange are compared with BMP4 original promoter whereas the p-value by the original promoter is in blue. 


\section{Future direction}

\section{Aim 1 \\ 1. To determine the putative role of $\mathrm{Rx}$ in the adult mouse neural retina}

To determine the putative role played by $\mathrm{Rx}$ in the retina at the adult stage, it is necessary to know the cell types expressing Rx in the photoreceptor layer and in the inner nuclear layer. To determine the cell types expressing $\mathrm{Rx}$ in the photoreceptor layer and inner nuclear layer, the double immunohistochemistry can be done. The current $\mathrm{Rx}-\mathrm{Ab}$ is known to bind to $\mathrm{Rx}$ in immunoblots, but binding of $\mathrm{Rx}$ to this antibody in vivo or on sections has not yet been successful. Rx expression will be detected using this Anti-Rx antibody which will be identified in the tissue using the fluorescently labeled appropriate secondary antibody. The antibody against neural retinal cell-specific protein marker can be used for running the second immunoreaction and will be identified using a different fluorescent dye labeled secondary antibody. The colocalization of these two different fluorescents will be detected using the confocal microscope.

This determination of the cell type will throw light on the putative role of $\mathrm{Rx}$ in the adult neural retinal maintenance.

\section{Aim 2a \\ 1. To determine the down stream target genes of $\mathrm{Rx}$ in the photoreceptor layer}

Other photoreceptor genes, besides those of arrestin and IRBP, have PCE-1 sequences in the promoter region. For example, the promoter region of the red-cone opsin gene contains the PCE-1 sequence (Moritz et al., 2002). Though it is not clear whether Rx acts through the PCE-1 site for all its target genes, Rx activates the photoreceptor layer-specific genes through this PCE-1 site. Therefore it would be interesting to analyze the regulation of all the PCE-1-containing photoreceptor-specific gene promoters by $\mathrm{Rx}$ protein. This regulation could be checked using the cotransfection assays described in Chapter 3. 
Whether Rx shows regulation of the rod photoreceptor specific genes or the cone photoreceptor specific genes, or of both the groups of genes, we can narrow down the putative Rx mediated activities in maintenance of the adult neural retinal region.

2. To determine the Rx downstream effectors during the embryogenesis

To determine the genes expressed only in the presence of $\mathrm{Rx}$, we can use a microarray analysis. One approach to perform this analysis would be to make a cDNA pools from the Rx WT and Rx null embryos starting with each day from the E8.0 to P0. Hybridize these fluorescently labeled cDNAs isolated from these two groups on the microarray chip. The chip should be arrayed with the cDNA library of the mouse genome. For more refined results instead of using the Rx null embryos, the Rx conditional knock-out embryos for each day can be used. The cDNA pool should be made from these samples after one day of introducing the knock-out. The genes expressed only in the presence of Rx can be the potential downstream effectors of Rx. The nature of this interaction can be further verified using the gel-shift assays with the $\mathrm{Rx}$ protein and the promoter regions of these genes.

\section{$\operatorname{Aim} 2 b$}

1. To determine the sequence in the promoter region of the target genes used during the Rx mediated promoter regulation

To find out the exact Rx binding site in the other target genes and in the BMP-4 promoter,

a. Carry out the gel-shift assays to see whether there is any direct binding between $\mathrm{Rx}$ and the $1.8 \mathrm{~Kb} \mathrm{BMP}-4$ region. If there is a direct binding observed, then divide the promoter region in further smaller fragments (500$600 \mathrm{bps})$, still responsive to the Rx binding.

b. Use DNA footprinting to know the exact sequence in the 500-600 neucleoteide, to which the RX protein binds. 
For the DNA footprinting, isolate the RX protein by in vitro translation reaction using the Rx mRNA for priming. This RX protein will then be subjected to binding with the 500-600bp radioactively end labeled BMP-4 promoter region. The DNase-1 will cleave any DNA randomly from the 3'end but the RX-bound region will remain undigested. Both the control (only BMP-4) and the test BMP-4 (RX + BMP-4) promoter will be run on sequencing acrylamide gel followed by autoradiography. The region bound by RX will be protected from the DNAse treatment and will therefore be identified on the gel. A comparison of the DNA fragments obtained in the control (only BMP-4) versus that of the test (RX + BMP-4) would indicate the absent fragments in the autoradiogram.

Comparing the autoradiogram of the test reaction with the autoradiogram of the control reaction will tell us the right Rx binding site(s) in the BMP-4 promoter region. 
Chapter IV

\section{References}


Acampora,D.; Mazan,S.; Lallemand,Y.; Avantaggiato,V.; Maury,M.; Simeone,A.; Brulet,P. 1995. Forebrain and midbrain regions are deleted in Otx2-/- mutants due to a defective anterior neuroectoderm specification during gastrulation. Development 121: 3279-3290.

Andreazzoli,M.; Gestri,G.; Angeloni,D.; Menna,E.; Barsacchi,G. 1999. Role of Xrx1 in Xenopus eye and anterior brain development. Development. 126: 2451-2460.

Andreazzoli M, Gestri G, Cremisi F, Casarosa S, Dawid IB, Barsacchi G. 2003. Xrx1 controls proliferation and neurogenesis in Xenopus anterior neural plate. Development. Nov;130(21):5143-54

Ang, S. L., Jin, O., Rhinn, M., Daigle, N., Stevenson, L., and Rossant, J. (1996). A targeted mouse Otx2 mutation leads to severe defects in gastrulation and formation of axial mesoderm and to deletion of rostral brain. Development 122, 243-52.

Adler, R. 1993. Determination of cellular types in the retina. Invest Ophthalmol. Vis. Sci. 34:1677-1682.

Asbreuk,C.H.; van Schaick,H.S.; Cox,J.J.; Smidt,M.P.; Burbach,J.P. 2002. Survey for paired-like homeodomain gene expression in the hypothalamus: restricted expression patterns of Rx, Alx4 and goosecoid. Neuroscience 114:883-889.

Bao,Z.Z.; Cepko,C.L. 1997. The expression and function of Notch pathway genes in the developing rat eye. J.Neuroscience 17: 1425-1434.

Barbieri,A.M.; Lupo,G.; Bulfone,A.; Andreazzoli,M.; Mariani,M.; Fougerousse,F.; Consalez,G.G.; Borsani,G.; Beckmann,J.S.; Barsacchi,G.; Ballabio,A.; Banfi,S. 1999. Proc.Natl.Acad.Sci.U.S.A. 96: 10729-10734. 
Barlow,A.J.; Francis-West,P.H.1997. Ectopic application of recombinant BMP-2 and BMP-4 can change patterning of developing chick facial primordia. Development.124:391-398.

Bar-Yosef, U., I.Abuelaish, T.Harel, N.Hendler, R.Ofir, and O.S.Birk. 2004. CHX10 mutations cause non-syndromic microphthalmia/ anophthalmia in Arab and Jewish kindreds. Hum. Genet. 115:302-309.

Beebe D. C., 1994. Homeobox genes and vertebrate eye development. Invest Ophthalmol.Vis.Sci.7: 2897-2900.

Beermann,F.; Schmid,E.; Schutz,G.1992. Expression of the mouse tyrosinase gene during embryonic development: recapitulation of the temporal regulation in transgenic mice. Proc.Natl.Acad.Sci.U.S.A 89, 2809-13.

Belecky-Adams, T., Tomarev, S., Li, H. S., Ploder, L., McInnes, R. R., Sundin, O., and Adler, R. (1997). Pax-6, Prox 1, and Chx10 homeobox gene expression correlates with phenotypic fate of retinal precursor cells. Invest Ophthalmol Vis Sci 38, 1293-303.

Bernier, G., Panitz, F., Zhou, X., Hollemann, T., Gruss, P., and Pieler, T. (2000). Expanded retina territory by midbrain transformation upon overexpression of Six6 (Optx2) in Xenopus embryos. Mech Dev 93, 59-69.

Blackshaw,S.; Harpavat,S.; Trimarchi,J.; Cai,L.; Huang,H.; Kuo,W.P.; Weber,G.; Lee,K.; Fraioli,R.E.; Cho,S.H.; Yung,R.; Asch,E.; Ohno-Machado,L.; Wong,W.H.; Cepko,C.L. 2004. Genomic analysis of mouse retinal development. PLoS.Biol. 2: E247. 
Bovolenta,P.; Mallamaci,A.; Briata,P.; Corte,G.; Boncinelli,E.1997. Implication of OTX2 in pigment epithelium determination and neural retina differentiation. J.Neurosci.17: 4243-4252.

Carl,M.; Loosli,F.; Wittbrodt,J. 2002. Six3 inactivation reveals its essential role for the formation and patterning of the vertebrate eye. Development. 129: 4057-4063.

Casarosa, S., M.Andreazzoli, A.Simeone, and G.Barsacchi. 1997. Xrx1, a novel Xenopus homeobox gene expressed during eye and pineal gland development. Mech. Dev. 61:187-198.

Chang,G.Q.; Hao,Y.; Wong,F. 1993. Apoptosis: final common pathway of photoreceptor death in rd, rds, and rhodopsin mutant mice. Neuron 11: 595-605.

Cheon EW, Kuwata O, Saito T. 2001 Muscarinic acetylcholine receptors in the normal, developing and regenerating newt retinas. Dev Brain Res. 2001 Mar 29;127(1):921.

Chen, C.M. and C.L.Cepko. 2002. The chicken RaxL gene plays a role in the initiation of photoreceptor differentiation. Development 129:5363-5375.

Cheyette, B. N., Green, P. J., Martin, K., Garren, H., Hartenstein, V., and Zipursky, S. L. (1994). The Drosophila sine oculis locus encodes a homeodomain-containing protein required for the development of the entire visual system. Neuron 12, 97796.

Chiba, C., K.Nakamura, S.Unno, and T.Saito. 2004. Intraocular implantation of DNAtransfected retinal pigment epithelium cells: a new approach for analyzing molecular functions in the newt retinal regeneration. Neurosci. Lett. 368:171-175. 
Chow,R.L.; Altmann,C.R.; Lang,R.A.; Hemmati-Brivanlou,A.1999. Pax6 induces ectopic eyes in a vertebrate. Development 126: 4213-4222.

Chuang, J.C., P.H.Mathers, and P.A.Raymond. 1999. Expression of three Rx homeobox genes in embryonic and adult zebrafish. Mech. Dev. 84:195-198.

Conlon,R.A.; Rossant,J. Exogenous retinoic acid rapidly induces anterior ectopic expression of murine Hox-2 genes in vivo. 1992, Development. 116: 357-368.

Cygan,J.A.; Johnson,R.L.; McMahon,A.P. Novel regulatory interactions revealed by studies of murine limb pattern in Wnt-7a and En-1 mutants. Development. 124: 5021-5032.

Dakubo,G.D.; Wang,Y.P.; Mazerolle,C.; Campsall,K.; McMahon,A.P.; Wallace,V.A.2003. Retinal ganglion cell-derived sonic hedgehog signaling is required for optic disc and stalk neuroepithelial cell development. Development. 130: 2987-2980.

Deschet, K., F.Bourrat, F.Ristoratore, D.Chourrout, and J.S.Joly. 1999. Expression of the medaka (Oryzias latipes) Ol-Rx3 paired-like gene in two diencephalic derivatives, the eye and the hypothalamus. Mech. Dev. 83:179-182.

Desire, L., Head, M. W., Fayein, N. A., Courtois, Y. and Jeanny, J. C. (1998). Suppression of fibroblast growth factor 2 expression by antisenseoligonucleotides inhibits embryonic chick neural retina cell differentiationand survival in vivo. Dev. Dyn. 212, 63-74.

Dorrell,M.I.; Aguilar,E.; Weber,C.; Friedlander,M. 2004. Global gene expression analysis of the developing postnatal mouse retina. Invest Ophthalmol.Vis.Sci. 45:1009-1019. 
Dyer, M. A., and Cepko, C. L. (2001). Regulating proliferation during retinal development. Nat Rev Neurosci 2, 333-42.

Eagleson,G.; Ferreiro,B.; Harris,W.A.1995. Fate of the anterior neural ridge and the morphogenesis of the Xenopus forebrain. J. Neurobiol. 28: 146-158.

Eggert, T., B.Hauck, N.Hildebrandt, W.J.Gehring, and U.Walldorf. 1998. Isolation of a Drosophila homolog of the vertebrate homeobox gene $\mathrm{Rx}$ and its possible role in brain and eye development. Proc. Natl. Acad. Sci. U. S. A 95:2343-2348.

Ekker,S.C.; Ungar,A.R.; Greenstein,P.; von Kessler,D.P.; Porter,J.A.; Moon,R.T.; Beachy,P.A.1995. Patterning activities of vertebrate hedgehog proteins in the developing eye and brain. Curr Biol. 5: 944-955.

Fantl,V.; Stamp,G.; Andrews,A.; Rosewell,I.; Dickson,C. 1995. Mice lacking cyclin D1 are small and show defects in eye and mammary gland development. Genes Dev. 9:2364-2372.

Fischer AJ, Reh TA, 2000. Identification of a proliferating marginal zone of retinal progenitors in postnatal chickens. Dev Biol. 2000 Apr 15;220(2):197-210

Fischer, A.J. and T.A.Reh. 2001. Transdifferentiation of pigmented epithelial cells: a source of retinal stem cells? Dev. Neurosci. 23:268-276.

Fuhrmann, S., E.M.Levine, and T.A.Reh. 2000. Extraocular mesenchyme patterns the optic vesicle during early eye development in the embryonic chick. Development 127:4599-4609.

Furukawa, T., C.A.Kozak, and C.L.Cepko. 1997. rax, a novel paired-type homeobox gene, shows expression in the anterior neural fold and developing retina. Proc. Natl. Acad. Sci. U. S. A 94:3088-3093. 
Furukawa,T.; Mukherjee,S.; Bao,Z.Z.; Morrow,E.M.; Cepko,C.L. 2000. rax, Hes1, and notch1 promote the formation of Muller glia by postnatal retinal progenitor cells. Neuron, 26: 383-394.

Furuta,Y.; Hogan,B.L.1998. BMP4 is essential for lens induction in the mouse embryo. Genes Dev, 12: 3764-3775.

Gallardo, M. E., Lopez-Rios, J., Fernaud-Espinosa, I., Granadino, B., Sanz, R., Ramos, C., Ayuso, C., Seller, M. J., Brunner, H. G., Bovolenta, P., and Rodriguez de Cordoba, S. (1999). Genomic cloning and characterization of the human homeobox gene SIX6 reveals a cluster of SIX genes in chromosome 14 and associates SIX6 hemizygosity with bilateral anophthalmia and pituitary anomalies. Genomics 61, 82-91.

Godbout,R.; Andison,R. 1996. Elevated levels of cyclin D1 mRNA in the undifferentiated chick retina.Gene, 182: 111-115.

Goding C. R. 2000. Mitf from neural crest to melanoma: signal transduction and transcription in the melanocyte lineage. Genes Dev. 14: 1712-1728.

Green, E. S., Stubbs, J. L., and Levine, E. M. (2003). Genetic rescue of cell number in a mouse model of microphthalmia: interactions between $\mathrm{Chx} 10$ and G1-phase cell cycle regulators. Development 130, 539-52.

Grainger, R.M. 1992. Embryonic lens induction: shedding light on vertebrate tissue determination. Trends Genet. 8:349-355.

Hallonet, M., T.Hollemann, T.Pieler, and P.Gruss. 1999. Vax1, a novel homeoboxcontaining gene, directs development of the basal forebrain and visual system. Genes Dev. 13:3106-3114. 
Hanson,I.M.; Fletcher,J.M.; Jordan,T.; Brown,A.; Taylor,D.; Adams,R.J.; Punnett,H.H.; van,Heyningen,V 1994. Mutations at the PAX6 locus are found in heterogeneous anterior segment malformations including Peters' anomaly. Nat Genet. 6: 168-173.

Harch, C., Chase, H. B., and Gonsalves, N. I. (1978). Studies on an anophthalmic strain of mice. VI. Lens and cup interaction. Dev Biol 63, 352-7.

Hill,R.E.; Favor,J.; Hogan,B.L.; Ton,C.C.; Saunders,G.F.; Hanson,I.M.; Prosser,J.; Jordan,T.; Hastie,N.D.; van,Heyningen,V 1991. Mouse small eye results from mutations in a paired-like homeobox-containing gene. Nature, 354: 522-525.

Hitchcock, P. F., Macdonald, R. E., VanDeRyt, J. T., and Wilson, S. W. (1996). Antibodies against Pax6 immunostain amacrine and ganglion cells and neuronal progenitors, but not rod precursors, in the normal and regenerating retina of the goldfish. J Neurobiol 29, 399-413.

Hodgkinson,C.A.; Moore,K.J.; Nakayama,A.; Steingrimsson,E.; Copeland,N.G.; Jenkins,N.A.; Arnheiter,H. 1993. Mutations at the mouse microphthalmia locus are associated with defects in a gene encoding a novel basic-helix-loop-helix-zipper protein. Cell 74: 395-404.

Hogan,B.L 1996. Bone morphogenetic proteins: multifunctional regulators of vertebrate development. Genes Dev 10:1580-1594.

Horsford D., Nguyen T., Sellar G, Kothary R, Heinz Arnheiter H and McInnes R. 2005Chx10 repression of Mitf is required for the maintenance of mammalian neuroretinal identity. Development 132: 177-877.

Hyer, J., T.Mima, and T.Mikawa. 1998. FGF1 patterns the optic vesicle by directing the placement of the neural retina domain. Development 125:869-877. 
Ishikawa, Y., M.Yoshimoto, N.Yamamoto, H.Ito, T.Yasuda, F.Tokunaga, M.Iigo, Y.Wakamatsu, and K.Ozato. 2001. Brain structures of a medaka mutant, el (eyeless), in which eye vesicles do not evaginate. Brain Behav. Evol. 58:173-184.

Jarriault,S.; Brou,C.; Logeat,F.; Schroeter,E.H.; Kopan,R.; Israel,A. 1995 Signalling downstream of activated mammalian Notch. Nature 377:355-358.

Jean, D., K.Ewan, and P.Gruss. 1998. Molecular regulators involved in vertebrate eye development. Mech. Dev. 76:3-18.

Kageyama,R.; Ishibashi,M.; Takebayashi,K.; Tomita,K. 1997. bHLH transcription factors and mammalian neuronal differentiation. Int.J.Biochem.Cell Biol. 29:1389-1399.

Kimura, A., D.Singh, E.F.Wawrousek, M.Kikuchi, M.Nakamura, and T.Shinohara. 2000. Both PCE-1/RX and OTX/CRX interactions are necessary for photoreceptorspecific gene expression. J. Biol. Chem. 275:1152-1160.

Klein LR, MacLeish PR, Wiesel TN.1990. Immunolabelling by a newt retinal pigment epithelium antibody during retinal development and regeneration. J Comp Neurol. 1990 Mar 15;293(3):331-9

Kobayashi,M.; Toyama,R.; Takeda,H.; Dawid,I.B.; Kawakami,K. 1998 Overexpression of the forebrain-specific homeobox gene six 3 induces rostral forebrain enlargement in zebrafish. Development 125: 2972-2982.

Koroma, B. M., Yang, J. M., and Sundin, O. H. (1997). The Pax-6 homeobox gene is expressed throughout the corneal and conjunctival epithelia. Invest Ophthalmol Vis Sci 38, 108-20. 
Koshiba-Takeuchi, K., J.K.Takeuchi, K.Matsumoto, T.Momose, K.Uno, V.Hoepker, K.Ogura, N.Takahashi, H.Nakamura, K.Yasuda, and T.Ogura. 2000. Tbx5 and the retinotectum projection. Science 287:134-137.

Laemle, L. K., and Rusa, R. (1992). VIP-like immunoreactivity in the suprachiasmatic nuclei of a mutant anophthalmic mouse. Brain Res 589, 124-8.

Lagutin,O.; Zhu,C.C.; Furuta,Y.; Rowitch,D.H.; McMahon,A.P.; Oliver,G.2001. Six3 promotes the formation of ectopic optic vesicle-like structures in mouse embryos. Dev Dyn 221:342-349.

Lagutin,O.V.; Zhu,C.C.; Kobayashi,D.; Topczewski,J.; Shimamura,K.; Puelles,L.; Russell,H.R.; McKinnon,P.J.; Solnica-Krezel,L.; Oliver,G. 2003. Six3 repression of Wnt signaling in the anterior neuroectoderm is essential for vertebrate forebrain development. Genes Dev 17:368-379.

Li, H.S., J.M.Yang, R.D.Jacobson, D.Pasko, and O.Sundin. 1994. Pax-6 is first expressed in a region of ectoderm anterior to the early neural plate: implications for stepwise determination of the lens. Dev. Biol. 162:181-194.

Liu,I.S.; Chen,J.D.; Ploder,L.; Vidgen,D.; van der,Kooy D.; Kalnins,V.I.; McInnes,R.R., 1994. Developmental expression of a novel murine homeobox gene (Chx10): evidence for roles in determination of the neuroretina and inner nuclear layer. Neuron 13:377-393.

Loosli,F.; Winkler,S.; Wittbrodt,J.1999. Six3 overexpression initiates the formation of ectopic retina. Genes Dev. 13:649-654.

Loosli, F., S.Winkler, C.Burgtorf, E.Wurmbach, W.Ansorge, T.Henrich, C.Grabher, D.Arendt, M.Carl, A.Krone, E.Grzebisz, and J.Wittbrodt. 2001. Medaka eyeless is 
the key factor linking retinal determination and eye growth. Development 128:4035-4044.

Ma C., Papermaster D., AND C. Cepko. 1998. A unique pattern of photoreceptor degeneration in cyclin DImutant mice. Developmental biology 95, 9938-9943.

Maeno,M.; Ong,R.C.; Suzuki,A.; Ueno,N.; Kung,H.F., 1994. A truncated bone morphogenetic protein 4 receptor alters the fate of ventral mesoderm to dorsal mesoderm: roles of animal pole tissue in the development of ventral mesoderm. Proc.Natl.Acad.Sci.U.S.A 91: 10260-10264.

Mailhos,C.; Andre,S.; Mollereau,B.; Goriely,A.; Hemmati-Brivanlou,A.; Desplan,C.1998 Drosophila Goosecoid requires a conserved heptapeptide for repression of pairedclass homeoprotein activators. Development 125: 937-947.

Marquardt,T.; Ashery-Padan,R.; Andrejewski,N.; Scardigli,R.; Guillemot,F.; Gruss,P. 2001. Pax6 is required for the multipotent state of retinal progenitor cells. Cell 105:43-55.

Marquardt T., 2003. Transcriptional control of neuronal diversification in the retina Prog Retin Eye Res. 2003 Sep;22(5):567-77.

Mathers, P.H., A.Grinberg, K.A.Mahon, and M.Jamrich. 1997. The Rx homeobox gene is essential for vertebrate eye development. Nature 387:603-607.

Mathura,J.R.,Jr.; Jafari,N.; Chang,J.T.; Hackett,S.F.; Wahlin,K.J.; Della,N.G.; Okamoto,N.; Zack,D.J.; Campochiaro,P.A. 2000. Bone morphogenetic proteins-2 and -4 : negative growth regulators in adult retinal pigmented epithelium. Invest Ophthalmol.Vis.Sci.41: 592-600. 
Matsuo,I.; Kuratani,S.; Kimura,C.; Takeda,N.; Aizawa,S.1995. Mouse Otx2 functions in the formation and patterning of rostral head. Genes Dev. 9:2646-268.

McWhirter,J.R.; Goulding,M.; Weiner,J.A.; Chun,J.; Murre,C.1997. A novel fibroblast growth factor gene expressed in the developing nervous system is a downstream target of the chimeric homeodomain oncoprotein E2A-Pbx1. Development, 124:3221-3232.

Mikkola, I., J.A.Bruun, T.Holm, and T.Johansen. 2001. Superactivation of Pax6mediated transactivation from paired domain-binding sites by dna-independent recruitment of different homeodomain proteins 5. J. Biol. Chem. 276:4109-4118.

Mitashov VI, Maliovanova SD., 1982. Cellular proliferative potentials of the pigment and ciliated epithelium of the eye in clawed toads normally and during regeneration Ontogenez. 1982 May-Jun;13(3):228-34

Mitashov VI., 1997. Retinal regeneration in amphibians Int J Dev Biol. 1997 Dec;41(6):893-905

Mochii, M., Agata, K., Kobayashi, H., Yamamoto, T. S. and Eguchi, G. (1988). Expression of gene coding for a melanosomal matrix protein transcriptionally regulated in the transdifferentiation of chick embryo pigmented epithelial cells. Cell Differ. 24, 67-74.

Morabito,M.A.; Yu,X.; Barnstable,C.J. 1991. Characterization of developmentally regulated and retina-specific nuclear protein binding to a site in the upstream region of the rat opsin gene. J. Biol Chem. 266:9667-96672.

Moralez M, Dolez V, Rodrigo I, Zaccarini R, Leconte L, Bovolenta P and Saule S, (2003), JBC, Vol. 278, No. 24, June 13: 21721-21731. 
Nguyen, M. and H.Arnheiter. 2000. Signaling and transcriptional regulation in early mammalian eye development: a link between FGF and MITF. Development 127:3581-3591.

Ohuchi, H., S.Tomonari, H.Itoh, T.Mikawa, and S.Noji. 1999. Identification of chick rax/rx genes with overlapping patterns of expression during early eye and brain development. Mech. Dev. 85:193-195.

Oliver,G.; Mailhos,A.; Wehr,R.; Copeland,N.G.; Jenkins,N.A.; Gruss,P. 1995. Six3, a murine homologue of the sine oculis gene, demarcates the most anterior border of the developing neural plate and is expressed during eye development. Development 121: 4045-4055.

Orts-Llorca, F. and J.M.Genis-Galvez. 1960. Experimental production of retinal septa in the chick embryo. Differentiation of pigment epithelium into neural retina. Acta Anat. (Basel) 42:31-70.

Pasquier,L.; Dubourg,C.; Blayau,M.; Lazaro,L.; Le Marec,B.; David,V.; Odent,S. 2000. A new mutation in the six-domain of SIX3 gene causes holoprosencephaly. Eur.J.Hum.Genet. 8: 797-800.

Pearson, B.J. and C.Q.Doe. 2004. Specification of temporal identity in the developing nervous system. Annu. Rev. Cell Dev. Biol. 20:619-647.

Percin EF, Ploder LA, Yu JJ, Arici K, Horsford DJ, Rutherford A, Bapat B, Cox DW, Duncan AMV, Kalnins VI, Kocak-Altintas A, Sowden JC, Trabousli E, Sarfarazi M, McInnes RR. 2001. Human microphthalmia associated with mutations in the retinal homeobox gene CHX10. Am J Ophthalmol. Jan;131(1):156-157. 
Perron, M., S.Kanekar, M.L.Vetter, and W.A.Harris. 1998. The genetic sequence of retinal development in the ciliary margin of the Xenopus eye. Dev. Biol. 199:185200.

Pittack, C., G.B.Grunwald, and T.A.Reh. 1997. Fibroblast growth factors are necessary for neural retina but not pigmented epithelium differentiation in chick embryos. Development 124:805-816.

Porter, F. D., Drago, J., Xu, Y., Cheema, S. S., Wassif, C., Huang, S. P., Lee, E., Grinberg, A., Massalas, J. S., Bodine, D., Alt, F., and Westphal, H. (1997). Lhx2, a LIM homeobox gene, is required for eye, forebrain, and definitive erythrocyte development. Development 124, 2935-44.

Reh, T.A. and E.M.Levine. 1998. Multipotential stem cells and progenitors in the vertebrate retina. J. Neurobiol. 36:206-220.

Reh TA, Nagy T, Gretton H, 1987. Retinal pigmented epithelial cells induced to transdifferentiate to neurons by laminin Nature. 1987 Nov 5-11;330(6143):68-71

Del Rio-Tsonis K, Tsonis PA., 2003. Eye regeneration at the molecular age. Dev Dyn. 2003 Feb;226(2):211-24

Raymond PA, Hitchcock PF., 2000. How the neural retina regenerates. Results Probl Cell Differ. 2000;31:197-218.

Saha, M.S., M.Servetnick, and R.M.Grainger. 1992. Vertebrate eye development. Curr. Opin. Genet. Dev. 2:582-588. 
Sakakibara S, Hiramatsu H, Takahashi Y, Hisatomi O, Kobayashi Y, Sakami S, Saito T, Tokunaga F., 2002. Opsin expression in adult, developing, and regenerating newt retinas Brain Res Mol Brain Res. 2002 Jun 30;103(1-2):28-35

Sasagawa, S., T.Takabatake, Y.Takabatake, T.Muramatsu, and K.Takeshima. 2002. Axes establishment during eye morphogenesis in Xenopus by coordinate and antagonistic actions of BMP4, Shh, and RA. Genesis. 33:86-96.

Schulte,D.; Furukawa,T.; Peters,M.A.; Kozak,C.A.; Cepko,C.L. 1999. Neuron, 24:541555.

Schimmenti,L.A.; de la,Cruz J.; Lewis,R.A.; Karkera,J.D.; Manligas,G.S.; Roessler,E.; Muenke,M. 2003. Novel mutation in sonic hedgehog in non-syndromic colobomatous microphthalmia. Am.J.Med.Genet 116A:215-221.

Schwarz, M., Cecconi, F., Bernier, G., Andrejewski, N., Kammandel, B., Wagner, M., and Gruss, P. (2000). Spatial specification of mammalian eye territories by reciprocal transcriptional repression of Pax2 and Pax6. Development 127, 432534.

Seimiya, M., and Gehring, W. J. (2000). The Drosophila homeobox gene optix is capable of inducing ectopic eyes by an eyeless-independent mechanism. Development $127,1879-86$.

Sicinski,P.; Donaher,J.L.; Parker,S.B.; Li,T.; Fazeli,A.; Gardner,H.; Haslam,S.Z.; Bronson,R.T.; Elledge,S.J.; Weinberg,R.A. 1995. Cell, 82:621-630.

Silver, J., and Hughes, A. F. (1974). The relationship between morphogenetic cell death and the development of congenital anophthalmia. J Comp Neurol 157, 281-301. 
Simeone, A., Acampora, D., Gulisano, M., Stornaiuolo, A., and Boncinelli, E. (1992). Nested expression domains of four homeobox genes in developing rostral brain. Nature 358, 687-90.

Simeone, A., Acampora, D., Mallamaci, A., Stornaiuolo, A., D'Apice, M. R., Nigro, V., and Boncinelli, E. (1993). A vertebrate gene related to orthodenticle contains a homeodomain of the bicoid class and demarcates anterior neuroectoderm in the gastrulating mouse embryo. Embo $J 12,2735-47$.

Simeone,A.; D'Apice,M.R.; Nigro,V.; Casanova,J.; Graziani,F.; Acampora,D.; Avantaggiato,V.1994. Neuron, 13: 83-101.

Smith, S. T., and Jaynes, J. B. (1996). A conserved region of engrailed, shared among all en-, gsc-, Nk1-, Nk2- and msh-class homeoproteins, mediates active transcriptional repression in vivo. Development 122, 3141-50.

Strickler,A.G.; Famuditimi,K.; Jeffery,W.R. 2002 Retinal homeobox genes and the role of cell proliferation in cavefish eye degeneration. Int.J. Dev. biol. 46:285-294.

Svistunov SA, Mitashov VI. 1985. Radioautographic study of the cellular proliferation of retinal pigment epithelium in axolotls. Ontogenez 1984 Nov-Dec;15(6):599-607.

Take-uchi, M., Clarke, J. D., and Wilson, S. W. (2003). Hedgehog signalling maintains the optic stalk-retinal interface through the regulation of Vax gene activity. Development 130, 955-68.

Torres, M., Gomez-Pardo, E., and Gruss, P. (1996). Pax2 contributes to inner ear patterning and optic nerve trajectory. Development 122, 3381-91.

Tropepe, V., B.L.Coles, B.J.Chiasson, D.J.Horsford, A.J.Elia, R.R.McInnes, and K.D.van der. 2000a. Retinal stem cells in the adult mammalian eye. Science 287:2032-2036. 
Toy, J., Yang, J. M., Leppert, G. S. and Sundin, O. H. (1998). The optx2 homeobox gene is expressed in early precursors of the eye and activatesretina-specific genes. Proc. Natl. Acad. Sci. USA 95, 10643-10648.

Ton,C.C.; Hirvonen,H.; Miwa,H.; $\quad$ Weil,M.M.; Monaghan,P.; Jordan,T.; van,Heyningen,V; Hastie,N.D.; Meijers-Heijboer,H.; Drechsler,M.1991. Cell, 67: 1059-74

Tucker,P.; Laemle,L.; Munson,A.; Kanekar,S.; Oliver,E.R.; Brown,N.; Schlecht,H.; Vetter,M.; Glaser,T. 2001.Genesis, 31:43-53.

Vogel-Hopker,A.; Momose,T.; Rohrer,H.; Yasuda,K.; Ishihara,L.; Rapaport,D.H. 2000.Mech Dev. 94:25-36.

Voronina,V.A.; Kozhemyakina,E.A.; O'Kernick,C.M.; Kahn,N.D.; Wenger,S.L.; Linberg,J.V.; Schneider,A.S.; Mathers,P.H. 2004. Mutations in the human RAX homeobox gene in a patient with anophthalmia and sclerocornea.

Hum.Mol.Genet13: 316-322.

Wallis,D.; Muenke,M.2000. Mutations in holoprosencephaly.Hum Mutat 16:99-108.

Webster, E. H., Jr., Silver, A. F., and Gonsalves, N. I. (1984). The extracellular matrix between the optic vesicle and presumptive lens during lens morphogenesis in an anophthalmic strain of mice. Dev Biol 103, 142-50.

Wetts, R. and S.E.Fraser. 1988. Multipotent precursors can give rise to all major cell types of the frog retina. Science 239:1142-1145.

Wetts, R., G.N.Serbedzija, and S.E.Fraser. 1989. Cell lineage analysis reveals multipotent precursors in the ciliary margin of the frog retina. Dev. Biol. 136:254-263. 
Winkler, S., F.Loosli, T.Henrich, Y.Wakamatsu, and J.Wittbrodt. 2000. The conditional medaka mutation eyeless uncouples patterning and morphogenesis of the eye. Development 127:1911-1919.

Yang, X.J. 2004. Roles of cell-extrinsic growth factors in vertebrate eye pattern formation and retinogenesis . Semin. Cell Dev. Biol. 15:91-103.

Yasuda,T.; Kajimoto,Y.; Fujitani,Y.; Watada,H.; Yamamoto,S.; Watarai,T.; Umayahara,Y.; Matsuhisa,M.; Gorogawa,S.; Kuwayama,Y.; Tano,Y.; Yamasaki,Y.; Hori,M.2002.Diabetes 51:224-230.

Zhang,L.; Mathers,P.H.; Jamrich,M. 2000. Function of Rx, but not Pax6, is essential for the formation of retinal progenitor cells in mice. Genesis 28: 135-148.

Zhang, X.M. and X.J.Yang. 2001. Temporal and spatial effects of Sonic hedgehog signaling in chick eye morphogenesis. Dev. Biol. 233:271-290.

Zwaan, J., and Silver, J. (1983). Crystallin synthesis in the lens rudiment of a strain of mice with congenital anophthalmia. Exp Eye Res 36, 551-7. 